Göttinger Bibliotheksschriften 19 


\section{CAII PLYNII SECVNDI NATVRAL]}

Africa

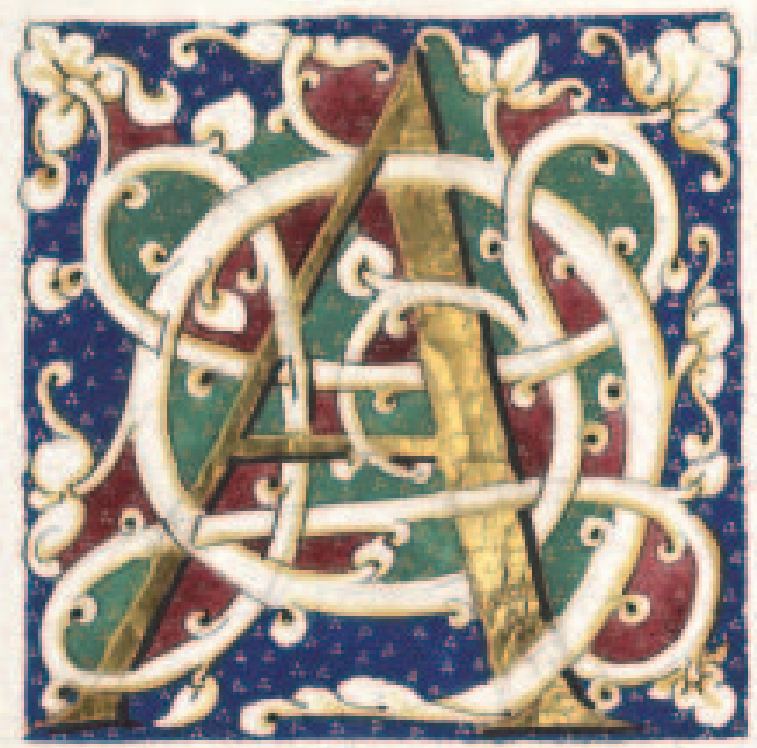

FRICAM uere:qua ma finitur. Nec finus:longe Populorum funt ieffabil caftella ferm

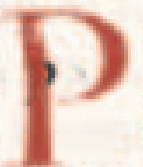
$\mathrm{Ma}$ Rinci ufg a regna : Sxul Promonton a gracis. Oppida fuere:liffa:cotta:ultra columna ab Anteo conditum: poftea a Claudio Cxfare $c$ iulia.Abeft a belone oppido beticx proximo traie quings mil. in ora oceanicolonia Augufti:iulia et iura i beticam petere iuffa:et ab eo.xxxii.M.p: lixos:uel fabulofffime $\mathrm{ab}$ antiquis narrata. Ibi $n$ hefperidum horti.Affunditur autem huic xftual draconis cuftodix inftar fuiffe nunc interpretant

Frontispiz (Kat.Nr. 1)

Plinius d. Ä.: Historia Naturalis, 1472, Initiale 'A'. 


\title{
Weltbild - Kartenbild
}

Geographie und Kartographie in der frühen Neuzeit

\author{
Ausstellung aus den Beständen der \\ Niedersächsischen Staats- und Universitätsbibliothek \\ Göttingen
}

Paulinerkirche

Historisches Gebäude der SUB

24. 2. - 7. 4. 2002

Bearbeitet von Mechthild Schüler

Hrsg. von

Elmar Mittler und Inka Tappenbeck

2., durchgesehene Auflage

Göttingen 2002 
Umschlagbild:

Indiae Orientalis, Insvlarvmque Adiacientivm Typus (Ausschnitt), aus: Abraham Ortelius: Theatrum Orbis Terrarum, Antwerpen 1595.

(Siehe Katalog-Nr. 31)

Bearbeitung für den Druck: Michael Kakuschke

Digitale Bildgebung und Umschlagentwurf: Martin Liebetruth

\section{Göttinger Bibliotheksschriften 19}

(C) Niedersächsische Staats- und Universitätsbibliothek Göttingen 2002

ISBN 3-930457-22-9

ISSN 0943-951X 


\section{Inhalt}

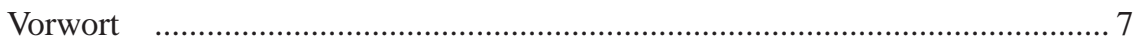

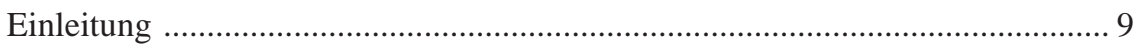

Die Wiederentdeckung der Geographie der Antike ........................................ 12

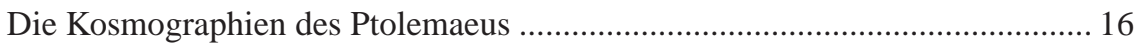

Zwei Weltkarten zwischen Mittelalter und Renaissance .................................... 22

Portulankarten des 15. und 16. Jahrhunderts ..................................................... 24

Von den ältesten gedruckten Straßenkarten ................................................... 28

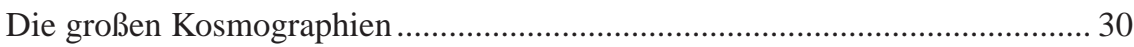

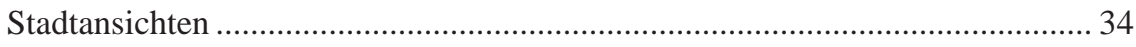

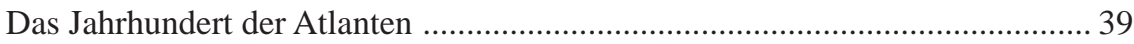

Beschreibungen von Reisen ins Heilige Land ................................................. 49

Landeskunden vom Mittelalter bis zur Neuzeit ............................................... 53

Die mathematischen Grundlagen zur Erweiterung des Weltbildes .................... 59

Die räumliche Erweiterung des Wissens: Die großen Entdeckungen ................ 66

Die räumliche Erweiterung des Wissens: Reisebeschreibungen ...................... 72

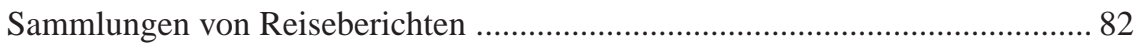

Die Geographie als Wissenschaft zwischen Renaissance und Barock ............... 86

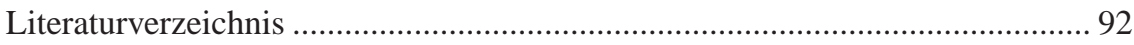

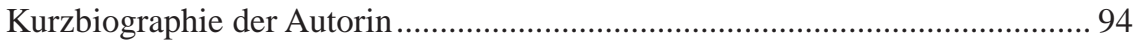





\section{Vorwort}

Das Jahr der Geowissenschaften 2002 ist für die Niedersächsische Staats- und Universitätsbibliothek Göttingen ein willkommener Anlass, eine Auswahl seltener und kostbarer Karten und geographischer Werke des 15. bis 17. Jahrhunderts zu zeigen.

In der Sammelpolitik der 1734 gegründeten Göttinger Universitätsbibliothek spielte die Erwerbung von Karten, von geographischer Literatur und von Reisebeschreibungen stets eine bedeutende Rolle. Durch die Übernahme großzügiger Schenkungen (schon der Grundstock der Bibliothek, die Bülowsche Sammlung, enthielt rund 2000 Karten), bedeutender Nachlässe sowie die Nutzung günstiger Kaufangebote im 18. und 19. Jahrhundert konnten wesentliche Grundlagen für die Forschung gelegt werden. Die Bestände bis 1900 umfassen nicht weniger als 65.000 Blatt, die bis zum Erscheinungsjahr 1850 in der IKAR-Datenbank erschlossen sind. Dieses seit 1985 von der Staatsbibliothek zu Berlin und der Bayerischen Staatsbibliothek mit der SUB aufgebaute elektronische Verzeichnis von inzwischen 218.000 Titeln und ca. 254.000 Bestandsnachweisen ist online über die Verbundzentrale des Gemeinsamen Bibliotheksverbundes Göttingen zugänglich <www.gbv.de/cgi-bin/nph-ikar>. Der Bestand nach 1945 umfasst ca. 215.000 Blatt. Mit Unterstützung der Deutschen Forschungsgemeinschaft wird er insbesondere im Bereich thematischer Karten intensiv ausgebaut. Die Karten werden mit der Software Toporama erschlossen, die schon jetzt eine schnelle Suche über die Merkmale Region, Maßstab, Thema und Zeit ermöglicht. In Gemeinschaft mit der Bayerischen Staatsbibliothek München, der Bibliothek der Eidgenössischen Technischen Hochschule Zürich und der Staatsbibliothek zu Berlin ist der Internetzugriff auf die vier größten Kartensammlungen im deutschsprachigen Raum mit Hilfe dieses Karteninformationssystems in Vorbereitung. Die Kartensammlung wird durch rund 200.000 Bände an geographischer Literatur ergänzt.

Die Kartensammlung ist im Historischen Gebäude der SUB Göttingen benutzbar, das in der Tradition der Göttinger Forschungsbibliothek des 18. Jahrhunderts zu einer Freihandbibliothek für die Sammlung Deutscher Drucke 18. Jahrhundert, die Wissenschaftsgeschichte und die Sondersammlungen ausgebaut wird. Der neu gestaltete Historische Raum in der Paulinerkirche ermöglicht darüber hinaus die Präsentation der bisher verborgenen Schätze der Staats- und Universitätsbibliothek Göttingen in einer auch für ein breiteres Publikum attraktiven Form. 
Die Ausstellung Weltbild - Kartenbild: Geographie und Kartographie in der frühen Neuzeit gibt Einblicke in den Wandel des Weltbildes an der Wende vom Mittelalter zur Neuzeit. Die Auswahl der Exponate geht auf einen Ausstellungsführer zurück, den Dr. Uta Klaer im Jahre 1979 zusammengestellt hat. Der vorliegende Katalog wurde von Mechthild Schüler, Leiterin der Kartenabteilung und Fachreferentin für Geographie, mit den begleitenden Texten versehen.

Ergänzt wird die Ausstellung durch eine von Tobias Möller bearbeitete CD-ROM, von der wichtige Teile auch im Internet zugänglich sind. Sie beruhen auf den Digitalisaten von Martin Liebetruth.

Allen, die diese Ausstellung gestaltet haben, möchte ich herzlich danken, insbesondere Frau Mechthild Schüler. Besonders erwähnt seien aber auch Michael Kakuschke (technische Vorbereitung des Kataloges), Wulf Pförtner (Ausstellungsaufbau), Dr. Inka Tappenbeck (Öffentlichkeitsarbeit) und für die Buchbinderei Burghard Teuteberg.

Möge der Erfolg der Ausstellung alle ihre Mühen belohnen.

Göttingen, im Februar 2002

Prof. Dr. Dr. h.c. Elmar Mittler

Direktor der Niedersächsischen Staats- und Universitätsbibliothek Göttingen 


\section{Einleitung}

Die Ausstellung Weltbild - Kartenbild. Geographie und Kartographie in der frühen Neuzeit zeigt eine Auswahl von bedeutenden historischen Atlanten, Stadtansichten, Länderbeschreibungen und Reiseberichten aus den Beständen der Niedersächsischen Staats- und Universitätsbibliothek Göttingen. Die Ausstellung hat damit eine Epoche zum Thema, die einen Höhepunkt der historischen Geographie und Kartographie darstellt. Die Entwicklung der Seefahrt führte damals zu einer Entfaltung der Geographie und der Kartographie, die sich sowohl auf empirische Untersuchungen der bislang unerforschten Teile der Welt als auch auf wissenschaftliche Grundlagen, vor allem der Mathematik, stützte.

In der Vorstellungswelt der Menschen am Vorabend der Neuzeit vermischten sich Wirklichkeit und Phantasie, gesichertes Wissen und Fabel miteinander. Die Erde mit den seit alters her bekannten Kontinenten Europa, Asien und Afrika galt als Scheibe, die vom Ozean umspült war. Obwohl die Kugelgestalt der Erde schon in der Antike erkannt worden war, stieß das Bild von der Welt als Kugel doch auf Unverständnis. Nur schwer konnte man sich vorstellen, dass die Menschen auf der anderen Seite des Erdballs, also auf dem Kopf stehend, nicht vom Globus ins All fielen.

An die antike Tradition knüpfte die mittelalterliche Kartographie an. Sie übernahm das kreisförmige Weltbild, wobei Jerusalem das Zentrum bildete. Aus dem Mittelalter sind auch die ersten Portulankarten überliefert, welche vor allem die Meeresküsten darstellten. Portulankarten mit Windrosen, später auch mit geographischen Netzen, lieferten den Seefahrern wichtige Informationen.

Die Entwicklung der Geographie - gleichsam eine 'geographische Renaissance' begann mit der Wiederentdeckung und Verbreitung der Schriften des Claudius Ptolemaeus, der als gelehrter Astronom und Geograph im 2. Jahrhundert nach Chr. in Alexandria gelebt hatte. Anfang des 15. Jahrhunderts wurden seine Schriften von griechischen Gelehrten nach Italien gebracht. Im Weltsystem des Ptolemaeus stand die Erde im Mittelpunkt des Himmelgewölbes, das Kugelgestalt habe und sich wie eine Kugel drehe (ptolemaeisches oder geozentrisches Weltbild). Im Zuge der Entdeckungen wurde das Werk des Ptolemaeus jedoch mit weiteren Karten ergänzt. Mit der Zeit verdrängten die Anhänge sogar die ursprünglichen Karten ganz.

Mit einem zeittypisch lebhaften Sinn für Kuriosa sahen die Chronisten von damals vor allem die überseeische Welt von Ungeheuern und Fabelwesen bevölkert. Wie 
der Humanist und Arzt Hartmann Schedel in seiner Weltchronik von 1493 berichtet, lebten in 'India' Einäugige und Menschen mit Hundsköpfen, in 'Libia' Wesen ohne Kopf, mit Augen, Mund und Nase auf dem Oberkörper. Nicht selten begegneten Mischformen zwischen Mensch und Tier. Die in der Ausstellung gezeigten frühen Kartenwerke besitzen zugleich hohen ästhetischen Reiz. Künstlerische Motive ergänzen das Kartenbild oder ersetzen es sogar zum Teil. So finden sich Darstellungen von Fabelwesen überall dort, wo die Karte noch unerforschte Teile der Welt zeigte. Gerade solche Phantasievorstellungen sind aufschlussreich für die Denk- und Sichtweisen der frühen Neuzeit.

Im 16. Jahrhundert erlangte die niederländische Kartographie besonderen Rang. Als ihr eigentlicher Begründer wird Gerard Mercator (1512 - 1594) angesehen. Mercator befreite die Kartographie vom Einfluss des Ptolemaeus und schuf die erste für die Seefahrt brauchbare Karte in winkeltreuer Projektion ('Mercator-Projektion'). Bereits vor Mercator hatte dessen Freund Abraham Ortelius sein Kartenwerk veröffentlicht. Den Höhepunkt der niederländischen Kartographie bildet das Wirken der Familie Blaeu (1571 - 1672) in Amsterdam.

Im Unterschied zu den Kartenwerken und Atlanten lag bei den Stadtansichten der Schwerpunkt auf den deutschen Werkstätten. Beispiele dafür bilden die Tätigkeit von Georg Braun und Franz Hogenberg, besondere Bedeutung erlangte auch die bekannte Kupferstecher-Familie Merian.

Bedeutende Leistungen in der Mathematik und der Astronomie erbrachten in der zweiten Hälfte des 15. Jahrhunderts Georg Peuerbach und Johannes Regiomontanus. Durch empirische Beobachtungen überprüften sie kritisch die antiken und scholastischen Überlieferungen und gelangten so zu neuen Erkenntnissen über die Planetenbewegungen. 1471 erschien das Tafelwerk 'Ephemerides' des Regiomontanus mit einer Vorausberechnung der Planetenstellungen für die Jahre 1475 - 1505, ein unentbehrliches Hilfsmittel für die Seefahrt, auf das sich auch Columbus stützte.

Die Gattung der Reisebeschreibungen ist außerordentlich vielfältig und bunt, auch wenn die Reisenden nicht immer die vertrauenswürdigsten und genauesten Nachrichten mit nach Hause brachten. An die Stelle von Spekulationen über das Bild der Welt trat seit dem ausgehenden 15. Jahrhundert allmählich durch Erkundung und Erfahrung gesichertes Wissen. Einen entscheidenden Beitrag dazu leisteten die Entdeckungsfahrten des 15. und 16. Jahrhunderts. Heinrich der Seefahrer (1394 - 1460) sandte Schiffe zur Erforschung der afrikanischen Küste aus, 1499 entdeckte Vasco da Gama den Seeweg nach Indien. 1505 - 1515 entstanden portugiesische Kolonien in Südasien. Der Versuch der Spanier, Indien auf dem Seeweg zu erreichen, führte Christoph Columbus 1492 an die Küste Amerikas. Die Erdumse- 
gelung durch den Portugiesen Ferdinand Magellan (1519 - 1522) setzte den Anfang für einen weltumspannenden Seeverkehr.

Dabei verbanden sich Erlebnis- und Abenteuerlust sowie Geld- und Machtgier mit dem Streben nach praktisch verwertbaren Neuerungen auf technischem Gebiet. Durch die Eroberung der Weltmeere und die Schaffung von Kolonialreichen gelangte Europa über Jahrhunderte zu einer uneingeschränkten Vorherrschaft. Im Zuge der Entdeckungen wurden neue Verkehrs- und Handelswege erschlossen, der Warenverkehr vervielfältigte sich.

Entscheidend begünstigt wurde die Erweiterung der Welt durch eine Reihe von technischen Erfindungen und wissenschaftlichen Erkenntnissen. Fortschritte machte der Schiffsbau. Die Erforschung von Himmel und Erde wurde durch verbesserte oder neue technische Geräte erleichtert. Wichtige Hilfsmittel der Geographie und Astronomie waren das geometrische Quadrat als Winkelmessgerät und zur Positionsbestimmung in der Seefahrt, der Quadrant zur Errechnung u. a. der Äquatorhöhe sowie Astrolab, Jakobsstab und Sextant für die Winkelmessung, ferner der Magnetkompass. Das Fernrohr wurde um die Wende zum 17. Jahrhundert erfunden.

Als Folge der Entdeckungen und durch die technischen Fortschritte - nicht zuletzt durch die Erfindung des Buchdrucks - begünstigt, nahmen die Geographie und die Kartographie seit dem späten 15. Jahrhundert einen gewaltigen Aufschwung. Sie erlangten ein immer stärkeres Maß an Zweckmäßigkeit und Genauigkeit und spiegeln zugleich den für die Geschichte der frühen Neuzeit bezeichnenden Wandel von spekulativer Theorie zu empirischer Praxis. 


\section{Die Wiederentdeckung der Geographie der Antike}

Mit der Wiederentdeckung des Wissens der Antike haben die Humanisten die Grundlage für das Zeitalter der großen Entdeckungen gelegt. Der Fall Konstantinopels brachte wertvolle Handschriften nach Italien und führte dazu, dass im Westen die Geographie des Ptolemaeus bekannt wurde. Aber nicht nur die großen griechischen Geographen revolutionierten das Weltbild, sondern auch römische Autoren wie Plinius der Ältere und Pomponius Mela. Die Entwicklung des Buchdrucks tat ihr Übriges zur Verbreitung des Wissens über die antike Geographie.

$1 \quad$ Plinius Secundus, Gaius:

Historia naturalis / [Hrsg.: Johannes <Andreas>]. - Venedig: Nicolas Jenson, 1472.

!HSD! 2 AUCT LAT IV, 723 INC

Plinius der Ältere (23 n. Chr. - 79 n. Chr.), unter Kaiser Claudius römischer Offizier und Verwaltungsbeamter, betätigte sich zugleich als Wissenssammler und vielseitiger Schriftsteller. Seine Historia Naturalis stellt in 37 Büchern alle Erscheinungen der Natur in enzyklopädischer Zusammenfassung dar. Es ist das größte erhaltene Prosawerk der lateinischen Antike. Plinius hat das ganze Wissen seiner Zeit zusammengetragen. Sein Ziel war es, eine geographische Gesamtdarstellung des Römerreiches zu liefern. Griechische und römische Fachbücher stellten die Quellen für sein naturwissenschaftliches Material dar, z. B. die Schriften von Aristoteles, Theophrastros und Hippokrates, Cato, Agrippa u. a. Die Indices nennen 146 römische und 327 griechische Autoren als Vorlagen. Das Werk des Plinius wurde im gesamten europäischen Mittelalter benutzt, mit erstaunlicher Priorität der Geographie. Plinius fand lebhafte Beachtung bei den Humanisten, die die 'Historia Naturalis' als Sachbuch ihren Theorien zugrunde legten.

Der Drucker Nicolas Jenson (gestorben 1480) stammte aus Sommevoire bei Troyes und war zunächst als königlicher Münzmeister tätig. Im Jahre 1458 wurde er vom französischen König Karl VII. nach Mainz entsandt, um bei Gutenberg die Kunst des Buchdrucks zu erlernen. Vermutlich hat er in Frankreich selbst nie gedruckt. Erst kurz vor 1470 hat er in Venedig sein erstes Buch herausgebracht. Die bedeutendste druckgeschichtliche Leistung des Nicolas Jenson ist die Schöpfung einer besonders schönen Antiqua-Type. 
2 Plinius Secundus, Gaius:

Historia naturalis / Philippus Beroaldus [Hrsg.]. - Parma: Stephan Corallus 1476.

!HSD! 2 AUCT LAT IV, 726 INC

Wiederholung der Ausgabe von 1472.

Vgl. auch Nr. 1.

3 Strabo Amasinus:

Geographia /lat. von Guarinus Veronensis und Gregorius Tiphernas. - [Treviso]: Johannes Rubeus, 26. VIII. 1480.

!HSD! 4 AUCT GR IV, 7080 INC

Strabo (63 v. Chr. - 26 n. Chr.), griechischer Historiker, Weltreisender und Geograph, schrieb seine Geographia in 17 Bänden in Form einer historisch ausgerichteten Länderkunde. Der Wert seines Werkes besteht vor allem darin, dass es die einzige vollständig erhaltene Geographie der Antike ist, die gleichzeitig Zugang bietet zu anderen Autoren seiner Zeit wie z. B. zu Eratosthenes u. a. Im Bereich der Länderkunde versuchte Strabo bereits, über die reine Beschreibung hinaus Kausalzusammenhänge zu erkennen, und zählt damit zu den großen Geographen vor Alexander von Humboldt.

4 Ptolemaeus, Claudius:

Cosmographia /lat. von Jacobus Angelus. - Vicenza: Hermann Liechtenstein, 13. 9. 1475.

!HSD! 4 AUCT GR V, 4140 INC

Der griechische Universalgelehrte Claudius Ptolemaeus (um 90 - um 168 n. Chr.) war im Mittelalter zunächst nur durch seine astronomischen Werke bekannt. Nachdem es dem Italiener Palla Strozzi gelungen war, aus Konstantinopel eine Handschrift der Cosmographia zu besorgen, wurde zu Beginn des 15. Jahrhunderts eine lateinische Übersetzung begonnen, die von Jacopo Angelo de Scarperia um 1410 zu Ende geführt wurde. Diese zunächst nur handschriftlich überlieferte Fassung 
hatte noch keine Landkarten. Sie wurden neu gezeichnet und mit Ortsnamen versehen. Die wissenschaftlich bedeutendste Leistung des Ptolemaeus bestand darin, das zu seiner Zeit bekannte Wissen über die Erde neu systematisiert und die Geographie durch Anwendung trigonometrischer und astronomischer Messungen auf eine neue Grundlage gestellt zu haben.

Während Strabo Repräsentant der beschreibenden länderkundlichen Geographie ist, vertritt Ptolemaeus die mathematisch-kartographische Richtung. Das Werk will zunächst nur eine Anleitung zu einer geodätisch fundierten Kartographie geben. Im ausführlichen Hauptteil zählt Ptolemaeus etwa 8.000 Orte mit Angabe ihrer geographischen Länge und Breite auf, dazu Flüsse, Seen, Inseln und Berge.

Der früheste Druck der Cosmographia in der lateinischen Übersetzung des Jacobo Angelo, herausgegeben von Angelus Vadius und Barnabas Picardus, erschien am 13. November 1475 in Vicenza. Diese Erstausgabe enthält noch keine Karten.

Vgl. auch Nr. 7 bis 10 .

5

Mela, Pomponius:

[Cosmographi Geographia] Pomponij Mellae Cosmographi Geographia. Prisciani quoque ex Dionys. Thessalonicenii de situ orbis interpretatio. Venedig: Erhard Ratdolt, 18. VII. 1482.

!HSD! 8 AUCT LAT III, 8388 INC

Pomponius Mela (um 50 n. Chr.) stammt aus dem spanischen Tingentera und gilt als erster Römer, von dem ein größeres geographisches Werk bekannt ist. Es enthält eine zonale Gliederung der Erde sowie die Beschreibungen der 'drei' Erdteile und einzelne Länder in Form eines Abrisses mit Lehrbuchcharakter. Von mathematischer Geographie im Sinne der griechischen Vorgänger ist bei Mela nichts mehr zu finden. Sein Werk stand wissenschaftlich hinter dem der griechischen Autoren weit zurück. Da es aber in lateinischer Sprache geschrieben war, blieb es länger das nachhaltig beeinflussende Lehrbuch als die Werke der Griechen.

Erhard Ratdolt, der Sohn eines Augsburger Holzbildschneiders, ließ sich 1476 in Venedig nieder, wo er eine der bedeutendsten Offizinen der Stadt begründete. Er wurde bekannt als Drucker mathematischer und astronomischer Werke, vor allem von Johannes Regiomontanus.

Vgl. Nr. 49 und 50. 
6 Albertus Magnus:

De natura locorum / Georg Tannstetter [Hrsg.]. - Argentorati: Matthias Schürer, 1515.

$43 \mathrm{Bl}$. - Mit Holzschnitten von Hans Baldung Grien.

!HSD! 8 PATR LAT 1764/95 RARA

Albertus Magnus (1193 - 1280) studierte in Venedig und Padua, wo er 1223 dem Dominikanerorden beitrat. Nach Stationen in verschiedenen Konventen des Ordens kam er 1248 nach Köln und errichtete dort eine internationale Ordenshochschule, die spätere Universität Köln. Es folgte eine ausgedehnte Wandertätigkeit zu mehr als 50 Konventen der Dominikaner.

Albertus, eine mittelalterlicher Universalgelehrter, war auf allen Gebieten des Wissens seiner Zeit, in der Theologie, der Philosophie, der Mathematik und den Naturwissenschaften tätig. $\mathrm{Zu}$ seinen großen Leistungen zählt die Rezeption und Kommentierung des Aristoteles. Er stützte sich außerdem auf Plinius, während Ptolemaeus ihm anscheinend unbekannt war. Albertus war der bedeutendste Beobachter der Natur im Mittelalter. Es lassen sich bei ihm bereits Ansätze zur empirischen und experimentellen Naturforschung entdecken, obwohl auch Alchemie und Magie zu seinem wissenschaftlichen Weltbild zählten.

1931 wurde er heilig gesprochen und 10 Jahre später zum Schutzpatron der Naturwissenschaftler erhoben. 


\section{Die Kosmographien des Ptolemaeus}

Die Cosmographia bzw. Geographia des Claudius Ptolemaeus war für die Entwicklung der europäischen Geographie über das Mittelalter hinaus bis in die Zeit des Humanismus und der Renaissance vor allem auf dem Gebiet der Kartographie von nachhaltigem Einfluss. Die Wiederentdeckung der Geographie des Ptolemaeus zu Beginn des 15. Jahrhunderts bedeutete die Bestätigung der Kugelgestalt der Erde und förderte die Suche nach einem präzisen mathematischen Projektionssystem. Von acht Büchern des Werkes enthalten allein sechs Tabellen geographischer Breiten- und Längenangaben, das achte eine Anleitung zum Entwurf von Landkarten.

Wesentlich für die Ausbreitung des Ptolemaeus war die Entwicklung des Buchdrucks. Die Ausgabe Rom 1478 ist die erste gedruckte Ausgabe, die auch 27 Kupferstichkarten enthält. Bereits 1482 kam auch in Deutschland die erste in Ulm gedruckte lateinische Ptolemaeusausgabe heraus. In den darauf folgenden 70 Jahren sind 14 weitere Ausgaben erschienen. Von 63 verschiedenen Drucken der Geographia des Ptolomaeus besitzt die Niedersächsische Staats- und Universitätsbibliothek Göttingen 39, darunter sechs Inkunabeln und 24 Ausgaben des 16. Jahrhunderts.

$7 \quad$ Ptolemaeus, Claudius:

[Cosmographia] Claudii Ptholomei Viri Alexandrini Cosmographie Liber.

- Ulm: Leonardus Hol, 16. 7. 1482. - 69 Bl., mit 64 Holzschnittkarten.

Aus dem Griechischen übersetzt von Jacobus Angelus de Scarperia. Mit Widmungsvorrede an Papst Paul II. von Nicolaus Germanus. Holzschnittkarten von Johannes Schnitzer aus Armsheim nach Vorlagen von Nicolaus Germanus.

!HSD! 2 AUCT GR V, 4145 INC RARA

Während die Erstausgabe der Cosmographia des Ptolemaeus noch ohne Landkarten gedruckt wurde, enthält diese erste in Deutschland gedruckte Ausgabe 32 Holzschnittkarten, davon 27 Karten nach ptolemaeischen Angaben und 5 neue Karten (Tabulae novae). Die von Lienhard Holl gedruckte Ausgabe der Cosmographie ist der erste Weltatlas, der nördlich der Alpen entstand. Die Landkarten haben die typische trapezförmige Projektion, die Darstellung der Gebirge, Gewäs- 


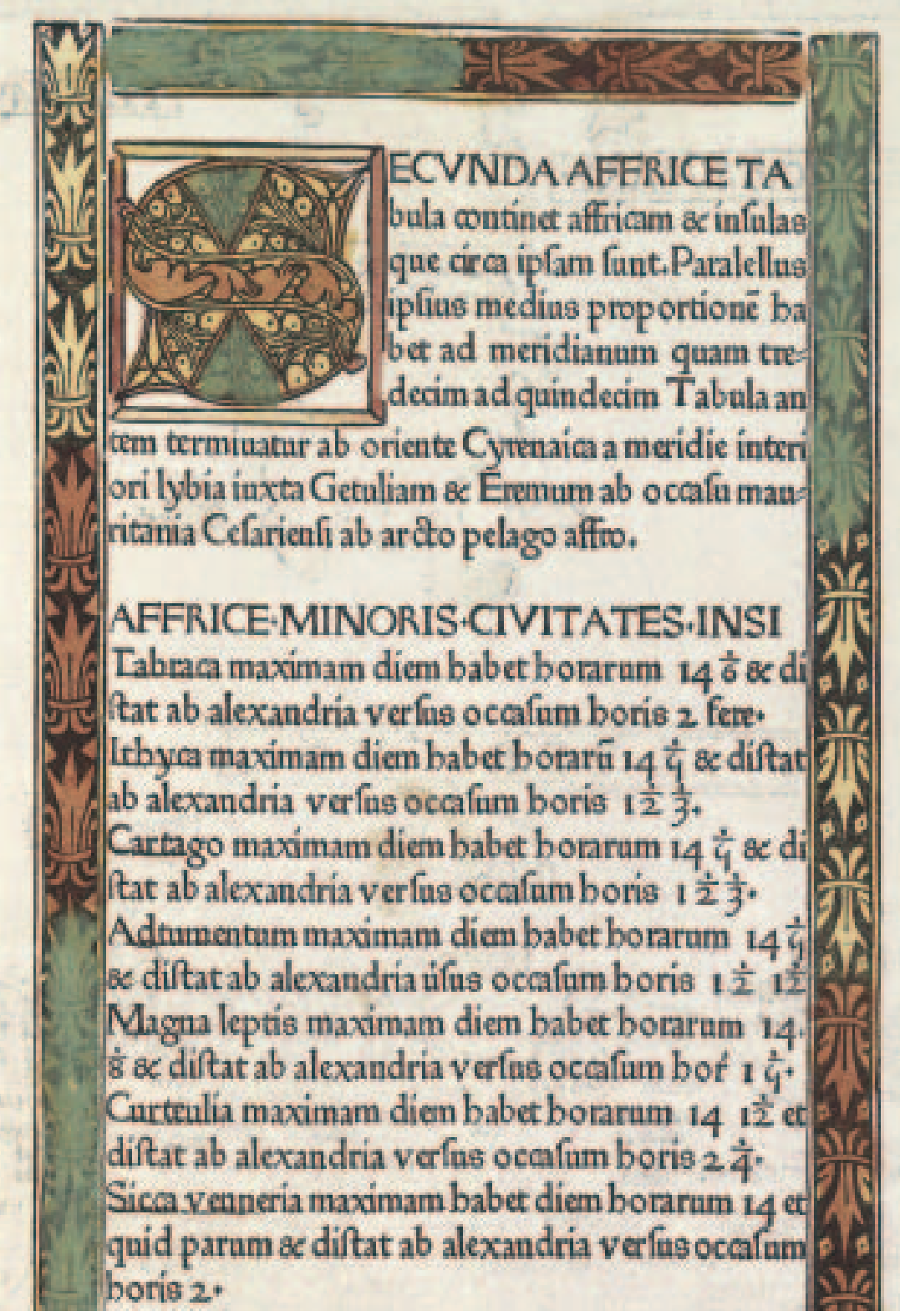

Abbildung 2 (Kat.Nr. 7)

Ptolemaeus: Cosmographia, 1482, Erläuterungen zur Afrika-Karte. 
ser und Landesgrenzen ist für die Zeit von erstaunlicher Exaktheit. Die Sorgfalt, mit der dieser Atlas hergestellt wurde, zeigt sich auch an der reichen künstlerischen Ausstattung und den schön kolorierten Karten.

$8 \quad$ Ptolemaeus, Claudius:

Cosmographia / Claudius Ptolemaeus. Nicolaus Germanus [Hrsg.]. Jacobus Angelus [Übers.]. Mit Registrum alphabeticum super octo libros Ptolemaei von Johann Reger. - Ulm: Johann Reger für Justus de Albano, 21. 7. 1486. 32 kolorierte Karten.

!HSD! 2 AUCT GR V, 4147 INC RARA

Lienhart Holl, Herausgeber der Ausgabe Ulm 1482, geriet durch den Ptolemaeus in arge finanzielle Schwierigkeiten. Er musste die Stadt verlassen und die Druckereiutensilien seinem Knecht als Ersatz für ausstehenden Lohn verpfänden. Der Dienstbote verkaufte sie an den Agenten des venezianischen Druckers Guisto d'Albano, Johann Reger aus Kemnath bei Bamberg. Reger gab mit diesen Platten 1486 die Cosmographie erneut heraus.

9 Ptolemaeus, Claudius:

[Geographiae opus] Claudii Ptolemei. - Hrsg. von Philesius und Waldseemüller. Argentoratum: Johann Schott, 1513. 47 kolorierte Karten.

!HSD! 2 AUCT GR V, 4155 RARA

Martin Waldseemüller (um 1470 - um 1518) stellte die meisten seiner Arbeiten in Kooperation mit dem Humanisten Matthias Ringmann (um 1482 - 1511) - Philesius Vogesigena - her, der hauptsächlich für Textgestaltung und Kommentare verantwortlich gewesen sein dürfte. Beide gehörten der Akademie des Gelehrtenkreis St. Dié / Lothringen an, die auch die einzige Druckerei der Stadt betrieb.

Etwa 1505 begannen Waldseemüller und Ringmann an einer Neuauflage der Geographie des Ptolemaeus zu arbeiten. 1513 erschien endlich nach Unterbrechungen - der Förderer René II. und Ringmann waren inzwischen gestorben, Waldseemüller als Bearbeiter ausgeschieden - diese wohl wichtigste Ptolemaeus-Ausgabe mit 27 alten Karten und 20 'Tabulae novae', von denen 11 von Waldseemüller selbst stammten. Die Holzschnitte besorgte Johann Grüninger, der auch sonst für Waldseemüller arbeitete, den Druck hingegen Johannes Schott, der Nachfolger Mentelins, eines Schülers Gutenbergs. 


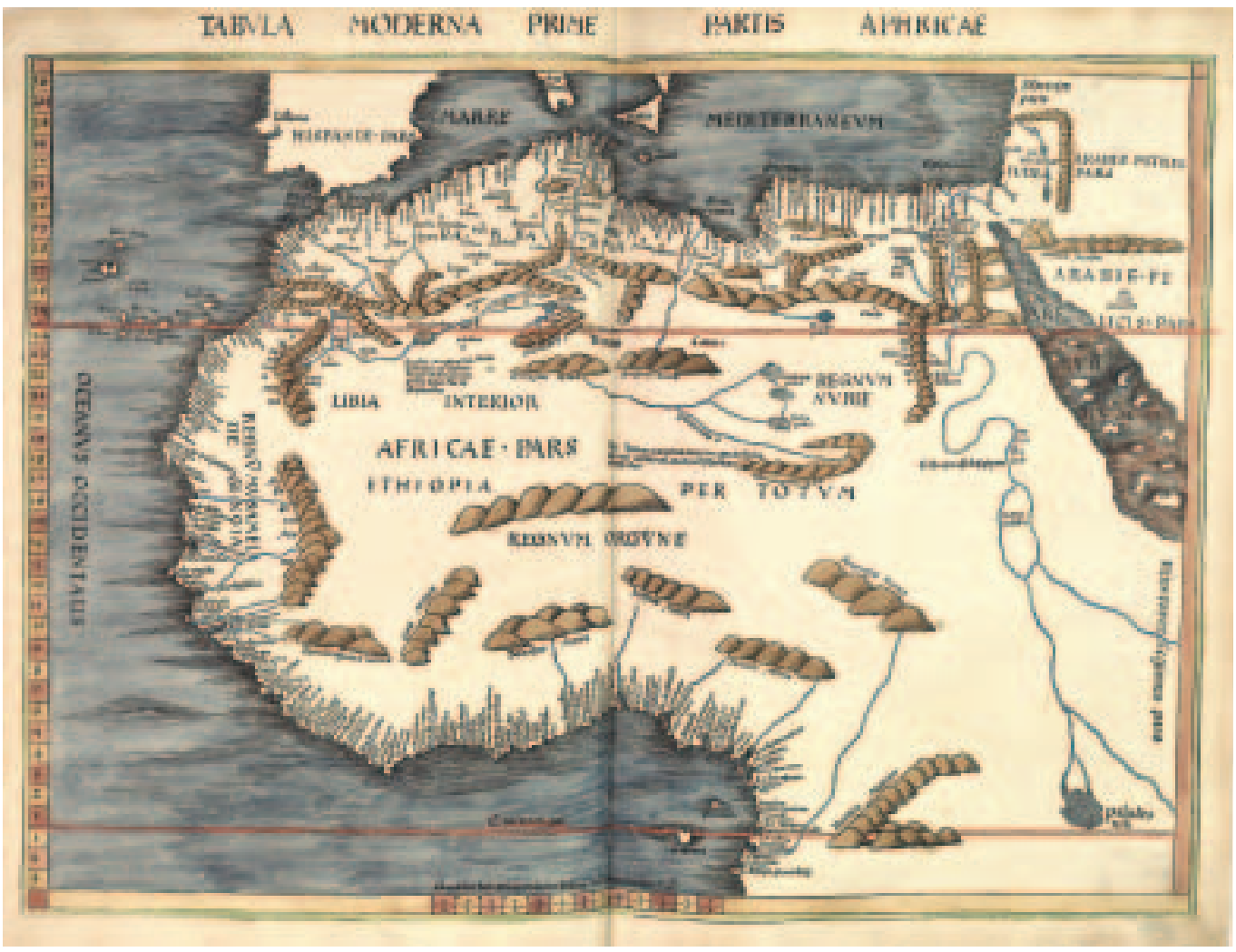

Abbildung 3 (Kat.Nr. 9)

Ptolemaeus: Geographia, 1513, Tabula Moderna Prime Partis Aphricae. 
Die 27 Karten des eigentlichen ptolemäischen Teils zeigen das gewohnte Bild, da sie ohne gravierende Änderungen von früheren Ausgaben der Geographie übernommen wurden. Für die 20 Tafeln des Supplementum zog Waldseemüller etliche weitere Quellen hinzu. So basiert die Karte Orbis Pictus auf der 1489 von dem in Florenz lebenden Henricus Martellus Germanus gezeichneten Weltkarte. Auch eine Karte der Neuen Welt fügt Waldseemüller hinzu. Es folgen eine Reihe von Regionalkarten, darunter die ältesten gedruckten Darstellungen der Rheinlande und der Schweiz.

Die künstlerische Ausführung der Karten bleibt weit hinter jener der vorangegangenen italienischen Kupferstiche zurück. Auch die Toponyme in Frakturschrift erscheinen häufig unschön, in manchen Fällen überhaupt unleserlich. Unterschiede in der Gebirgszeichnung und bei der Umrahmung der Blätter lassen auf mehrere Holzschneider oder Herstellungsphasen schließen.

Vgl. auch Nr. 51.

10 Ptolemaeus, Claudius:

[Geographia] Geographiae Claudii Ptolemaei ... Libri VIII, partim a Bilibaldo Pirckheymero translati ac commentario illustrati ... Tabulae novae quae hactenus in nulla Ptolemaica editione uisae sunt, per Sebastianum Munsterum. - Basel: Heinrich Petri, 1552. 195 S., 54 Illustrationen. !HSD! 4 AUCT GR V, 4177 RARA

Sebastian Münster (1488 - 1552) wurde nach dem Studium in verschiedenen oberrheinischen Franziskanerklöstern Professor für Hebräisch in Heidelberg. Nach dem Übertritt zur Reformation 1529 lebte und wirkte er in Basel hochgeachtet. Er starb an der Pest. Münsters 70 Werke sind vor allem der Hebraistik gewidmet, nur einige der Geographie, darunter die seit 1540 mehrfach aufgelegte Geographia des Ptolemaeus. Die hier vorliegende Ausgabe ist eine Wiederholung der Ausgabe Basel 1540 mit 27 alten Karten und 27 Tabulae novae. Die Neuübersetzung des griechischen Textes und der Kommentar stammen von dem Nürnberger Humanisten Willibald Pirckheimer (1470 - 1530), der Kartenteil von Sebastian Münster.

Vgl. auch Nr. 21. 


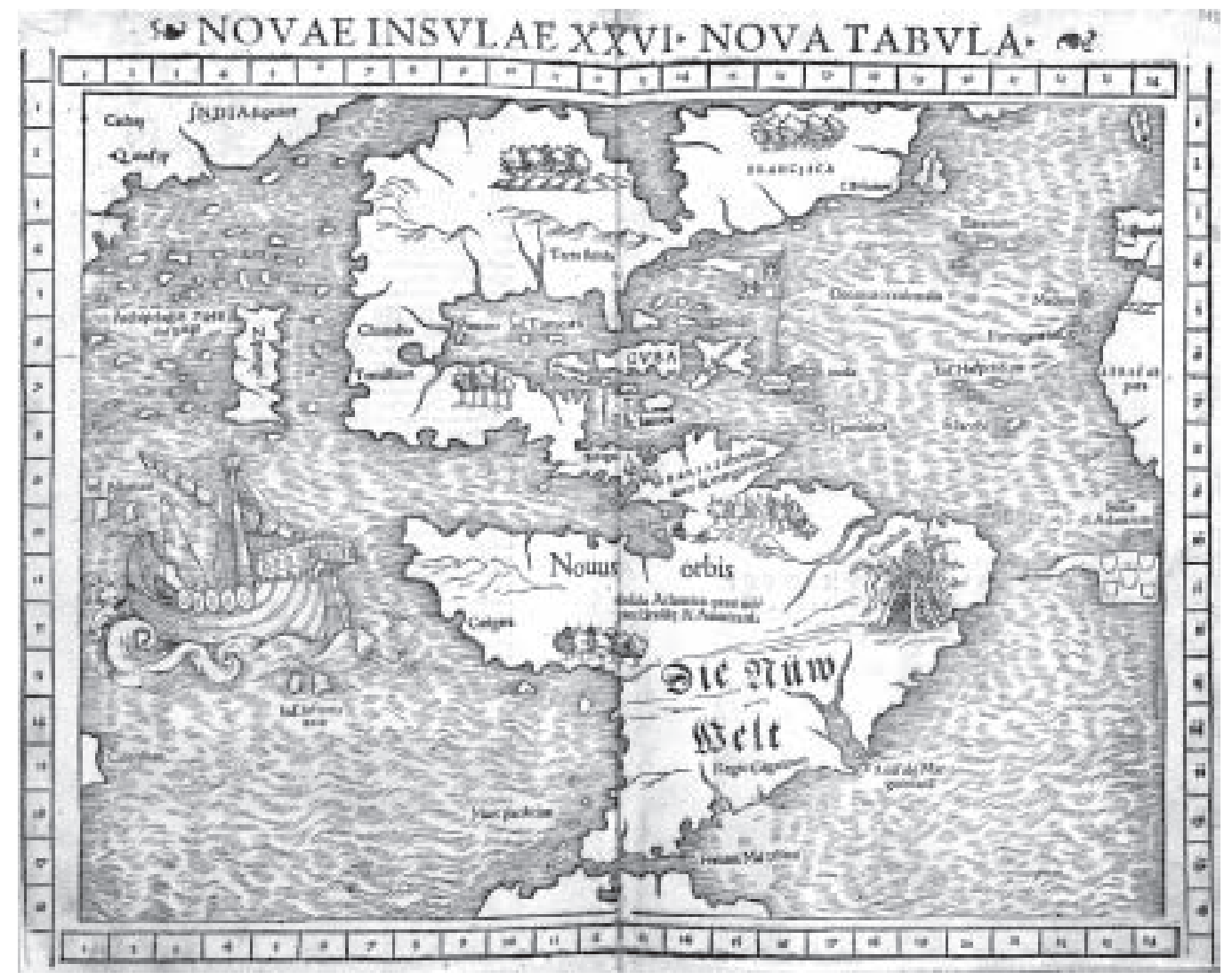

Abbildung 4 (Kat.Nr. 10)

Ptolemaeus: Geographia, 1552, Novae insulae. 


\section{Zwei Weltkarten zwischen Mittelalter und Renaissance}

Wie auf anderen Gebieten vollzog sich der Übergang vom Mittelalter zur Neuzeit auch in der Kartographie nicht plötzlich. Wie vorher die Manuskripte wurden nun die ersten gedruckten Ausgaben mit Reproduktionen der handgezeichneten Karten eines früheren Zeitalters ergänzt, die das Weltbild der mittelalterlichen Kirchenväter überliefern.

11 Rudimentum noviciorum sive Chronicarum et historiarum epitome. - Lübeck: Lucas Brandis, 1475. 474 Bl., zahlreiche Illustrationen.

!HSD! 2 H UN II, 11 INC

Im 15. Jahrhundert reproduzierte man immer noch in Druck und Holzschnitt die handgezeichneten Karten des Mittelalters. Im Jahre 1475 wurde in Lübeck ein anonymes Werk gedruckt, das die Welt nach dem Vorbild von Isidor von Sevilla beschreibt und eine Weltkarte des Sallusttypus enthält sowie eine Karte von Palästina, die früheste gedruckte regionale Karte. Die Weltkarte ist eine der ältesten sicher datierten Holzschnittkarten.

Der kolorierte Holzschnitt stellt eine nach Osten orientierte Radkarte dar. Die kontinentale Gliederung erfolgt in Anlehnung an das mittelalterliche T-Schema - unten links: Europa, unten rechts: Afrika und oben: Asien. Im Osten, wo im Mittelalter in der Regel das Paradies abgebildet wurde, erscheinen hier zwei disputierende Männer, ein Jude und ein Christ. Im Mittelpunkt Europas ist Rom, an der unteren Ecke die Säulen des Herkules.

Die Karte zeigt schon den Versuch einer topographischen Darstellung: Die Oberfläche ist mit kleinen Hügeln bedeckt, zwischen denen Wasser fließt. Meere werden aber noch nicht verzeichnet.

12 Schedel, Hartmann:

Liber chronicarum <dt.> - Anthon Koberger ... zu Nürnberg gedruckt, 23. XII. 1493.

!HSD! 2 H UN II, 56 INC 
Die Weltchronik des Hartmann Schedel (1440 - 1514) enthält zwei Karten, eine Weltkarte, die wohl von Schedel selbst gestochen wurde, und eine Karte von Mitteleuropa des Nürnberger Arztes Hieronymus Münzer (1437 - 1508). Wie die gesamte Chronik beinhaltet die Weltkarte eine Mischung aus antikem und mittelalterlichem Gedankengut. So steht der Karteninhalt in der ptolemaeischen Tradition und zeigt die drei bis dahin bekannten Erdteile Europa, Asien und Afrika. Die Karte wird von Darstellungen der Söhne Noahs eingerahmt, die die Karte halten: Sem für Asien, Ham für Afrika und Japhet für Europa. Die Randleiste der Karte ist mit Fabelwesen verziert, die die Vorstellungen von fremden Völkern in fernen Ländern wiedergeben.

Vgl. auch Nr. 25. 


\section{Portulankarten des 15. und 16. Jahrhunderts}

Portulane sind alte Seekarten, zu denen ursprünglich auch Schifferhandbücher und Navigationstabellen gehörten. Diese Seekarten ergänzten als wichtige Orientierungshilfe die schriftlichen Segelanweisungen. Unter Vernachlässigung des Binnenlandes sind die Küsten mit allen für die Schifffahrt notwendigen Angaben, wie Häfen, Ankerplätzen, Untiefen usw. wiedergegeben. Die Karten sind von einem Netz von Linien überzogen, die strahlenförmig in die Richtungen der Kompassrose verlaufen: sie dienten zur Bestimmung des Segelkurses. Eines der größten Verdienste der Portulankarten seit ihren Anfängen war die Korrektur der traditionell übertriebenen Ausdehnung des Mittelmeeres.

Von der einmal sehr großen Anzahl von Portulankarten sind durch den Gebrauch auf See nur verhältnismäßig wenig Exemplare erhalten geblieben. Sie gehören heute zu den wertvollen Stücken in den Bibliotheken.

\section{Agnese, Baptista: \\ Portulankarte des Mittelmeeres und Mitteleuropas, um 1525/30 \\ Handzeichnung auf Pergament. Gesamtgröße ca. $100 \times 70 \mathrm{~cm}$. !HSD! Cod. MS Mapp 9}

Baptista Agnese bezeichnete sich selbst als Genuese, fast alle seine Karten entstanden in Venedig zwischen 1535 und 1564, seine genauen Lebensdaten sind unbekannt. Erhalten sind über 80 handgezeichnete Portulankarten, von denen etwa die Hälfte einen Herstellervermerk aufweist. Agnese hat seine Karten ausschließlich auf Pergament gezeichnet.

Die nach Norden orientierte Karte umfasst das gesamte Mittelmeer und die atlantischen Küsten der unmittelbar angrenzenden Kontinente. Der Norden Europas wird bis Süd-Norwegen, der Osten bis zum Persischen Golf und der Süden bis Nordafrika dargestellt.

Es handelt sich um eine feine, zart kolorierte Zeichnung mit mehr Konturen- als Flächenkolorit in den Farben blau, oliv, rot und gold. 16 kleine Kompassrosen umgeben eine Zentralrose, die im nördlichen Albanien lokalisiert ist. Am Rand sind 7 Windköpfe aufgemalt. Die Karte besticht durch ihre künstlerische Gestaltung und war als Luxusausgabe wohl nicht für den praktischen Gebrauch bestimmt. 


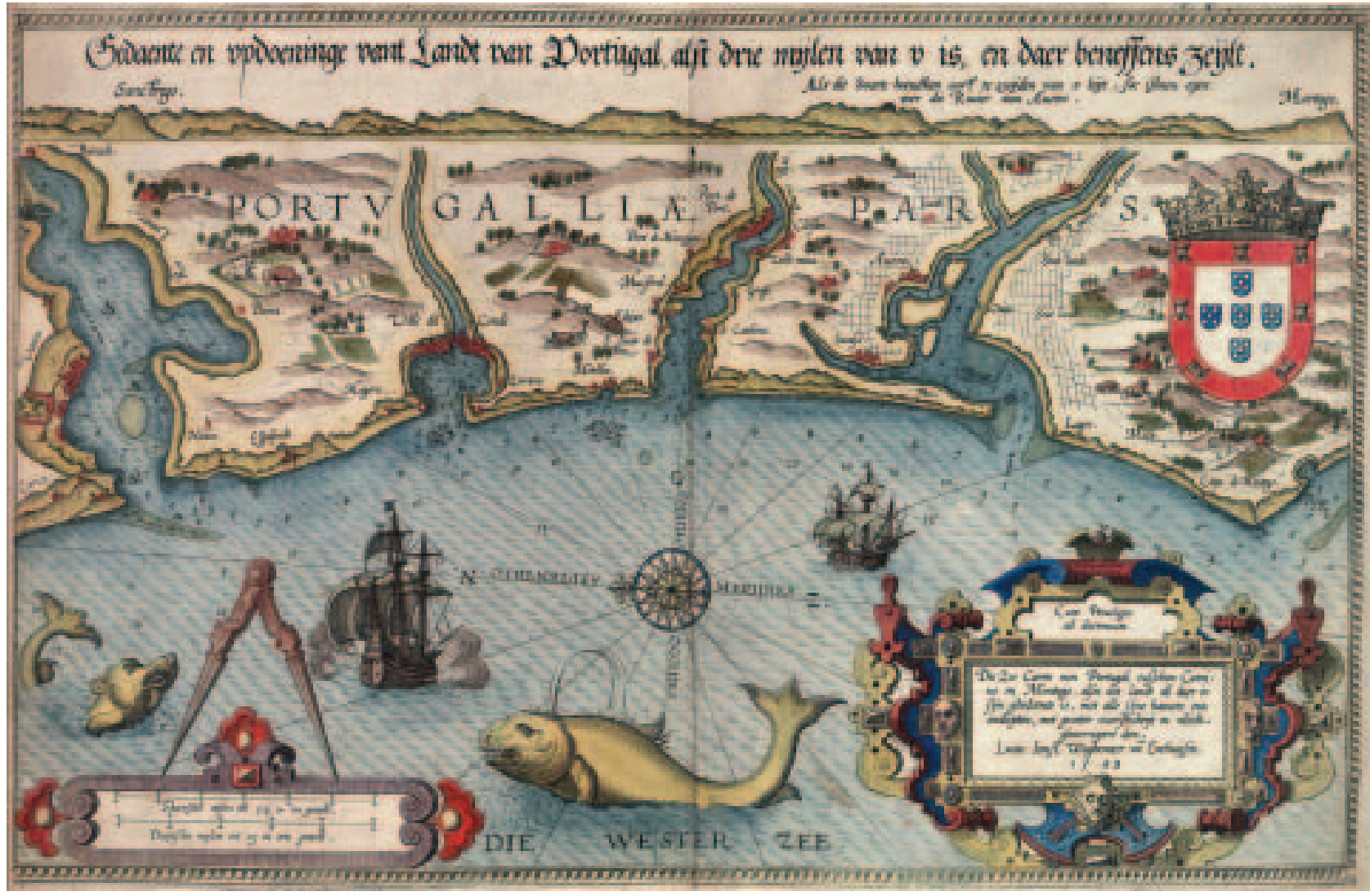

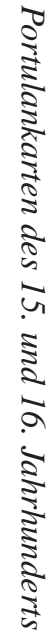

Abbildung 5 (Kat.Nr. 14)

Waghenaer: Teerste Deel van de Spieghel der Zeevardt, 1584, Zee-Caerte van Portugal. 
14 Waghenaer, Lucas Janszoon:

Teerste Deel Van de Spieghel der Zeevaerdt, van de nauigatie der Westersche Zee. Innehouhende alle de Custen van Vranckrijck, Spaignen en t'principaelste deel van Engelandt. In diuersche Zee Caerten begrepen. - Leyden: Plantin, 1584. 22 kolorierte Karten.

!HSD! 2 GEOGR 231 RARA

Der Seeatlas des Niederländers Lucas Janszoon Waghenaer (1534 - 1606) gilt als Meilenstein in der Entwicklung der westeuropäischen Navigation. Anstelle der bisher gebräuchlichen kleinformatigen Segelbeschreibungen bot Waghenaer mit seinem Seeatlas ein Folio-Format an. Neben den in Kupfer gestochenen Seekarten enthält das Werk auch kurze Segelanweisungen. Ein Novum war die kombinierte Darstellung von Küstenprofil und Küstenverlauf auf derselben Karte. Als erste Kombination von Karten und Segelanweisungen wurde es rasch in verschiedene Sprachen übersetzt und gewann z. B. in England eine derartige Beliebtheit, dass man dort ganz allgemein für derartige Seeatlanten die Bezeichnung 'Waggoner' einführte.

\section{Waghenaer, Lucas J:}

Speculum Nauticum super nauigatione maris Occidentalis confectum. Amstelredami: Apud Cornelium Nicolai, 1591.

!HSD! 2 GEOGR 234 RARA

Mit Waghenaers Segelhandbüchern setzte sich die niederländische Seekartographie auf dem europäischen Markt durch und beherrschte ihn während des gesamten 17. Jahrhunderts. Mit der stürmischen Entwicklung der niederländischen Handelsmarine ging der Bedarf an besseren Seekarten Hand in Hand. In Nord-Holland wurden sie durch eine Gruppe von Kartographen angefertigt, die man unter dem Namen 'Niederländische Kartographenschule' mit Zentren in Edam und Enkhuisen zusammenfasst. Höhepunkte von deren Produktion wurden die Arbeiten von Waghenaer, die richtungsweisend für die gesamte Entwicklung der westeuropäischen Navigation werden sollten. Andere bedeutende Hersteller der Nordholländischen Kartographenschule waren Cornelis Doedsz und Joris Carolus. Ihre Werke publizierten teilweise die Amsterdamer Verleger Cornelis Claesz, Willem J. Blaeu und Everard Cloppenburg. 
16 Waghenaer, Lucas J.:

Thresoor Der Zee-Vaert. Inhoudende de geheele Navigatie ende Schip-vaert vande Oostersche, Noordtsche, Westersche ende Middelantsche zee, met alle de Zee-caerten daer toe dienende. Insghelijcx het oude vermaerde Leescaertboeck van Wisbuy vermeerdert, ende van ontallijcke fauten en valsche coersen ghesuyvert. Mitsgaders de streckinghe van Ruslandt, ende in de Witte-zee tot Ombay in Laplant. Ende oock de streckinghe vande Middellandtsche oft Levantsche zee, door de Gricxsche Eylanden tot Trapezonde in Asien - Leiden: François vam Raphelengien, 1592. 206 S., 44 Bl., überwiegend Text.

!HSD! 4 GEOGR 232 RARA

Nach seinem Spieghel der Zeevaert erschien 1592 Waghenaers zweiter Seeatlas, der vier weitere Auflagen erlebte. Ihn zeichnen verbesserte, ausführlichere Gewässer- und Küstenbeschreibungen sowie Segelanweisungen aus. Im Thresoor spiegelt sich die Erweiterung des Fischerei- und Handelsgebietes der Niederländer deutlich wieder. Der Atlas erschien in dem für den Seemann geeigneteren OblongFormat, zur optimalen Ausnützung der Tafeln sind die Karten verschieden orientiert. 


\section{Von den ältesten gedruckten Straßenkarten}

Straßenkarten dienen mit ihrer besonderen Hervorhebung des Wegenetzes samt Klassifizierung und Entfernungsangaben der Orientierung und sind stets auf eine praktische Anwendung ausgerichtet. Die Tabula Peutingeriana, die das Straßennetz des römischen Reiches wiedergibt, und die Straßenkarten von Etzlaub gehören zu den ältesten Straßenkarten.

17 Tabula Itineraria ex illustri Peutingerorum Bibliotheca / Beneficio Marci Velseri ... in lucem edita. - Nicht maßstäbig. - Antwerpen: Plantin, 1598.

1 Kt. in 8 Teilen. Kupferstich. Gesamtgröße $395 \times 19 \mathrm{~cm}$.

!HSD! 2 GEOGR 129/b, 38 RARA

Die ursprünglich aus 11 Pergamentsegmenten bestehende $675 \mathrm{~cm}$ lange, aber nur $34 \mathrm{~cm}$ breite Darstellung zeigt das Imperium Romanum, im Norden von der Donau begrenzt, im Osten bis nach Indien erweitert. Das äußere Format der Karte ermöglichte keine Projektion, sondern erzwang eine grobe Verzerrung des Kartenbildes. Hauptzweck der Karte war die schematisierte Wiedergabe des Straßennetzes mit Etappenorten sowie Entfernungsangaben. Die Lage der Orte zueinander und die Entfernungen sind durch Linien und Meileneintragungen gekennzeichnet. Die Karte stellt große Teile der damals bekannten Welt als Straßenkarte dar, doch kann sie keinesfalls als typisches Produkt der römischen Kartographie angesehen werden. Ihren Namen erhielt die Karte nach dem Augsburger Humanisten Konrad Peutinger (1465 - 1547), in dessen Besitz sie 1508 gelangte.

18 Fragmenta Tabulae antiquae in quis aliquot per Romanas prouincias Itinera: Ex Peutingerorum bibliotheca / Edente [et] explicante Marco Velsero. Venetiis: Aldus, 1591.

8 GEOGR 134

Das Manuskript zweier Fragmente der Tabula Peutingeriana wurde noch vor der Auffindung der gesamten Pergamentrolle durch den Augsburger Gelehrten Martin Welser (1558 - 1614) kopiert und veröffentlicht. 1598 erschien dann die erste Gesamtausgabe von Abraham Ortelius. 
19 [Erhard Etzlaub]:

Das ist der Rom-Weg von meylen zu meylen mit puncten verzeychnet von eyner stat zu der andern durch deutzsche landt. - [Ca. 1:5.600.000]. [Nürnberg], [ca. 1500].

Holzschnitt. $29 \times 36 \mathrm{~cm}$.

!HSD! Mapp 2570

Abbildung auf S. 38

Diese für Rompilger für das Heilige Jahr 1500 gedachte Karte ist nach Süden orientiert und folgt, wie die übertrieben schräge Lage von Italien zeigt, noch Ptolemaeus. Die Himmelsrichtungen heißen Aufgang, Mittag und Undergang. Am linken Rand sind die Breitengrade angegeben, am rechten die Dauer des längsten Tages in Stunden. Die wichtigsten Pilgerstraßen nach Rom sind punktiert eingetragen, wobei der Abstand zwischen zwei Punkten jeweils 1 Meile beträgt. Im Mittelpunkt der Karte liegt Nürnberg. Erhard Etzlaub, um 1460 - 1532, war Nürnberger Instrumentenmacher und Kartograph.

Von dieser ältesten Straßenkarte sind mindestens 6 Exemplare aus drei Auflagen bekannt, neben dem Exemplar der SUB Göttingen eines im Germanischen Nationalmuseum in Nürnberg und jeweils eines in der Bibliothèque Nationale in Paris und in der British Library in London.

Etzlaubs Straßenkarte war neben der Cusanus-Karte (1491) die wichtigste Darstellung Mitteleuropas. Sie beruhte zweifellos auf praktisch gewonnenen Erfahrungen und berücksichtigte wohl auch noch Zeichnungen der Fridericus-Karte, der ältesten kartographischen Darstellung Mitteleuropas aus der ersten Hälfte des 15. Jahrhunderts, die aber nicht erhalten ist. Martin Waldseemüller ließ sich davon bei der Arbeit für seine Deutschland-Karte inspirieren. 


\section{Die großen Kosmographien}

Seit der Antike galt das Beschreiben der Topographie, der Landschaften, aber auch der Sitten und Bräuche der Völker als fester Bestandteil der geographischen Wissenschaft. Sowohl das Beschreiben von Ländern als auch das Anfertigen von Karten bezeichnete man als Kosmographie. Tatsächlich wurden die Begriffe Kosmographie und Geographie weitgehend synonym gebraucht.

20 Pius <Papa, II.>:

Historia rerum ubique gestarum. Cvm locorvm descriptione non finita. Asia minor incipit. - Venedig: Johannes de Colonia und Johannes Manthen de Gherretz, 1477.

!HSD! 4 H UN II, 64 INC

Eneas Sylvio Piccolomini (1405 - 1464), Papst seit 1458, war einer der bedeutendsten Humanisten seiner Zeit. Seine Kosmographie lehnt sich stark an Ptolemaeus an, behandelt aber hauptsächlich nur Asien. Eneas Silvius gehörte zu den ersten, die bewusst in die freie Natur gingen, um mit Genuss eine Landschaft zu betrachten, und sich auch darum bemühten, diesen Eindruck zu schildern.

21 Munsterus, Sebastianus:

Cosmographiae universalis lib. VI. in quibus iuxta certioris fidei scriptorum traditionem describuntur. Omnium habitabilis orbis partium situs, pro priaeque dotes ... - Basileae: Petri, 1559. 1162 S.

!HSD! 2 GEOGR 625 RARA

Sebastian Münster (1489 - 1552), Theologe, Hebraist und Kosmograph, seit 1521 Professor in Basel, Schüler des Tübinger Mathematikers, Astronomen und Kosmographen Johannes Stoeffler, arbeitete an seiner Cosmographie seit 1524. Das Werk sollte zunächst ein kommentierter Atlas sein. Münster selbst hat oberrheinisches Gebiet bereist, um in eigener Beobachtung Kartengrundlagen zu schaffen - ein bedeutsamer Vorgang, der ihn zwar nicht als Forschungs-, aber doch als Erkundungsreisenden auswies. Als sein Werk 1544 in erster Auflage erschien, wurde 


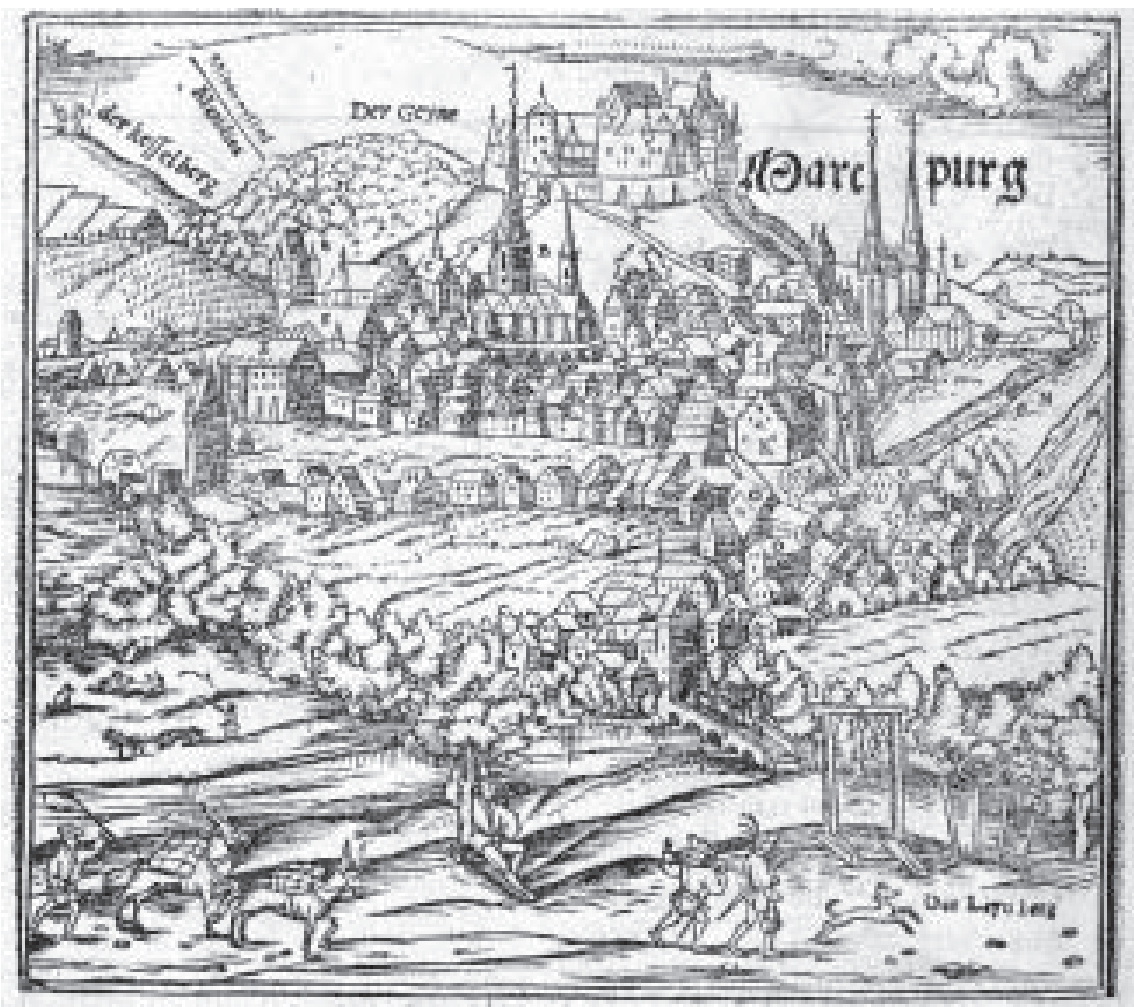

Abbildung 6 (Kat.Nr. 21)

Seb. Münster: Cosmographiae universalis lib. VI, 1559, Ansicht von Marburg. 
es zum großen Erfolg. Für 100 Jahre blieb es das bekannteste geographische Werk. 1550, zwei Jahre vor Münsters Tod, erreichte es in seiner deutschen Version seinen Höhepunkt. Die Ausgabe enthielt bis zu 1000 Holzschnittillustrationen (z.T. von H. Holbein d. J. und Matthäus Merian d. Ä.). Die Holzschnittkarten sind naiv gestaltet, besitzen aber dennoch eine hohe attraktive Wirkung, vor allem durch die dekorativen Beigaben wie Schiffe und Fabelwesen. Das Werk vereinigte Geschichte und Beschreibung in einem. Zwar ist diese Weltbeschreibung nicht der Beginn der Geographie in Deutschland, wohl aber deren bis dahin international bekanntestes Zeugnis. Es erlebte von 1544 bis 162821 deutsche Auflagen. Von ca. 50.000 gedruckten Exemplaren sind etwa 2.500 erhalten. Sie gilt als der Höhepunkt der Weltbeschreibung in der Renaissance.

Vgl. auch Nr. 10.

22 Rauw, Johann:

Cosmographia / Johann Rauw. - Frankfurt am M., 1597.

!HSD! 2 GEOGR 642 RARA

Im Mittelalter verfasste man Kosmographien als Einführungen zu Weltchroniken oder als eigene Kapitel in enzyklopädischen Kompendien. In einem völlig neuen Sinn verwandte Sebastian Münster den Begriff Kosmographie, als er eine von ihm zusammengestellte Kompilation geographischen, historischen und altertumskundlichen Wissens als Cosmographia bezeichnete, obwohl nur eines von 6 Büchern sich mit der mathematischen Geographie auseinander setzte. Der neue Typ löste den alten ab. Einer der Epigonen Münsters war Johann Rauw (? - 1600), Pfarrer und Kosmograph. Er benutzte für die Karten seiner Kosmographie die Platten des Matthias Quad. Seine Kosmographie war aber bei weitem nicht so erfolgreich wie die Münsters.

23 Thevet, André:

La Cosmographie universelle. - Paris, 1575.

!HSD! 2 GEOGR 635:1.2 RARA

Der Franziskanermönch André Thevet (1502 - 1590) nahm im Auftrag der französischen Krone an einer Orientfahrt 1542 und an einer Expedition nach Brasilien 1555 - 1557 teil. Er sammelte umfangreiche Informationen aus allen ihm zur Ver- 
fügung stehenden Quellen, die er teilweise wenig kritisch übernahm. So stellte er in seinen Reisebeschreibungen die Ereignisse in der französischen SüdamerikaKolonie und die calvinistischen Missionsbestrebungen stark verzerrt dar. Informationen über die unerträglichen sozialen Zustände findet man bei ihm nicht, dennoch gibt er ein anschauliches Bild über Religion, Sprache und Kultur der TupiIndianer im 16. Jahrhundert. 1556 bringt Thevet erstmals Tabaksamen nach Frankreich. Seine große Kosmographie von 1575 enthält unter anderem vier Karten der Erdteile. Für seine Arbeiten wurde er zum Cosmographe du Roy ernannt.

24 Merula, Paulus:

Cosmographia generalis. - Ex Officina Plantiniana Raphelengij ... Vaeneunt etiam Amsteldami apud Cornelium Nicolai, 1605. 1358 S. und zahlreiche Karten.

!HSD! 4 GEOGR 644 RARA

Das letzte Buch, das den Titel Kosmographie führte, ist das Werk des Niederländers Paulus Merula (1558 - 1607). Es erschien zuerst 1605 mit insgesamt 4 Auflagen bis 1648. Die Kosmographie war ganz im alten Stil gehalten. Mit wenig kritischen Ansätzen und ohne eigenes wissenschaftliches System sind darin Zitate aus der Antike, dem Mittelalter und aus der Bibel zusammengestellt, Bücherwissen im Stil der älteren Vorgänger. Merula war ein über die Niederlande hinaus bekannter Jurist, der später Geschichte an der Universität Leiden lehrte. Fünf Karten aus dem Werk wurden von Johann und Baptist Doetecum graviert, Mitglieder einer bedeutenden niederländischen Stecherfamilie, die in mehreren Generationen u.a. die Karten für L. J. Waghenaer Spieghel der Zee-vaerdt, für de Jodes Speculum Orbis Terrarum oder J. H. van Linschotens Itinerario gestochen haben. 


\section{Stadtansichten}

Stadtansichten, graphische Wiedergaben der gesamten Stadt als selbständiges Bildmotiv, kommen als Holzschnitt oder Kupferstich in Welt- und Länderbeschreibungen vor allem des 16. und 17. Jahrhunderts vor. Einen Höhepunkt in der Entwicklung der Stadtansicht stellt unbestritten die Tätigkeit Matthäus Merians als Stecher und später auch als Verleger dar.

25 Schedel, Hartmann:

Liber chronicarum <dt.> - Anthon Koberger ... zu Nürnberg gedruckt, 12. 7. 1493.

!HSD! 2 H UN II, 53/b INC

Die aus zahlreichen Quellen zusammengestellte Weltchronik des Nürnberger Arztes und Humanisten Hartmann Schedel ist mit 1809 Holzschnitten das am reichsten illustrierte Werk des 15. Jahrhunderts. Die in dieser Weltchronik zahlreich enthaltenen Ansichten in Holzschnitt entsprachen nur zum Teil der Wirklichkeit, zum Teil entsprangen sie der Phantasie. Die Stadtansichten werden als Aufrisszeichnungen - wie von einem gegenüberliegenden Hügel aus gesehen - dargestellt. Während in früheren Druckwerken nur schematische, kleine, mehrfach für verschiedene Städte verwendete Holzschnitte zu finden sind, weisen die Karten der Weltchronik topographische Realität auf, allerdings noch mit ornamenthafter Anordnung der Architektur.

Vgl. auch Nr. 12.

26 Braun, Georg:

Beschreibung und Contrafactur der vornembster Stät der Welt / Georg Braun; Franciscus Hogenbergius; Simon Novellanus. - Cölln, 1572 - 1598. 5 Bde.

!HSD! 2 GEOGR 707 RARA

Georg Braun (1542 - 1622) war Dechant zu Köln, Topograph und Herausgeber der sogenannten Kölner Cosmographie, einer Sammlung von Städtekupfern mit kur- 


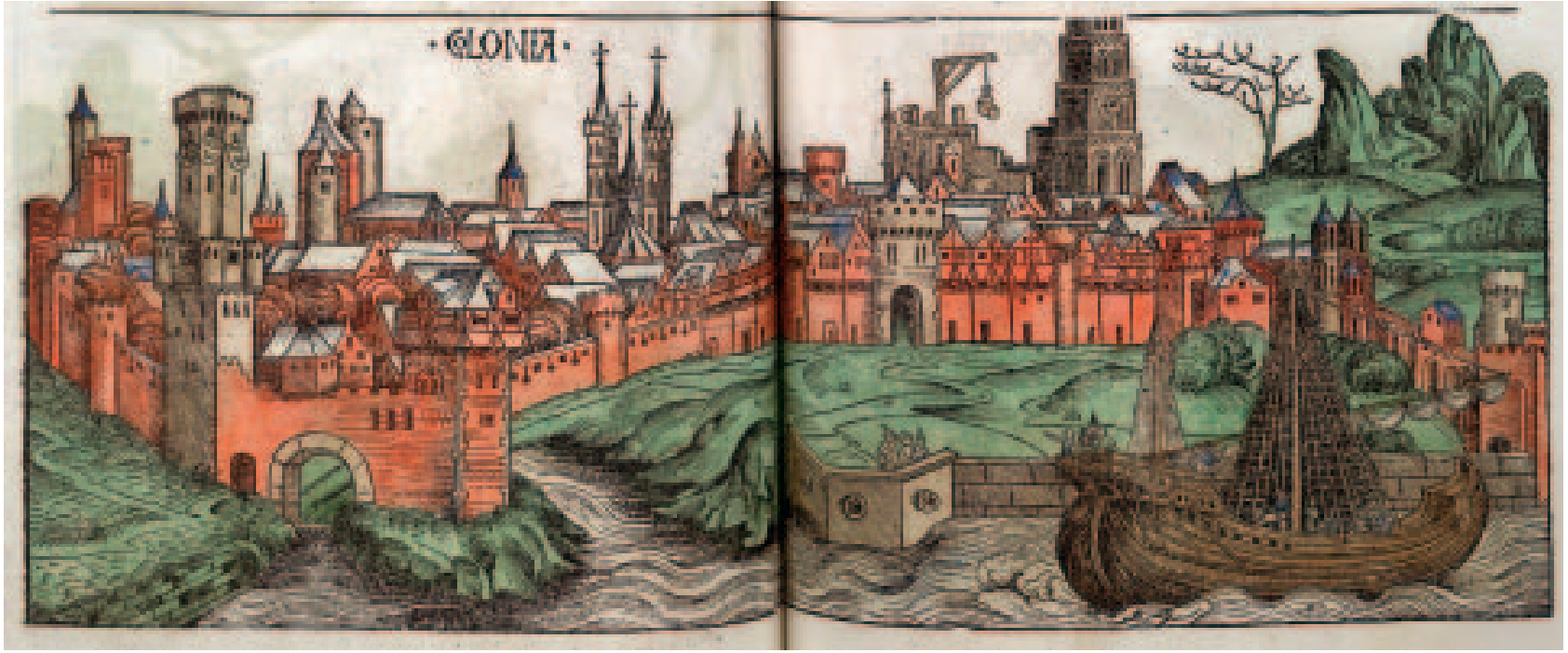

$\frac{1}{3}$
$\frac{1}{3}$
$\frac{1}{3}$
$\frac{1}{2}$

Abbildung 7 (Kat.Nr. 25)

Hartmann Schedel: Liber chronicarum, 1493, Ansicht von Köln. 
zer historisch-geographischer Beschreibung. Zum ersten Mal wurden die wichtigsten Städte der Welt mit kartographischer und topographischer Genauigkeit abgebildet. Das Städtewerk setzte neue Maßstäbe in der Darstellung, da es neben der Seitenansicht der Städte vor allem die Ansicht aus der Vogelschau in einer Art Militärperspektive mit deutlich verbreiterten Straßen zur besseren Einsicht in den Straßengrundriss verwendete. Radierungstechnik und Großformatierung erlaubten gegenüber den früheren kleinen Holzschnitten, z. B. bei Sebastian Münster, einen Zugewinn an Detailtreue. Bis ins 18. Jahrhundert wurden Platten dieses Werkes benutzt. Die Aufnahmen stammten z. B. von dem Antwerpener Zeichner Georg Hoefnagel (1542 - 1600). Stecher waren u. a. Franz Hogenberg (1540 - um 1590), Simon van den Neuwel und Abraham Hogenberg.

27 Merian, Matthäus / Zeiller, Martin:

Topographia und eigentliche Beschreibung der vornembsten Stäte, Schlösser, auch anderer Plätze und Örter in denen Hertzogthümer Braunschweig und Lüneburg, und denen dazu gehörenden Grafschafften, Herrschafften, und Landen / Matthaeus Merian inventor et sculpsit. - Franckfurt: Matthaei Merians S. Erben, 1654. 220 S., zahlreiche Kupferstiche und Karten. !HSD! 2 GEOGR 680 RARA

\begin{abstract}
Alphabetisch nach Ortschaften geordnete topographische Beschreibung der Braunschweig-Lüneburgischen Lande. Das Werk besteht überwiegend aus Stadtbeschreibungen von Martin Zeiller mit zahlreichen Stadtansichten von Matthäus Merian.
\end{abstract}

Matthäus Merian (1593 - 1650) war Schüler des Kupferstechers, Verlegers und Druckers Johann Theodor de Bry in Frankfurt am Main, dessen Tochter er 1619 heiratete. Auf seinen Reisen, vor allem aber in Basel, entstanden viele Zeichnungen, Kupferstiche und Radierungen von hohem künstlerischen Rang. 1623 übernahm Merian das Geschäft seines Schwiegervaters und widmete sich von da an ganz dem Verlagsunternehmen. In rascher Folge wurden etliche Kupferstichwerke veröffentlicht, darunter die 16-bändige, von Martin Zeiller verfasste Topographie.

Dieses Werk erschien von 1642 bis 1688. Es enthält 1486 Kupfer mit 2142 Einzelansichten und 92 Landkarten. Sachlich sind die Bände geordnet nach deutschen Kreisen und Ländern. Unter Merians Söhnen folgten später die Nachbarländer Schweiz, Niederlande, Frankreich und Italien. Ein Teil der Tafeln, besonders Ansichten aus dem südwestdeutschen Raum und der Schweiz, wurden von Merian selbst gestochen und vielfach auch gezeichnet. Der größte Teil entstand aber nach fremden Vorlagen und wurde von verschiedenen Stechern und Radierern ausgear- 
beitet. Vieles wurde aus anderen Werken kopiert, wie auch umgekehrt Merians Stiche häufig als Vorlagen für andere Veröffentlichungen dienten. Eigenständige Entwürfe sind Merians meist sehr genaue Vogelperspektiven. Die Darstellung einer Stadt aus der Vogelperspektive kam dem Käuferpublikum durch ihre Anschaulichkeit sehr entgegen. Gerade durch Merian fand dieses Genre im 17. Jahrhundert große Verbreitung. Der erfolgreiche Verlag Merians wurde durch seine Söhne, die ebenfalls als Künstler, Verleger und Drucker wirkten, weitergeführt. Verlag und Druckerei bestanden bis 1727 in Frankfurt a. M.

28 Merian, Matthäus / Zeiller, Martin:

Topographia Helvetia, Rhæetia, Et Valesia. Das ist, Beschreibung vnnd eygentliche Abbildung der vornehmsten Stätte vnd Plätze in der Hochlöblichen Eydgnoßschafft, Graubündten, Wallis, vnd etlicher zugewandten Orthen. - In dieser andern Edition mit sonderm fleiß durchgangen, und von vorigen Fehlern corrigirt, vermehrt und gebessert. - Frankfurt am Mayn, Zum Truck verlegt von denen Merianischen Erben ..., 1654, [erschienen] ca. 1655. - 90 S., [5] Bl., 77 Taf. (Kupferstiche).

!HSD! 2 GEOGR 683 RARA

Topographie der Schweiz mit Stadtbeschreibungen von Martin Zeiller und mit Stadtansichten von Matthäus Merian. Der Band erschien erstmals 1642, die hier vorliegende ist die dritte deutsche Ausgabe, erschienen nach 1654, vermutlich 1655. Der Kupfertitel ist derselbe wie in der Erstausgabe, der Karten- und Textteil wurde von Merians Sohn Caspar neu zusammengestellt und ergänzt.

Merians Schweiz ist unter allen Topographiebänden der interessanteste und in qualitativer Hinsicht gewiss der wertvollste, in seiner Zusammensetzung aber auch der unausgeglichenste. Die alle späteren Bände kennzeichnende Gleichförmigkeit findet sich bei ihm noch nicht ausgeprägt. Die Schweizer Topographie erwies sich für Merian als bedeutender kommerzieller Erfolg. Er sah sich in der Absicht, ihr weitere Bände folgen zu lassen, bestätigt, und setzte den Plan einer allgemeinen deutschen Topographie auch sogleich in die Tat um, indem er jährlich ein bis zwei weitere Bände herausbrachte.

Matthäus Merian lebte in seiner Kindheit und Jugend von 1593 bis 1607 in Basel. 1615 kehrte er nach Ausbildungsstationen in Zürich, Straßburg und Paris nach Basel zurück. Hier entstand 1615/17 sein großer Basler Stadtplan, von dem er eine verkleinerte, inhaltlich aber fast identische Version der Topographie beifügte.

Vgl. auch Nr. 27. 


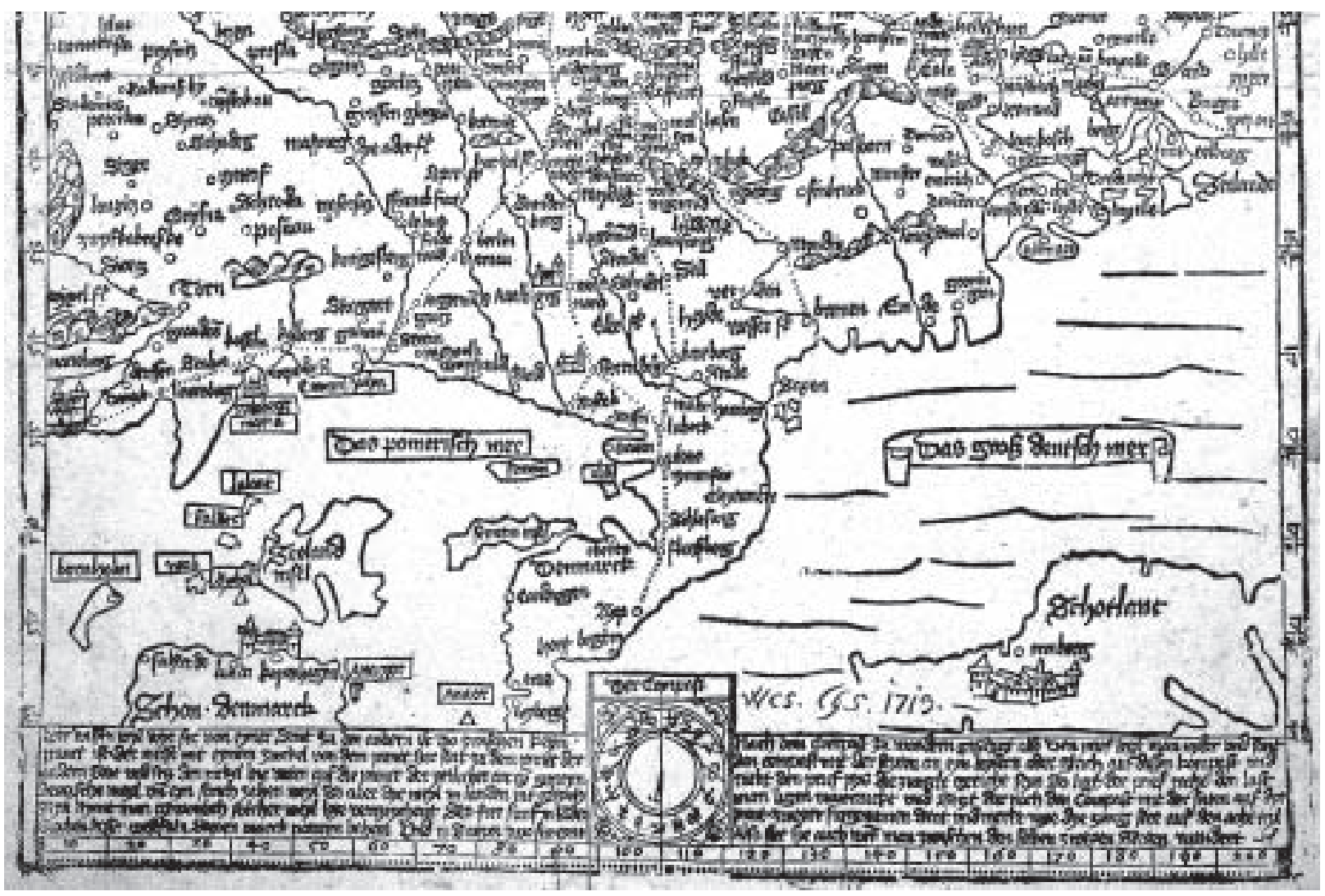

Abbildung 7a (Kat.Nr. 19)

[Etzlaub]: Das ist der Rom-Weg ... [Ca. 1 : 5.600.000]. - [Um 1500].

(Ausschnitt u. a. mit Göttingen) 


\section{Das Jahrhundert der Atlanten}

Sammelbände von Karten gab es schon lange, bevor der Begriff Atlas aufkam. Bis zur beginnenden Neuzeit gab es keinen einheitlichen Begriff für diese Kartenbände: Theatrum, Speculum, Tabulae geographicae, Prospectus oder Landtafeln wurden diese Kartensammlungen in Buchform bezeichnet. Die Karten, die der Geographie des Ptolemaeus beigefügt waren, umfassten die Welt, soweit sie diesem bekannt war. Sie stellten also schon eine Art Weltatlas dar. Die entscheidende Wende in der Atlaskartographie ging aber von den Niederländern aus, als sie ab 1570 begannen, Verlegeratlanten mit einer pro Ausgabe festen Anzahl und Reihenfolge von Karten gleicher Größe zu publizieren. Einen vorläufigen Höhepunkt dieser Entwicklung erreichte Gerard Mercator mit seinem zwischen 1585 und 1595 lieferungsweise veröffentlichten Kartenwerk.

29 Mercator, Gerard:

Atlas sive cosmographicae meditationes de fabrica mundi et fabricati figura - Dusseldorpii // Düsseldorf: Bernardus Busius, 1602. Mit mehreren Kupfertiteln $u$. Verfasserporträt.

!HSD! 2 GEOGR 155/a RARA

Es kann kein Zweifel darüber bestehen, dass Gerard Mercator (1512 - 1594) als der bedeutendste und umfassendste Kartograph des 16. Jahrhunderts anzusehen ist. Von ihm kennt man eine Reihe herausragender Leistungen in den unterschiedlichsten Teildisziplinen wie der Projektionslehre (Mercatorprojektion), historischen Kartographie, der Globenkunde usw. Mercator war nicht ausschließlich Kartograph, sondern noch mehr Philosoph und Humanist, der sich besonders für die geistigen Strömungen seiner Zeit interessierte.

In seiner Duisburger Werkstatt begnügte sich Mercator nicht damit, seine Karten zu entwerfen und zu zeichnen, sondern er fertigte auch selbst die Kupferstiche an. Die Vollendung seines Atlas wurde dadurch verzögert, dass Mercator nicht genügend Kupferstecher zur Verfügung hatte. An dem vorliegenden Atlas arbeitete Mercator seit 1569, einzelne Teile erschienen seit 1585. Erst ein Jahr nach dem Tod Mercators gab sein Sohn Rumold 1595 das Gesamtwerk mit 107 Karten heraus, in dessen Titel erstmals der Name Atlas verwendet wurde. Der Atlas wurde nach seinem Erscheinen nicht sofort populär. Unter den direkten Erben Mercators er- 
lebte er nur eine einzige Neuauflage 1602. Schließlich gingen die Kupferplatten und Druckrechte 1604 an Jodocus Hondius in Amsterdam über, der von 1606 an viele neue Ausgaben mit zunehmender Breitenwirkung veröffentlichte.

Gegenüber Ortelius Theatrum lassen die Karten von Mercator eine starke Versachlichung in wissenschaftlicher Hinsicht erkennen. Die Projektionsarten variieren nach Bedarf, alle Tafeln weisen eine Randgraduierung auf. Der Nullmeridian verläuft durch die Inselgruppe der Azoren. Der kartographische Inhalt selbst wird klar, einfach und weitgehend schmucklos dargeboten.

30 Jode, Cornelis de:

Speculum Orbis Terrarum/[Cornelius De Iudaeis]. - Antwerpen: Arnoldus Coninx, 1593. $190 \mathrm{Bl}$. und zahlreiche Karten.

!HSD! 2 GEOGR 155/d RARA

Die Familie de Jode gehört zu jenem Kreis von Kupferstechern aus den nördlichen Provinzen der Niederlande, die in Antwerpen eine erfolgreiche Karriere als Kupferstich- und Kartenhändler sowie Verleger machten. Gegründet von Gerard de Jode (1509 - 1591), wurde der Verlag nach dessen Tod von seiner Witwe und seinem Sohn Cornelis (1558 - 1591) weitergeführt. Haupteinnahmequelle des Geschäftes war zunächst der Handel mit Kupferstichen, später kamen lose Kartenblätter hinzu.

Ausgestellt ist die zweite Ausgabe des Speculum orbis terrarum, herausgegeben durch Cornelis de Jode, mit zum Teil neuen oder revidierten Kartenblättern. Die Erstausgabe 1578 erfolgte durch Gerard de Jode, dessen Karten größtenteils schon ab den 1570er Jahren als Einzelblätter im Handel waren. Das an Ortelius verliehene Privileg zur Herausgabe eines Weltatlasses Theatrum Orbis Terrarum verhinderte erfolgreich das Erscheinen des Speculum vor 1578. Obwohl de Jodes Atlas, was die dekorative Gestaltung anbelangt, wahrscheinlich die gefälligsten aller Renaissancekarten enthält, konnte er sich dennoch nicht gegen das bereits bestens eingeführte Konkurrenzwerk von Abraham Ortelius behaupten.

Alle Darstellungen sind von versierten Kupferstechern sorgfältig ausgeführt, und zwar von den Brüdern Joannes und Lucas van Doetecum, die ein neues, besonders für Karten geeignetes Ätzverfahren entwickelt hatten. Mit der ornamentalen Umrahmung, den prächtigen Kartuschen, dem reichen figuralen Schmuck sowie den Sagentieren entsprachen die Tafeln ganz dem Zeitgeschmack. Wegen der geringen Auflagen ist der Atlas heute selten. 


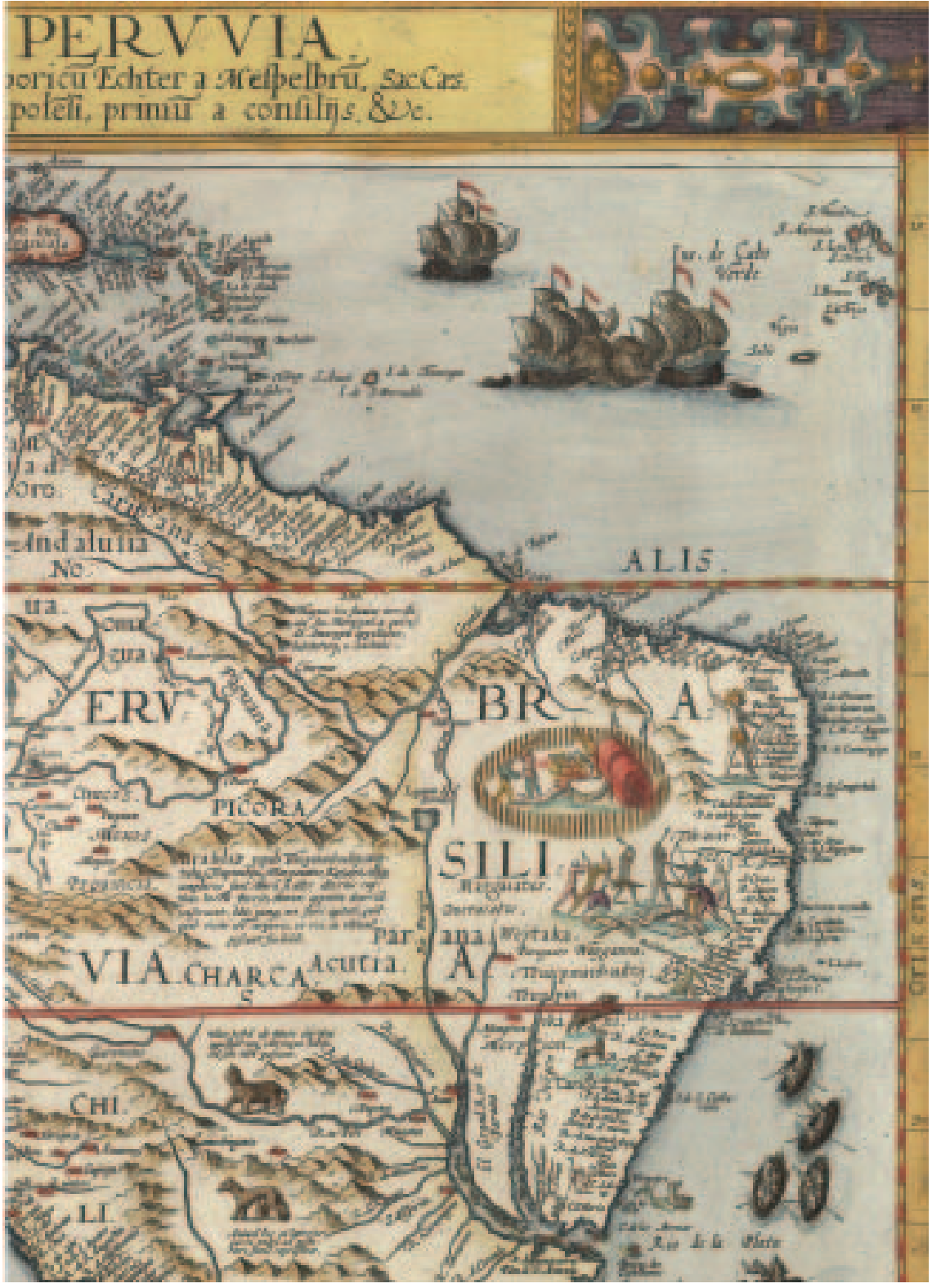

Abbildung 8 (Kat.Nr. 30)

de Jode: Speculum Orbis Terrarum, 1593, Brasilia et Peruvia (Ausschnitt). 
31 Ortelius, Abraham:

Theatrum Orbis Terrarum, denuo recognitum. Antwerpen: Officina Plantiniana, 1595. 146 Karten, mit einem Kupfertitel und einem Verfasserporträt. !HSD! 2 GEOGR 153/d RARA

Abraham Ortelius (1527 - 1598), berühmter Antwerpener Kartograph, gelang es erstmals, eine Anzahl nach bestimmten Gesichtspunkten ausgewählter Karten unterschiedlicher Herkunft und Größe auf gleiches Format zu bringen und in Buchform zusammenzufassen. 1570 veröffentlichte er den ersten Kartenatlas unter dem Titel Theatrum Orbis Terrarum. Dieser ersten Auflage mit 70 Karten, die meisten gestochen von Franz Hogenberg (1535 - 1590), folgten bis 1612 über 40 weitere Auflagen. Die große Zahl von Auflagen zeigt, dass nach einem modernen Atlas eine enorme Nachfrage bestand und Ortelius mit seinen sorgfältig gestalteten Karten den Zeitgeschmack genau traf. Die Karten basieren auf den besten verfügbaren Vorlagen jener Epoche, darunter sehr vielen italienischen. Mit seinen kartographischen Leistungen gelangte Ortelius nicht nur zu großem Wohlstand und hohen Ehren, sondern er beeinflusste maßgeblich den Entwicklungsgang der Kartographie.

Das im Renaissancestil ausgeführte Titelblatt gibt die vier Kontinente allegorisch als Frauengestalten wieder: Europa als Kaiserin mit Weltkugel und Kreuz, Asien als Priesterin, Afrika als Negerin und schließlich Amerika, das erstmals als gleichberechtigter Erdteil erscheint, als nackte Barbarin. Daneben steht noch eine Büste der Magellanica mit einer Fackel, womit das fiktive Südland und Feuerland symbolisiert werden sollten.

\section{Ortelius, Abraham:}

Epitome Theatri Orbis Terrarum Abrahami Ortelii / De nova recognita, aucta, et Geografica ratione restaurata a Michaele Coigneto. - Antwerpen: Ioannes Keerbergius, 1601. 123 Karten, mit einem Kupfertitel. !HSD! 8 GEOGR 154/d RARA

Seit 1576 wurden auf der Grundlage des Theatrum orbis terrarum Atlanten im Kleinformat als sogenannte Taschenatlanten herausgegeben. Sie waren offensichtlich für eine andere, weniger finanzkräftige Käuferschicht bestimmt. Der Erfolg der Taschenatlanten war beträchtlich, sie erschienen in zahlreichen Auflagen in verschiedenen Sprachen. 


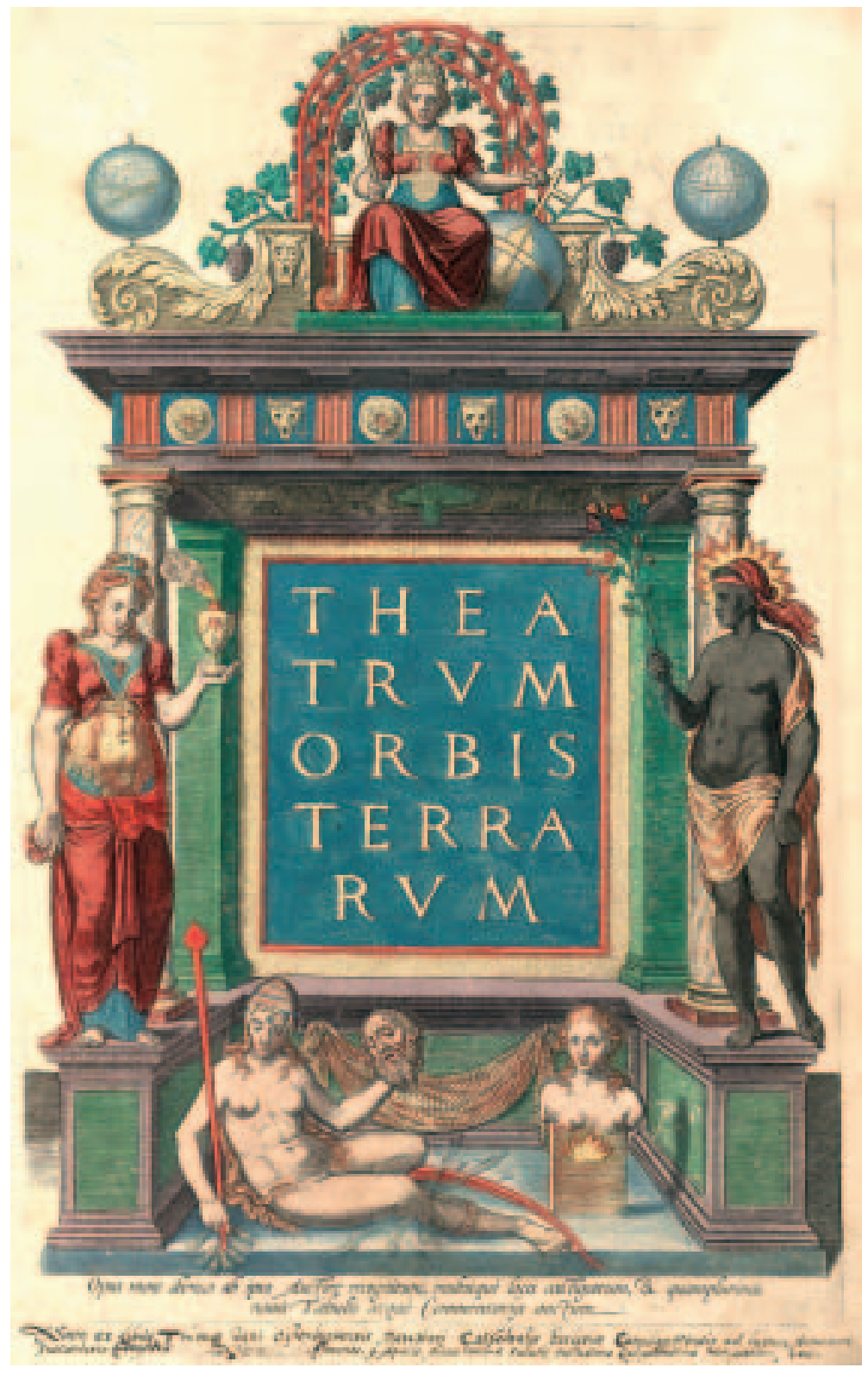

Abbildung 9 (Kat.Nr. 31)

Abraham Ortelius: Theatrum Orbis Terrarum, Antwerpen 1595, Titelkupfer. 
33 Bertius, Petrus:

Tabularum geographicarum contractarum libri quatuor. - Amsterdam: Cornelius Nicolai, 1600. 645 Seiten, 169 Karten.

!HSD! 8 GEOGR 153 RARA

Die Jahre um 1590 und danach erlebten eine große Expansion in der Verbreitung geographischen Wissens. Neben den Folio-Atlanten entstanden im ausgehenden 16. und frühen 17. Jahrhundert in den Niederlanden weitere Taschenatlanten so wie dieser des Petrus Bertius (1565 - 1629), der als Kosmograph, Theologe und Historiker in Leiden tätig war.

34 Hondius, Jodocus:

Atlas Minor. Das ist: Eine kurtze jedoch gruendliche Beschreibung der ganzen Welt und aller ihrer Theyl / Erstlich von Gerardo Mercatore in Latein beschrieben. Folgends durch Iodocum Hondium mit vielen Kupfern gebessert und vermehrt und endlich in unsere hoch-teutsche Sprach versetzt. Amsterdam: Ioannes Ianssonius, 1631. 600 Seiten, zahlreiche Karten.

!HSD! 4 GEOGR 155/c RARA

Im Jahr 1604 kaufte Jodocus Hondius (1563 - 1612) die Kupferplatten von Gerard Mercators Atlas. War Hondius bis dahin vor allem als Stecher, Globenmacher und Hersteller von Einzelkarten bekannt, wurde er nun auch Verleger größeren Formats. 1606 kam die mit 36 neuen Karten erweiterte Auflage von Mercators Atlas auf den Markt, womit Amsterdam eine Weltposition auf dem Gebiet der Kartographie erwarb. Diese Atlas-Ausgabe wurde ein großer Erfolg. Hondius reduzierte auch die Karten und publizierte sie in mehreren Auflagen als Atlas minor.

35 Blaeu, Joan:

Atlas Mayor, sive Cosmographia Blaviana qva, solvm, salvm coelvm accvratissimae describvntur. - Amstelaedami, 1662.

!HSD! gr 2 GEOGR 160 RARA

Willem Blaeu (1571 - 1630), Begründer des in Holland über fast eine Jahrhundert führenden kartographischen Verlages und Schüler des dänischen Astronomen Tycho 


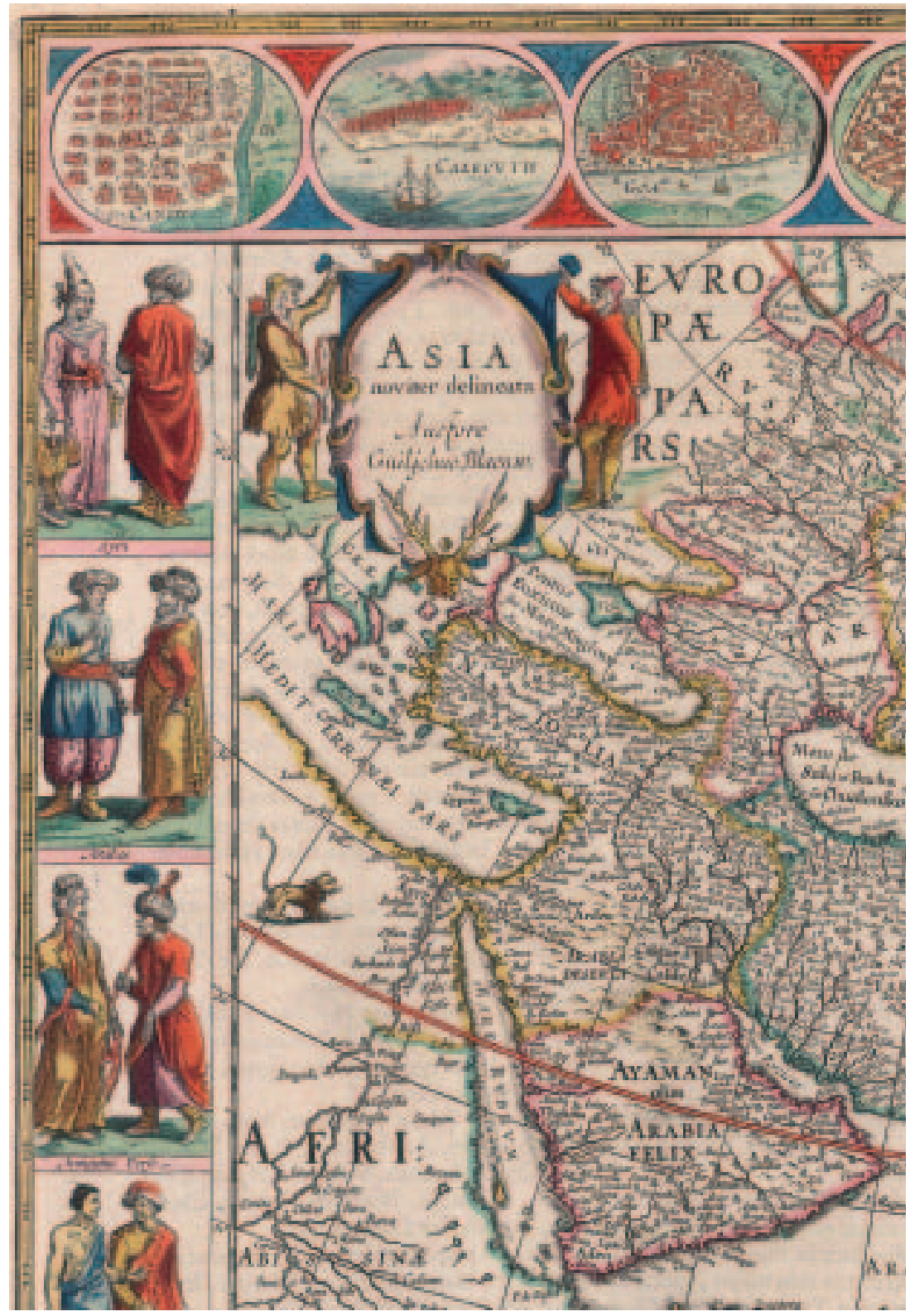

Abbildung 10 (Kat.Nr. 35)

Willem und Joan Blaeu: Atlas Major, 1662, Asia noviter (Ausschnitt). 
Brahe, erwarb 1629 von Jodocus Hondius auf eine nicht näher bekannte Art originale Druckplatten von dessen Atlas und brachte damit sowie mit eigenen Arbeiten ein Kartenwerk heraus.

1635 erschien die erste Ausgabe des von ihm gemeinsam mit seinem Sohn Joan herausgegebenen zweibändigen Atlas. Von dieser Zeit an führte Willem Janszoon Blaeu - und später sein Sohn Joan - einen unerbittlichen Kampf gegen die Firma Hondius-Janssonius, der beide Betriebe zu immer beachtlicheren Leistungen anspornte. Im Verlauf der Auseinandersetzung ging man nicht gerade zimperlich miteinander um. Plagiate waren an der Tagesordnung und auch vor Verunglimpfungen schreckte man nicht zurück. Dennoch gelang es Blaeu bis zu seinem Tod, sein aus dem Nichts aufgebautes Geschäft zum angesehensten kartographischen Verlag der Niederlande und Europas auszubauen.

Blaeu bildete mit seinen Karten einen allmählichen Übergang von der Renaissance zum Barock. Während in der Anfangszeit noch italienische Formen überwogen, schuf er mit der Zeit den für ihn typischen Stil mit einer verfeinerten topographischen Gestaltung, mit Figurengruppen, sorgfältig ausgeführten Kartuschen und heraldischen Beigaben. Viele zeitgenössische Stecher versuchten Blaeu zu kopieren, aber keiner erreichte seine Eleganz. Seine Karten sind ästhetisch ansprechend, zumal sie bei allem Form- und Farbreichtum nie aufdringlich wirken. Blaeu beschäftigte die besten verfügbaren Stecher, Drucker und Buchmaler.

Der Atlas wuchs bis zu den 12 Bänden der Geographia Blaviana. Im Jahre 1672 vernichtete ein Feuer den Verlag fast vollständig. Die noch brauchbaren Platten wurden an Peter Schenk und Gerard Valck verkauft.

\section{Honterus, Johannes:}

Rudimenta cosmographica. - Tiguri, 1548.

!HSD! 8 GEOGR 637 RARA

Als wichtigstes Werk von Johannes Honter (1498 - 1549), Humanist, Pädagoge, Reformator der Siebenbürgener Sachsen, gilt das Geographie-Lehrbuch, das über 20 Auflagen erlebte. 1530 erschien die erste Ausgabe in Prosa, 1542 eine stark erweiterte Ausgabe in Hexametern zum leichteren Auswendiglernen. Der mit 16 Karten überwiegend von Europa ausgestattete erste Schulatlas im Taschenformat wurde von Honter selbst in Holz geschnitten. 


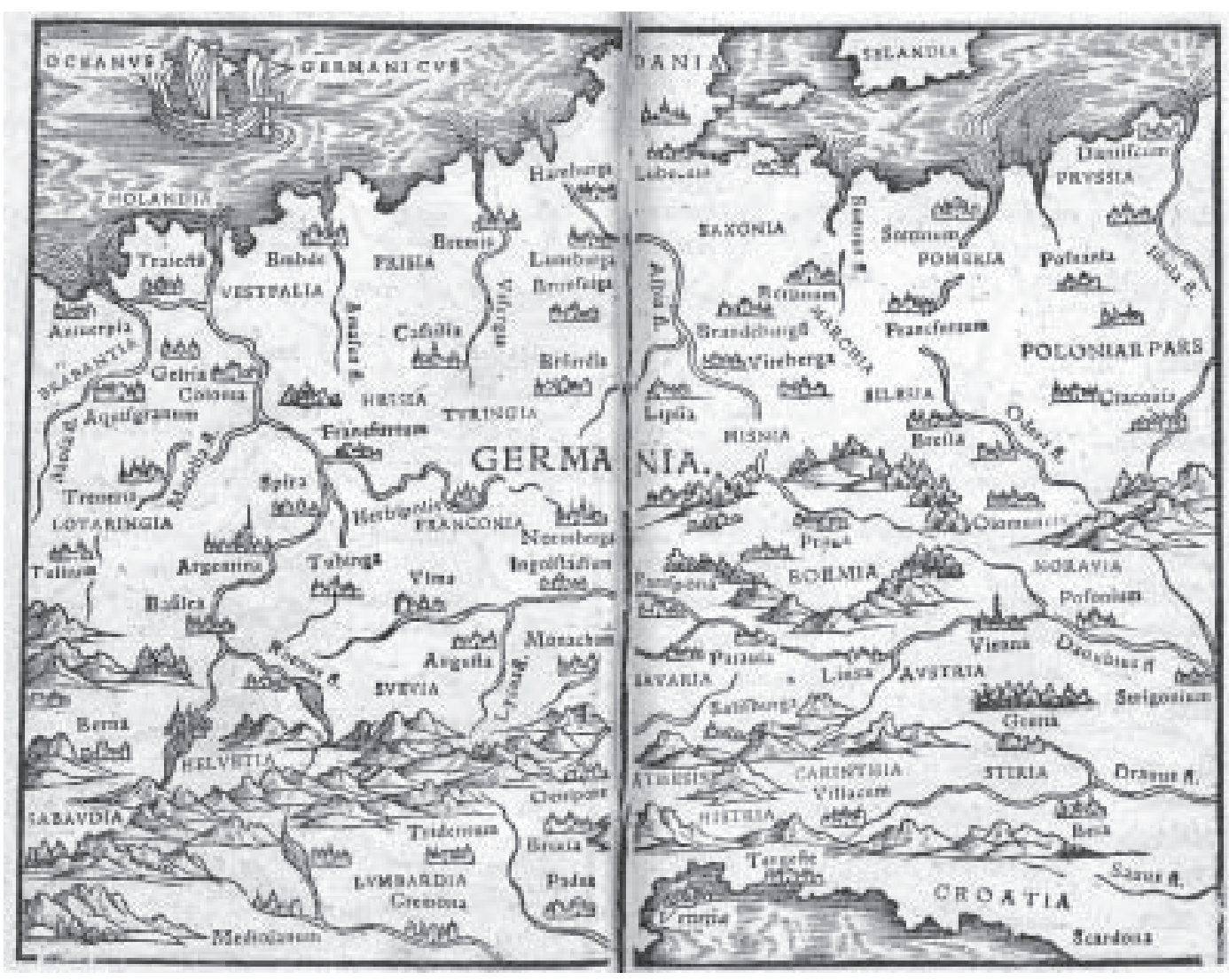

है

Abbildung 11 (Kat.Nr. 36)

Johannes Honter: Rudimenta cosmographia, 1548, Germania-Karte. 
37 Quad, Matthias:

Europae, totius terrarum orbis partis praestantissimae descriptio - Coloniae: Bussemecher, 1594 [erschienen] 1596. - 66 Karten. !HSD! 4 GEOGR 378 RARA

Matthias Quad (1557 - 1613), Kölner Kartograph, Holzschneider und Kupferstecher, machte nach der in Heidelberg verbrachten Schulzeit eine Goldschmiedeund Kupferstecherlehre. Anschließend durchwanderte er Deutschland und die Niederlande. Von 1590 an begann er, sich mit der Anfertigung von Karten für seinen Atlas von Europa zu befassen, der erstmals 1592 erschien, mit Neuauflagen 1594 und 1596. Einige Jahre später wurde der Umfang so weit vergrößert, dass er die ganze Welt einschloss. Alle Karten basierten auf dem Atlas von Ortelius. Einen Teil der Tafeln nahm Johannes Rauw in seine Kosmographie auf (vgl. Nr. 22). Für einen längeren Zeitraum wurden anschließend keine deutschen Atlanten mehr veröffentlicht, da die Werke von Ortelius und Mercator, Hondius und Blaeu in deutschsprachigen Ausgaben auf den Markt kamen. 


\section{Beschreibungen von Reisen ins Heilige Land}

Palästina als das 'Heilige Land' der Juden und der Christen sowie als ein Gebiet heiliger Stätten der Mohammedaner nimmt seit dem Mittelalter eine zentrale Stellung ein und weist eine ungebrochene kartengeschichtliche Kontinuität auf. Das Interesse an Palästina dokumentiert sich am deutlichsten an der langen Reihe von Reiseberichten und Palästina-Karten von der Renaissance bis ins 17. Jahrhundert.

38 Breydenbach, Bernhard von:

Peregrinatio in terram sanctam. - Mainz: Erhard Reuwich, 11. 2. 1486. Zahlreiche Holzschnitte.

!HSD! 4 ITIN I, 2293/m INC

Der Mainzer Domherr Bernhard von Breydenbach (um 1440 - 1497) unternahm von April 1483 bis Januar 1484 eine Pilgerfahrt nach Jerusalem und auf den Sinai. Begleitet wurde er von dem aus Utrecht stammenden Maler Erhard Reuwich, der die Aufgabe erhielt, die wichtigsten Eindrücke von Städten und Gebäuden, von Menschen und Kulturdenkmälern in Bildern festzuhalten. Nur zwei Jahre nach der Rückkehr erschien am 11. Februar der von Reuwich geleitete deutsche Erstdruck des Reiseberichts in lateinischer Sprache in Mainz.

Der große Erfolg des Reiseberichts liegt in seinem Inhalt und seiner künstlerischen Ausstattung. Bernhard von Breydenbach ergänzte den eigentlichen Reisebericht durch eine Beschreibung Palästinas, eine Biographie Mohammeds, Berichte über Belagerungen von Konstantinopel und Rhodos sowie Notizen über Recht und Sitten der Bewohner des Heiligen Landes. Reuwich selbst übertrug seine Skizzen in Holzschnitte von starker malerischer Ausdruckskraft, verbunden mit großer Naturtreue. Damit ist das reich ausgestattete Werk das erste Holzschnittwerk, dessen Illustrator namentlich bekannt ist, und das erste topographische Werk, dessen Stadtansichten weitgehend der Wirklichkeit entsprechen, darunter das ein Zweidrittel des Kreisumfangs darstellende, zentralperspektivisch konstruierte Panorama von Venedig.

Die Holzschnitte Reuwichs haben u. a. die Ausstattung der Schedel'schen Weltchronik beeinflusst. 
39 Breydenbach, Bernhard von:

Die heylighe beuarden tot dat heylighe grafft in iherusalem. - Mentzs: Eerhaert Rewich, 24. V. 1488. 188 Bl., zahlreiche Holzschnitte.

!HSD! 4 ITIN I, 2296 INC

Der Reisebericht Bernhard von Breydenbachs erschien zunächst in lateinischer Sprache, wurde dann aber schnell mehrfach aufgelegt und übersetzt. Bereits vier Monate nach der Erstausgabe erschien die deutsche Übersetzung und am 24. Mai 1488 auch eine niederdeutsche Version.

40 Tucher, Hans:

Reise in das gelobte Land. - Nürnberg: Konrad Zeninger, 1483.

!HSD! 8 ITIN I, 2676 INC

Zu den zahlreichen Palästinaberichten des ausgehenden 15. Jahrhunderts gehört auch das viel verbreitete Pilgerbuch des Nürnberger Patriziers Hans Tucher (1428 - 1491). 1479 trat Tucher eine 49 Wochen dauernde Reise ins Heilige Land an, auf der er Jerusalem und im Anschluss daran das Katharinenkloster auf dem Sinai sowie die ägyptischen Städte Kairo und Alexandria besuchte. Tucher verfasste darüber einen Reisebericht, dem er mehrere Kataloge mit ausführlicher praktischer Reiseinstruktion sowie thematisch verwandten Texten (Chronikauszug über Jerusalem, Beschreibung des Heiligen Grabes usw.) beifügte. Der Bericht, den Tucher selbst in Druck beförderte, war als 'Handbuch' für Jerusalemreisende konzipiert. Die Zahl der Inkunabelausgaben - sechs Drucke von 1482 bis 1486 - lässt den raschen Erfolg des Werkes erkennen.

41 IERUSALEM, et suburbia eius, sicut tempore Christi floruit. Cum locis, in quibus Christus passus est, quae religiose a Christianis observata, etiam nunc Venerationi habentur. Descripta per Christianum Adrichom Delphum. - Coloniae Agrippinae // Köln, 1584. - I Plan. Kupferstich. 72 x49 cm. Osten oben.

!KTS! MAPP 205

Der Theologe Christian van Adrichom (1533 - 1585) ist wohl die wichtigste Autorität für biblische Topographie im 16. Jahrhundert. Forschergeist und Bibel- 


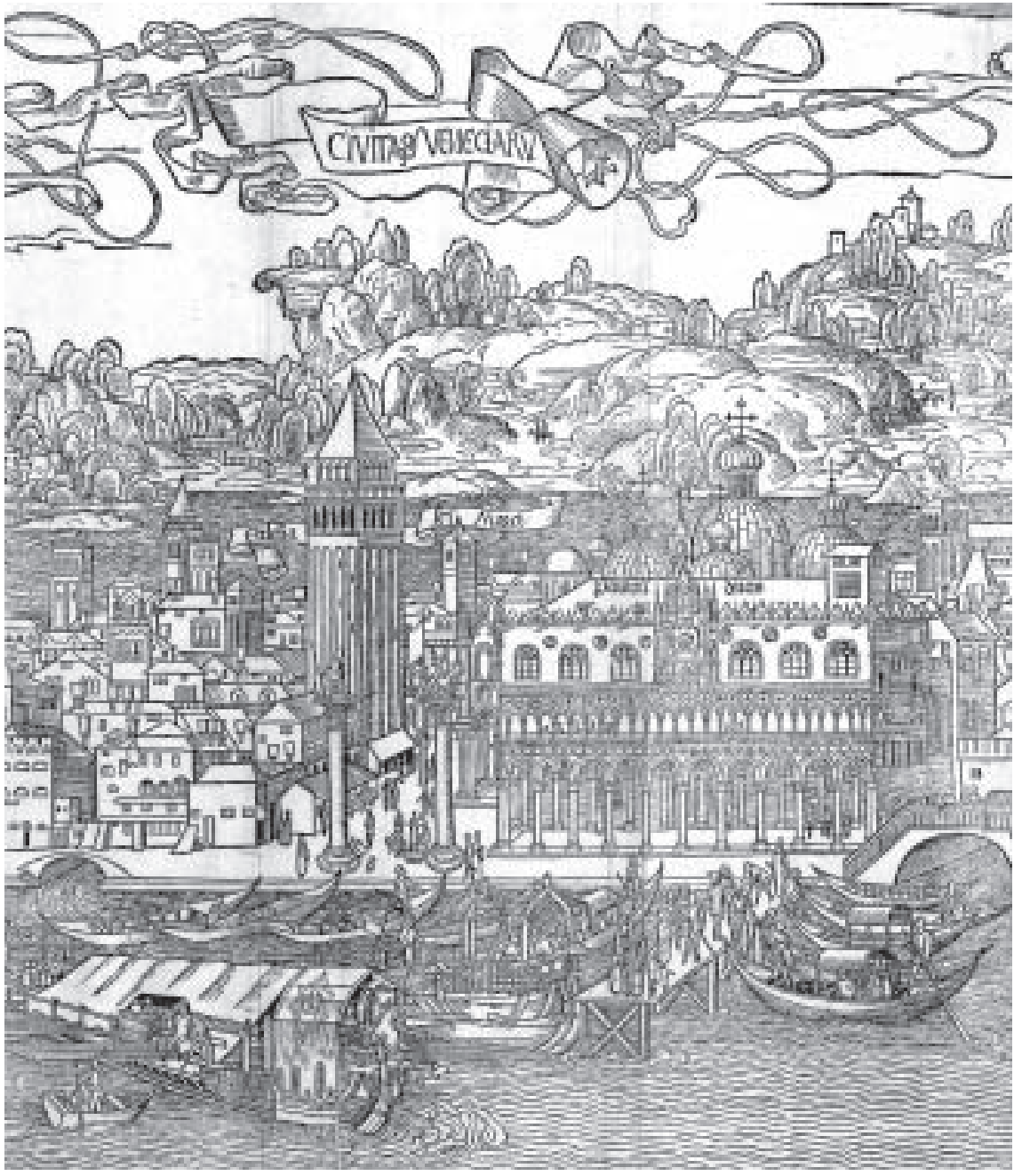

Abbildung 12 (Kat.Nr. 39)

Breydenbach: Peregrinatio in terram sanctam <dt.>, 1488, Venedig (Ausschnitt). 
gläubigkeit gehen in seinem Werk eine charakteristische Verbindung ein. Der großformatige, von zwei Platten gedruckte Jerusalem-Plan fand viel Beachtung. Die ungewöhnliche Form des länglichen Rechtecks birgt imaginäre Anlagen, aber auch einige wirklichkeitsnahe Elemente. Adrichom fasste die Stadt vor allem als Schauplatz des letzten Lebensabschnitts Jesu Christi auf und bereicherte sie mit alttestamentlichen Episoden. In den Straßen und außerhalb der Stadtmauern befinden sich Darstellungen biblischer Szenen u. a. der Kreuzweg. Der Plan enthält das adrichomische Familienwappen, eine aufsteigende Schlange.

Die heute seltene Karte war für mehr als ein Jahrhundert die Vorlage für weitere Jerusalem-Darstellungen. 


\section{Landeskunden vom Mittelalter bis zur Neuzeit}

Neben den durch die Entdeckungsfahrten motivierten Originalberichten über Reisen und den darauf begründeten Beschreibungen der neu entdeckten Länder entstanden im 16. Jahrhundert erstmals topographische oder ortsbeschreibende Aufnahmen kleinerer Landstücke und Gebiete.

42 Mela, Pomponius:

[Cosmographia tribus libris digesta] Cosmographia Pomponii Melae - tribus libris digesta. Praecipuo quodam compendio Jo. Coclei Norici adaucta. Norimbergae: Johann Weyssenburger, 1512.

!HSD! 8 AUCT LAT III, 8398 RARA

Johannes Cochlaeus (1479 - 1552), Humanist und katholischer Kontroverstheologe, war seit 1510 Rektor der Lateinschule St. Lorenz in Nürnberg. Er veröffentlichte Lehrbücher und Kommentare zu antiken Autoren. Seine 1512 veröffentlichte Edition der Kosmographie des Pomponius Mela enthält als Anhang eine Beschreibung Deutschlands mit dem Titel Brevis Germaniae Descriptio. Sie gilt als die erste vollständige Landeskunde von Deutschland nach der Germania des Tacitus. Äußerlich ist sie ein Anhang zur Weltgeographie, inhaltlich ein selbständiges Werk. Cochlaeus nennt 17 Autoren, die er benutzt hat, und zitiert diese teilweise mit Quellenangaben.

43 Tschudi, Aegidius:

De prisca ac vera Alpina Rhaetia. - Basileae: Isingrinius, 1538. 8 H HELV IV, 7600

Aegidius Tschudi (1505 - 1572), schweizerischer Staatsmann, Historiker und Topograph, sammelte auf vielen Reisen das Material für seine berühmte SchweizKarte, die 1538, von Sebastian Münster gestochen, als Beilage zu seinem Werk die uralt warhafftig Alpisch Rhetia erschien. Die Karte von Tschudi blieb bis zu Mercator die Grundlage der Schweiz-Karten. Ausgestellt ist ein Nachdruck der Karte aus dem Atlas Theatrum Orbis Terrarum von Abraham Ortelius. - Antwerpen: 1573. (Signatur: !HSD! 2 GEOGR 154/a RARA). Süden ist oben. 
44 Simlerus, Josias:

Vallesiae descriptio, libri duo. De Alpibus commentarius Iosia Simlero auctore. - Tiguri: Froschauer, 1574. $151 \mathrm{Bl}$.

8 H HELV IV, 1510:Beibd. 2

Josias Simler (1530 - 1576), Theologe und geographischer Schriftsteller, schrieb die erste ausschließlich den Alpen gewidmete topographische Darstellung, die er als Vorarbeit benutzte für eine allgemeine Geschichte der Schweiz. Er behandelt den Namen des Gebirges, Ausdehnung, Lage, Breite, Höhe, die Alpen in der Geschichte, verschiedene Teile der Alpen, Pässe und Wege, Schwierigkeiten und Gefahren der Reisewege, die Bevölkerung, Gewässer, Pflanzen und Tierwelt. Simlers Darstellung begründet sich auf das Studium antiker Autoren und zeitgenössischer Humanisten, Simler konnte wegen eines Gichtleidens die Alpen selbst nie bereisen. Während zur gleichen Zeit neue Kontinente entdeckt wurden, stellten die Alpen noch eine beinahe unüberwindliche Mauer dar. So behandelte auch Simler nur die Topographie in den Gegenden der Alpenübergänge, das Mont-BlancMassiv dagegen wird nicht angeführt. Dennoch berichtet es sehr anschaulich - in einem heute noch ansprechenden Werk - über die Alpen.

45 Apian, Philipp:

Bairische Landtafeln XXIIII darinnen das hochlöblich Fürstenthumb Obern unnd Nidern Bayrn sambt der Obern Pfaltz.Ertz unnd Stifft Saltzburg Eichstet unnd andern mehrern anstossenden Herschafften. (Mit Text) / Mit vleiß beschriben und in Druck gegeben. Durch Philippum Apianum. - Inngolstadt, 1568 .

!HSD! 2 H BAV I, 3 RARA

Philipp Apian (1531 - 1589), Sohn des Peter Apian, war seit 1552 Professor der Mathematik, Astronomie und Kartographie in Ingolstadt. In den Sommern der Jahre 1554 - 1561 kartierte Apian Bayern im Auftrag Herzog Albrechts IV. im Maßstab 1:45.000. Durch Verkleinerung der Originalaufnahmen auf den Maßstab 1:135.000 und Aufteilung in 24 Blätter entstanden die bekannten Baierischen Landtafeln. Die Karte zeigt reichen topographischen Inhalt wie vollständiges Gewässernetz, alle Siedlungen, naturähnliche Ortsbilder in Schrägansicht und Gebirgszeichnung. Bemerkenswert ist die Verwendung von Metall-Lettern für die Kartenbeschriftung. Die Druckstöcke bearbeitete der Züricher Holzschneider Jost Amman. 


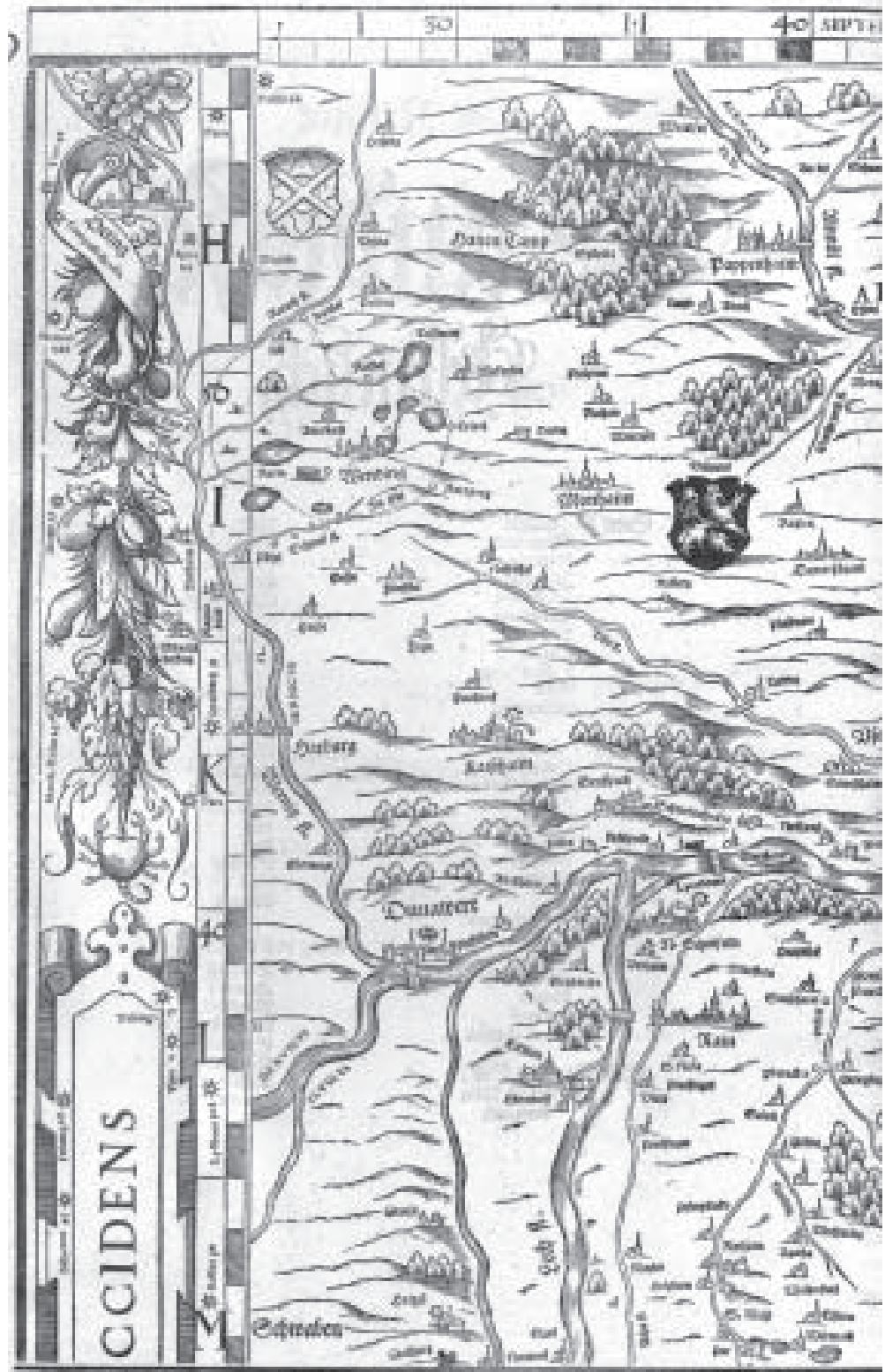

Abbildung 13 (Kat.Nr. 45)

Philipp Apian: Baierische Landtafeln, 1568, Gegend um Donauwörth. 
1568 musste Apian Bayern verlassen, da er sich weigerte, den im Zug der Gegenreformation verlangten Eid auf das Tridentinum abzulegen. Bis zu seinem Tod blieb er als Privatgelehrter in Tübingen.

46 Clüverus, Philippus:

Germania antiqua. Opus post omnium curas elaboratissimum, tabulis geographicis et imaginibus, priscum Germanorum cultum moresque referentibus exornatum. - Lugduni Batavorum: Elzevir, 1616. 899 S., Kupfer.

2 H GERM VII, 2

Philipp Clüver (1580 - 1622), ein Kaufmannssohn aus Danzig, später Universitätsprofessor in Leiden, gilt als der Begründer der historischen Länderkunde. Er bereiste 1607 bis 1613 Europa und lebte einige Zeit in England. Als Frucht dieser Jahre entstanden Werke wie Germania antiqua (1616), Sicilia antiqua (1619) und Italia antiqua (herausgegeben 1624). Das Erscheinen seiner Germania antiqua, einer bebilderten Altertumskunde, wurde zum Anlass, ihn zum Geographus Academicus in Leiden zu ernennen.

Auf zahlreichen beigegebenen Kupfern sind die Lebensbedingungen der Germanen dargestellt.

Vgl. auch Nr. 80.

$47 \quad$ Varenius, Bernhardus:

Descriptio regni Japonicae et Siam. - Amstelodami, 1649.

!HSD! 8 H AS II, 6410 RARA

Varenius eröffnete mit dieser ersten landeskundlichen Gesamtdarstellung Japans aus der Hand eines Europäers seine geographische Laufbahn. Auch wenn sie noch nicht der später von ihm selbst entwickelten Form der Landeskunde entspricht, enthält sie bereits ein Quellenverzeichnis, Zitate, unterscheidet historische und physische Kausalität, bindet wichtige Erkenntnisse und Informationen über Land und Leute ein. Es ist ein Text, den man auch heute noch interessant und ansprechend findet. Die Ausgabe gehört als 33. und letzte zu den Elzevir'schen Republiken und ist als einzige von ihnen nicht in Leiden erschienen.

Vgl. auch Nr. 83 und 84. 
48 'Respublicae'- Elzevirsche Republiken.

Lugdunum Batavorum, apud Elzeviros oder ex officina Elzivorum 1625 1649.

Einzelsignaturen

Es handelt sich um eine Sammlung gleichartig ausgestatteter Bändchen, die Elzevir'schen Landeskunden oder Staatsbeschreibungen, die in gedrängter Form die Grundzüge der geographischen, historischen und politischen Verhältnisse eines Landes aufzeigen. Die Sammlung umfasst 33 Nummern der Erscheinungsjahre 1625 bis 1649. Mit Ausnahme der letzten Schrift über Japan von Varenius sind alle Bändchen bei Abraham und Bonaventura Elzevier in Leiden erschienen.

Elzevier war eine niederländische Verleger- und Druckerfamilie des 17. Jahrhunderts, deren Handelsbeziehungen sich bis nach Deutschland, Frankreich, England, Italien und Dänemark erstreckten. Gründer des Hauses war Ludwig Elzevier (um 1540 - 1617). Er ließ sich 1580 in Leiden nieder, zunächst als Buchbinder, dann als Buchhändler. Ende des Jahrhunderts begann der Aufschwung der Firma, die unter seinen Nachkommen bis 1712 in Leiden und 1638 - 1681 in Amsterdam bestand. 



\section{Die mathematischen Grundlagen zur Erweiterung des Welt- bildes}

Voraussetzung für die Durchführung von Entdeckungsfahrten und wissenschaftlichen Reisen war die Entwicklung der mathematischen und technischen Grundlagen zur Positionsbestimmung. Das im 15. Jahrhundert verbesserte Astrolabium, ein Instrument zur Bestimmung der geographischen Breite, ermöglichte eine Verbesserung der astronomischen Ortsbestimmungen. Das gelang um so besser, als auch Tabellen berechnet wurden, mit deren Hilfe man die beobachtete Sonnenhöhe in die geographische Breite umrechnen konnte.

49 Regiomontanus, Johannes:

Ephemerides siue Almanach perpetuum. - Venetijs: Petrus Liechtenstein [für Johannes Lucilius Santritter], 15. 10. 1498. 122 Bl.

!HSD! 8 ASTR II, 1715 INC

1436 wurde in Königsberg in Unterfranken Johannes Müller geboren. Der latinisierte Name Regiomontanus (= der Königsberger), unter dem er der Nachwelt bekannt geworden ist, kam erst lange nach seinem Tod auf und geht auf Philipp Melanchthon zurück, der ihn 1531 erstmals verwendete.

Regiomontanus gilt als wichtigster Astronom und Mathematiker des Spätmittelalters und Wegbereiter des kopernikanischen Weltbildes. Er erhielt seine Ausbildung in Leipzig und Wien, wo sich die damals bedeutendste mathematisch-astronomische Schule Mitteleuropas befand. Weitere Stationen seines Lebens waren Rom und Ungarn. 1471 zog er nach Nürnberg, wo er im kulturell, wirtschaftlich und wissenschaftlich anregenden Klima der Reichsstadt seine Forschungen fortsetzen wollte. Er eröffnete eine eigene Druckerei mit Werkstatt, in der er seine komplizierten mathematischen und astronomischen Berechnungen von den besten Setzern in optimaler Qualität herstellen ließ. Zugleich errichtete er in Nürnberg ein Observatorium, eine unter den Bedingungen der Zeit äußerst moderne, höchsten wissenschaftlichen Standards genügende Sternwarte. Aus der Nürnberger Zeit stammen die Ephemerides astronomicae, naturwissenschaftliche Jahrbücher (für die Jahre 1475 - 1506) mit astronomischen und meteorologischen Berechnungen, die für die Geschichte der Seefahrt immense Bedeutung erhalten sollten. Mit den Ephemeriden brachte Regiomontanus eine Arbeit heraus, die wegen ihrer hohen Ge- 
nauigkeit neue Maßstäbe setzte und auch von Columbus als Navigationshilfe bei seiner Reise verwendet wurde.

Regiomontanus starb 1476 in Rom. Er ist als ein typischer Vertreter des Humanismus in der Renaissance anzusehen, der neu, unvoreingenommen und selbständig, aber zugleich in stetiger Auseinandersetzung mit den Überlieferungen der alten Zeit nach verlässlichen Grundlagen des Wissens sucht.

50 Regiomontanus, Johannes:

Epytoma in Almagestum Ptolomei. - Venedig: Grosch \& Römer, 31. VIII. 1496. $107 \mathrm{Bl}$.

!HSD! 4 AUCT GR V, 4255 INC

1461 begab sich Regiomontanus nach Rom, wo dem mittlerweile als mathematisches Genie erkannten 25-Jährigen die von Georg von Peuerbach begonnene Aufgabe einer kritischen Kommentierung des Almagest des Ptolemaeus übertragen wurde. Im wissenschaftlichen Austausch mit dem bedeutenden italienischen Gelehrten Giovanni Bianchini vollendete er diese Arbeit, die später Kopernikus und Galilei als Lehrbuch dienen sollte.

51 Waldseemüller, Martin:

Cosmographiae introductio cum quibusdam Geometriae ac astronomiae principiis ad eam rem necessariis. - Saint Dié: Gualterus Lud, 7. 5. 1507. !HSD! 8 GEOGR 623 RARA

Der Theologe, Kosmograph und Kartograph Martin Waldseemüller (um 1470 1521) wirkte nach einem Studium in Freiburg am Gymnasium von St. Dié / Lothringen und an einer vom lothringischen Herzog René II. geförderten wissenschaftlich-literarischen Akademie. Die meisten seiner Arbeiten stellte er in Kooperation mit dem Humanisten Matthias Ringmann (Philesius) (1482 - 1522) her, der hauptsächlich für Textgestaltung und Kommentare verantwortlich gewesen sein dürfte.

1505 begannen Waldseemüller und Ringmann an einer Neuauflage der Geographie des Ptolemaeus zu arbeiten. 1507 publizierte Waldseemüller die Universalis Cosmographia, eine großformatige Weltkarte, in der modifizierten konischen (herzförmigen) Projektion des Ptolemaeus. Erstmals auf einer Weltkarte erscheint 


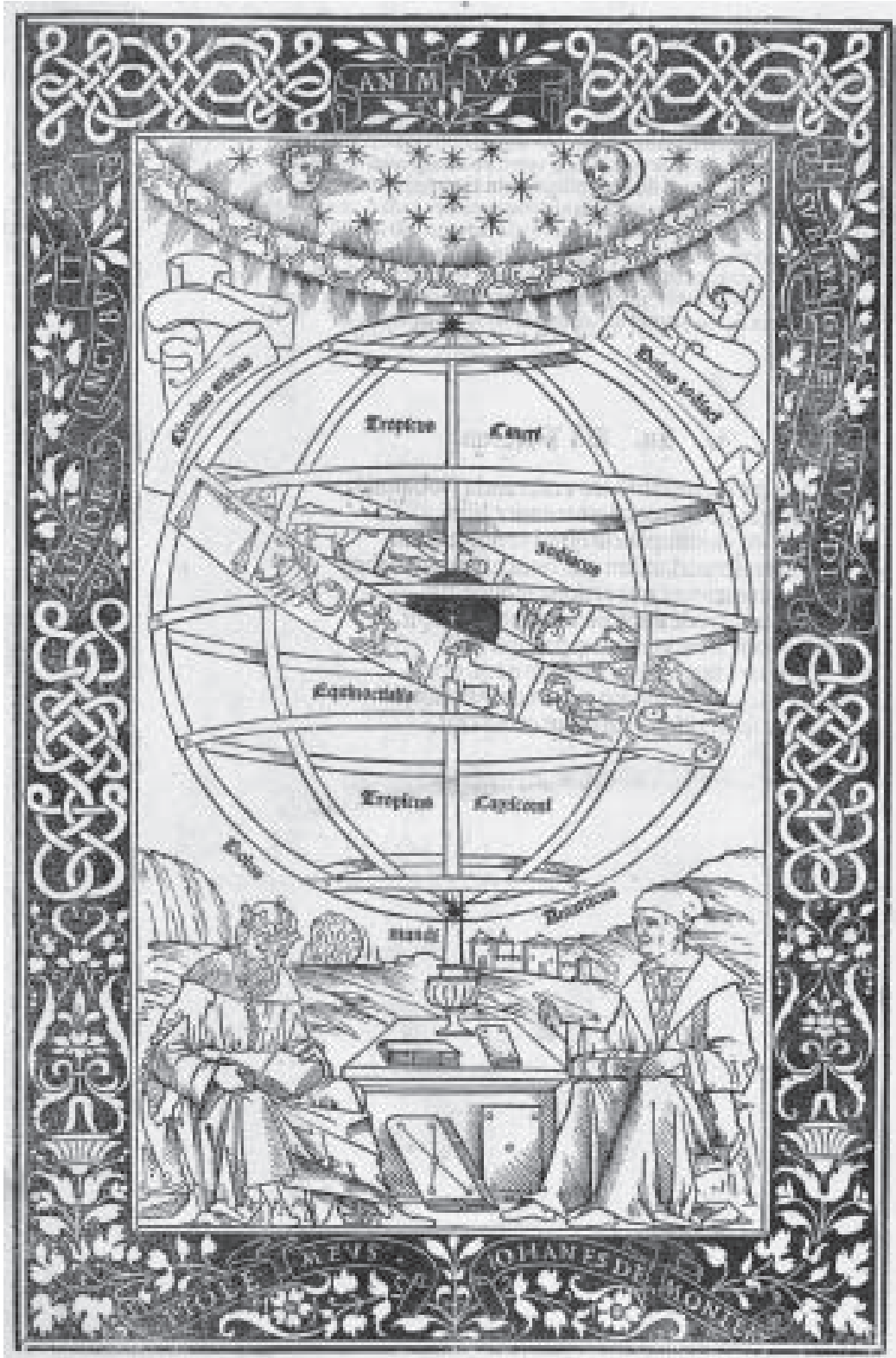

Abbildung 14 (Kat.Nr. 50)

Regiomontanus: Epytoma in Almagestum Ptolomei, 1496, Disputierende Gelehrte. 
die Neue Welt - mit einer relativ genauen Ost-Küste -, und erstmals kommt der Name Amerika, beschränkt auf eine Region Südamerikas, vor. Die Karte wirkte sehr stark auf nachfolgende Kartographen und wurde u.a. zur Vorlage für Henricus Glareanus, Peter Apian, Johann Schöner, Johannes Honter und Sebastian Münster. Ebenfalls 1507 veröffentlichte Waldseemüller Segmente für einen Erdglobus, dessen Kartenbild eine vereinfachte Verkleinerung der Weltkarte darstellt. Zu Karte und Globus gehört ein von Ringmann verfasster Kommentar Cosmographiae Introductio. Auch darin findet sich die Bezeichnung America, von Ringmann nach dem Vornamen des Amerigo Vespucci in offensichtlicher Überschätzung von dessen Verdiensten um die Entdeckung des neu gefundenen Kontinents eingeführt.

Vgl. auch Nr. 9.

52 Schoner, Johannes:

Luculentissima quaedam terrae totius descriptio: cum multis utilissimis Cosmographiae iniciis ... . - Norimbergae: Stuchs, 1515. 65 Bl. !HSD! 8 GEOGR 363 RARA

Johannes Schöner (1477 - 1547) lebte als Mathematiker, Astronom und Geograph in Nürnberg. Nach einem kurzen Studium in Erfurt war Schöner zunächst als Pfarrer in Bamberg und anderen süddeutschen Orten tätig. Durch Vermittlung Willibald Pirckheimers und Philipp Melanchthons war er seit 1526 Mathematikprofessor in Nürnberg. Schöner schuf 1515 seinen ersten Erdglobus. Das Kartenbild entspricht weitgehend der Weltkarte des Waldseemüller von 1507. Als Kommentar - nach dem Vorbild von Waldseemüllers Cosmographiae introductio - schrieb Schöner die Luculentissima quedam terrae descriptio mit den Koordinaten zahlreicher europäischer Städte.

53 Schöner, Johann:

Opera mathematica. - Nürnberg: In officina Ioannis Montani und Ulrici Neuberi, 1551. [Format Großquart] !HSD! 4 ASTR I, 500 RARA

Nach Pirckheimers Tod 1532 wurde Schöner mit der Bearbeitung des wissenschaftlichen Nachlasses von J. Regiomontanus beauftragt. Infolgedessen wandte er sich zunehmend der Astronomie zu. 


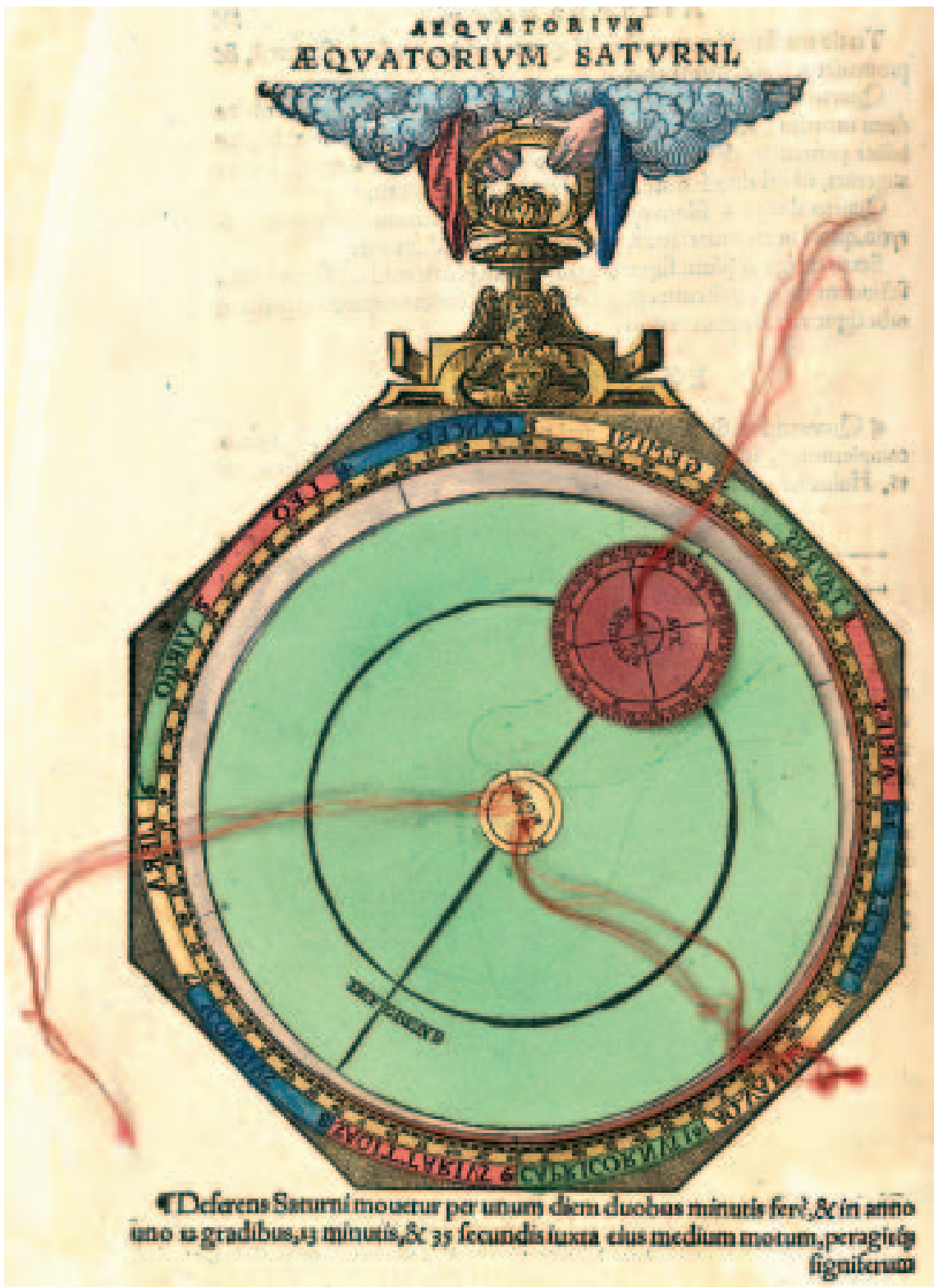

Abbildung 15 (Kat.Nr. 53)

Johann Schöner: Opera mathematica, 1551, Planetenbahn des Saturn. 
54 Apian, Petrus:

Cosmographicus liber. - Landshut: Joannis Weyssenburger, 1524. !HSD! 8 GEOGR MATH 80 RARA

Petrus Apian (1495 - 1552), Mathematiker, Astronom, Kartograph und Geograph in Ingolstadt, befasste sich mit Ortsbestimmungen, Kartenentwürfen und mit allgemeinen methodologischen und wissenschaftssystematischen Fragestellungen. Seine Cosmographicus liber gibt eine Anleitung zum Anfertigen von Landkarten.

Um die westliche und östliche Hemisphäre besser darstellen zu können, kam es im 16. Jahrhundert zur Weiterentwicklung der schon im Mittelalter bekannten Planigloben. Die Methode, den Hauptmeridian gleichzuteilen und die Parallelkreise als gerade längentreue Linien zu zeichnen, stammt vermutlich von Peter Apian. Die erstmalige Angabe der Konstruktionsart erfolgte im Cosmographicus Liber, seinem wissenschaftlichen Hauptwerk. Der Äquator ist orientierende Hauptlinie, doch ist Apian das Verhältnis zwischen Mittelmeridian und Äquator nicht bekannt. Apians Cosmographicus Liber enthielt in der Erstausgabe 1524 eine Tabelle der Länge der Parallelkreise in Äquatorialminuten. Ferner enthält das Werk eine Liste mit den geographischen Koordinaten von 1417 Orten, die im Bereich von Mitteleuropa von bemerkenswerter Genauigkeit sind.

\section{Apian, Petrus:}

Cosmographia Petri Apiani /per Gemmam Frisium. - Paris: Vaeneunt apud Viuantium Gaultherot, 1551. 74 Bl., 2 Holzschnitte.

!HSD! 8 GEOGR MATH 85 RARA

Der Erstausgabe von 1524 dieses weitverbreiteten kosmographischen Werkes der mathematischen Richtung folgten mehr als 20 weitere Auflagen, zum Teil von Gemma Friesius (1508 - 1555) überarbeitet. Nur die Erstausgabe erschien als Cosmographicus Liber, alle weiteren unter dem Titel Cosmographia.

Gemma Friesius, belgischer Arzt, Astronom und Kartograph, veröffentlichte später einen wichtigen Beitrag zur Geographie und Kartographie, in der er eine Methode zur Bestimmung der geographischen Länge entwickelte. Ausgehend von der Tatsache, dass jede Differenz von 15 Längengraden einen Zeitunterschied von 1 Stunde zwischen Lokalzeit und der Zeit des Ausgangspunktes von Reisenden entspricht, schlug Gemma Friesius vor, bei Gebrauch einer genauen Reiseuhr durch 
Vergleich zwischen der angezeigten Zeit und der Lokalzeit die geographische Länge zu bestimmen. Sobald solche Uhren konstruiert waren, war seine Methode für Längenbestimmungen einsetzbar.

56 Glareanus, Henricus:

De geographia liber unus, ab ipso auth. iam recognitus. - Basel, 1528. !HSD! 8 GEOGR MATH 73 RARA

Henricus Glareanus (1488 - 1563), Professor der Mathematik in Basel, Paris und Freiburg, Musiktheoretiker und Kartograph, war einer der wichtigsten und vielseitigsten Humanisten und gehörte dem Kreis um Erasmus von Rotterdam an, blieb aber katholisch. Einer seiner Schüler war Aegidius Tschudi. In seinem Buch De geographia gab Glareanus eine der frühesten Anleitungen zur Konstruktion von Globensegmenten und erwähnte als erster die magnetische Deklination. 


\section{Die räumliche Erweiterung des Wissens: Die großen Entdeckungen}

An die Stelle von Spekulationen über das Bild der Welt trat seit dem ausgehenden 15. Jahrhundert allmählich durch Erkundung und Erfahrung gesichertes Wissen. Einen entscheidenden Beitrag dazu leisteten die Entdeckungsfahrten des 15. und 16. Jahrhunderts. In diesem Zeitraum wuchs der bekannte Bereich der Welt von einem Viertel bis auf fast den ganzen Erdball. Der wichtigste Impuls kam dabei weniger vom Entdeckerdrang oder der reinen Freude am Abenteuer als vielmehr vom wirtschaftlichen Interesse an einer räumlichen Ausdehnung des Handels.

57 Càda Mosto, Aloise:

Itinerarium Portugallensium e Lusitania in Indiam et inde in occidentem et demum ad aquilonem. - 0 . O., 1508.

!HSD! 4 ITIN I, 3846 RARA

Cadamosto (1432 - 1488), venezianischer Seefahrer, wurde 1455 von Heinrich dem Seefahrer zur Erforschung des Seewegs entlang der westafrikanischen Küsten entsandt. 1456 glückte Cadamosto die Erstentdeckung der Kapverdischen Inseln. Die Suche eines Weges über den Gambia zum Reich des 'Priesterkönigs Johannes' scheiterte dagegen mehrmals.

Cadamosto ist der einzige der von Heinrich dem Seefahrer entsandten Kapitäne, der über seine Fahrten berichtet hat. Seine Reisen brachten wichtige Erkenntnisse über die nordwestafrikanischen Küsten, zumal er eine Reisebeschreibung verfasste, die ungeheuer lebendig war und seine Beobachtungen in allen Einzelheiten darstellte. Sie wurde allerdings erst 20 Jahre nach seinem Tod gedruckt. In diesem Bericht ist auch die älteste Beschreibung des bekannten Sternbildes der südlichen Breiten, des Kreuzes des Südens, enthalten.

58 Càda Mosto, Aloise:

Newe unbekanthe landte und ein newe weldte in kurtz verganger zeythe erfunden. - Nüreinbergk: Georg Stüch $\beta$, 22. 9. 1508.

!HSD! 4 ITIN I, 3846/a RARA 
Deutsche Übersetzung der Itinerarium Portugallensium e Lusitania in Indiam et inde in occidentem et demum ad aquilonem aus dem gleichen Jahr.

Vgl. auch Nr. 57.

59 Polo, Marco:

Il milione <dt.> - Hie hebt sich an das puch des edeln Ritters vn landtfarers Marcho Polo. In dem er schreibt die grossen wunderlichen ding dieser Welt. - Nürnberg: Fritz Creußner 1477.

!HSD! 4 ITIN I, 2268 INC

Einen neuen Anstoß erhielt die Geographie durch die Ausweitung der konkreten Raumkenntnisse infolge von Handelsreisen. Dabei kam dem Venezianer Marco Polo (1254 - 1324), einem der bedeutendsten Reisenden des Mittelalters, große Bedeutung zu. Von 1271 an lebte er 17 Jahre in China und führte von 1271 bis 1292 große Reisen durch. Nach seiner Rückkehr 1295 verfasste er seine berühmten Reisebeschreibungen, die von großem Einfluss auf die geographisch-landeskundlichen Vorstellungen des 14. und 15. Jahrhunderts waren.

Die Schilderungen Marco Polos von dem Glanz im Osten, seinen Millionenstädten und Reichtümern fanden bei den Zeitgenossen wenig Glauben. Man sträubte sich gegen den Gedanken, dass es im Fernen Osten Kulturen gäbe, die der im damaligen Europa in vielem überlegen waren. Sein Werk ist nicht frei von Fehlern, denn er war Kaufmann, nicht wissenschaftlicher Forscher. Zum Beispiel sind seine Entfernungsangaben häufig zu hoch gegriffen, so dass die Kartographie besonders des 16. Jahrhunderts den Ostrand Asiens viel zu weit nach Osten verlegte. Die Angaben aus den Gebieten, die er selbst gesehen hatte, stellten sich im nachhinein meist als richtig heraus, während bei Ländern, die er nicht gesehen hatte, manche Übertreibungen zu finden sind. Zum ersten Mal hörte man durch ihn in Europa von Papiergeld, von mit Bäumen gesäumten Straßen und anderen Einrichtungen, die in Süd- und Westeuropa bald nachgeahmt werden sollten.

60 Colom, Christoforus:

Epistola de insulis nuper inventis. - Paris in campo Gaillardi, nach 29. IV. 1493.

!HSD! 8 H AM I, 502 INC RARA 


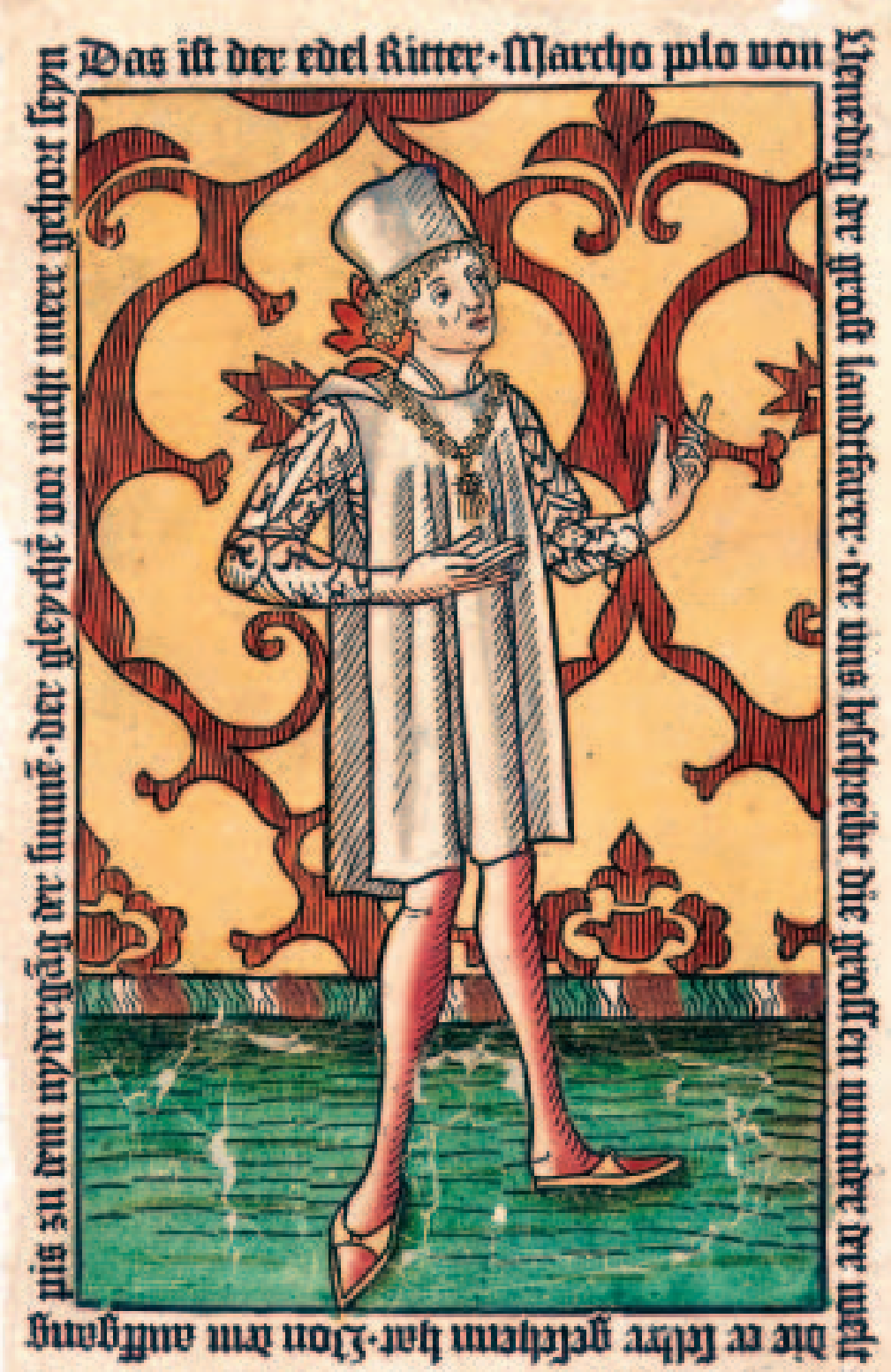

Abbildung 17 (Kat.Nr. 59)

Marco Polo: Il milione <dt.>, 1591, Frontispiz 
Christopher Columbus (1443 - 1506), genuesischer Seefahrer, hatte sich schon in jungen Jahren in den Kopf gesetzt, Indien auf westlicher Route zu erreichen. Der Versuch, die portugiesische Regierung, die seit Heinrich dem Seefahrer für die Erforschung neuer Schifffahrtswege sehr aufgeschlossen war, für diesen Plan zu gewinnen, scheiterte. Daraufhin wandte sich Columbus nach Spanien und erlangte 1492 endlich die Unterstützung durch König Ferdinand und vor allem durch Königin Isabella. Nach einer zehnwöchigen Reise erreichte er am 12. 10. 1492 San Salvador und kam dann nach Kuba und Haiti, wo er eine spanische Niederlassung gründete. Bei seiner Rückkehr nach Spanien wurde ihm ein triumphaler Empfang zuteil. Bis 1504 unternahm er noch drei weitere Fahrten, auf denen er die Küsten Mittel- und Südamerikas entdeckte. Bis zuletzt glaubte er, den westlichen Seeweg nach Japan und Indien gefunden zu haben. Erst seine Nachfolger merkten, dass er einen neuen Kontinent entdeckt hatte. In dem Namen Westindien für die mittelamerikanische Inselwelt und der Bezeichnung ihrer Bewohner als Indios lebt bis heute der Irrtum Columbus fort.

Das Charakterbild des Columbus war und ist umstritten. Die einen empfahlen seine Heiligsprechung, andere warfen ihm schiere Goldgier und Forcierung des Sklavenhandels vor. Ein Forscher im modernen Sinne war Columbus nicht, dazu waren seine Untersuchungen zu unsystematisch.

Die Columbusbriefe sind die erste gedruckte Kunde von der neuen Welt, abgesehen von einigen Hinweisen in Universalhistorien und geographischen Werken. Mit seinen Entdeckungen trat 1492 die Neue Welt als vierter Erdteil in den Mittelpunkt des Interesses.

61 Vespucci, Amerigo:

Mundus novus. - Antwerpen: Willem Vostermann, 1504. 4 Bl. !HSD! 8 H AM I, 621 RARA

Amerigo Vespucci (1451 - 1512), italienischer Entdeckungsreisender in spanischem und portugiesischem Auftrag, erkundete auf seinen Reisen die gesamte südamerikanische Küste etwa vom Golf von Venezuela bis in die Gegend von Bahia Blanca. Schon auf der ersten Fahrt kam er dabei zu der Ansicht, dass diese Küste zu einem großen Festland gehören müsse, glaubte allerdings noch, dass dies Asien sei. Nach der zweiten Reise erkannte er, dass es sich um einen selbständigen Erdteil handelte. Dies brachte er auch auf seinen Karten zum Ausdruck, die zum ersten Mal eine ziemlich richtige Vorstellung von dem Verhältnis von Europa und Asien zu dem neuen Kontinent gaben. Vespuccis anschauliche Reisebeschreibung erregte in 
Europa großes Aufsehen. Seine Logbücher und die Karten gingen verloren, was bis ins 20. Jahrhundert hinein zu gewissen Zweifeln an seiner Leistung geführt hat.

62 Vespucci, Amerigo:

Hie folget eyn kurtzer begriff der schiffarten Albericj Vespucij. Von der Newen welt ...

In:

Die Newwelt, der landschaften unnd Insulen, so bis hie her allen Altweltbeschrybern unbekant, jungst aber von den Portugalesern unnd Hispaniern im Nidergenglichen Meer befunden. / Ins deutsche übersetzt durch Michael Herr. - Gedruckt zu Straßburg durch Georgen Ulricher von Andla, 14. 3. 1534.

4 ITIN I, 3842/a

Die deutsche Ausgabe erschien 1534 in einer Sammlung von Reiseberichten, in der unter anderen auch die Reisenberichte des Columbus abgedruckt wurden.

Vgl. auch Nr. 61. 


\section{Die räumliche Erweiterung des Wissens: Reisebeschreibungen}

Reisebeschreibungen waren wesentliche Informationsquellen für Geographen, um mit der Darstellung der neuen Länder die alten Kosmographien zu vervollständigen. Die frühen Reiseberichte hatten oft übertreibenden oder phantastischen Charakter, wurden aber bis zum Ende des 17. Jahrhunderts durch wissenschaftliche Reisebeschreibungen abgelöst.

63 John $\langle$ Mandeville $\rangle$ :

Voyages 〈dt.> - Von der erfarün[g] des strengen Ritter[s] iohannes von montauille. - Deutsch von Otto von Diemeringen. - Straßburg: Bartholomaeus Kistler, 2. IX. 1499.

!HSD!4 ITIN I, 2276/h INC

Jean de Mandeville (? - um 1372), von dessen Leben nur bekannt ist, dass er im 14. Jahrhundert gelebt hat, spiegelt in seinen Berichten das Weltbild des Hochmittelalters wieder. Er hat selbst keine Reisen unternommen, sondern fasste wahre und fabulöse Reiseberichte zu einem schillernden Bild der im 14. Jahrhundert bekannten außerchristlichen Welt zusammen.

Sein Original-Manuskript hat sich nicht erhalten, zahlreiche Abschriften verbreiteten den Text. Nach der Erfindung des Buchdrucks zählte das Werk bis ins 16. Jahrhundert hinein zu den meistgelesenen Büchern.

Mandeville war kein 'Märchenerzähler', sondern ein Schriftsteller, der vorhandene Berichte ordnete und sie oft kritisch auswertete. Dabei gehörten jedoch die Wunder märchenhafter fremder Länder zu seinem Weltbild, wie überhaupt nach seiner mittelalterlichen, scholastisch geprägten Vorstellung die Erde in der Hand eines christlichen Gottes ruhte.

64 Staden, Hans:

Warhaftig Historia und Beschreibung eyner Landschafft der Wilden, Nacketen, Grimmigen, Menschenfresser Leuthen, in der Newenwelt America gelegen, vor und nach Christi Geburt im Land zu Hessen unbekant, biß uff dise 11 nechst vergangene jar, da sie Hans Staden von Homberg auß Hes- 


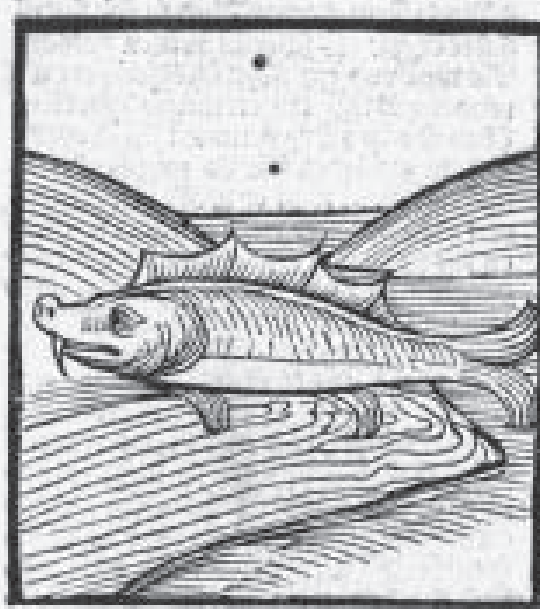

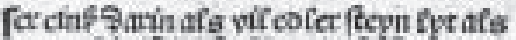

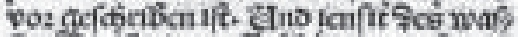

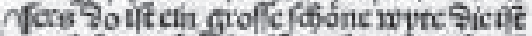

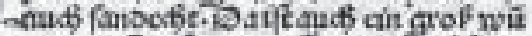
ocr mit for foanch vff gatis solatifeno

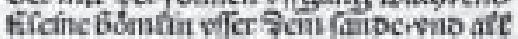

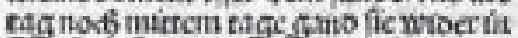

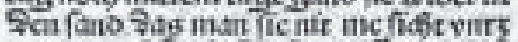

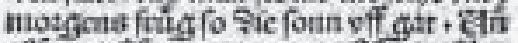

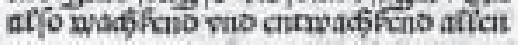

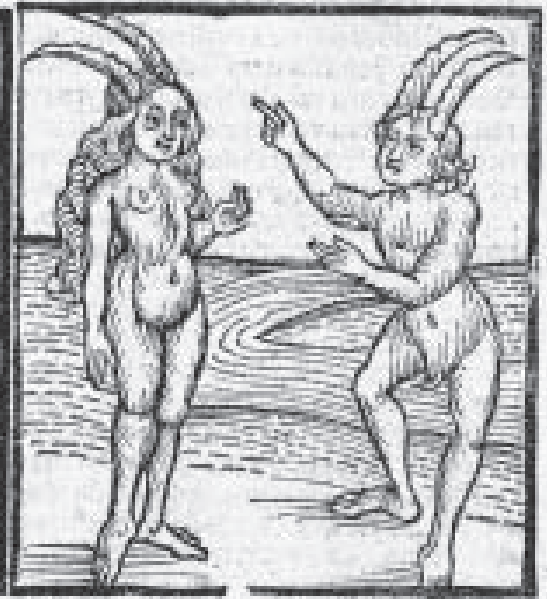

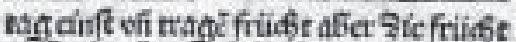

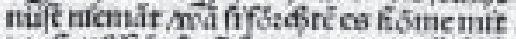

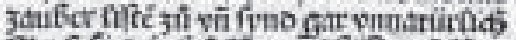

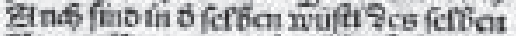

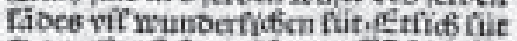

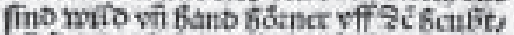
ví fino ytef gckar vî firufvin geftabet,

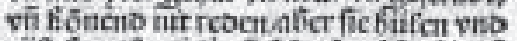

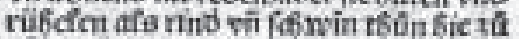

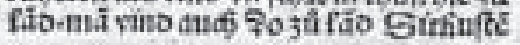
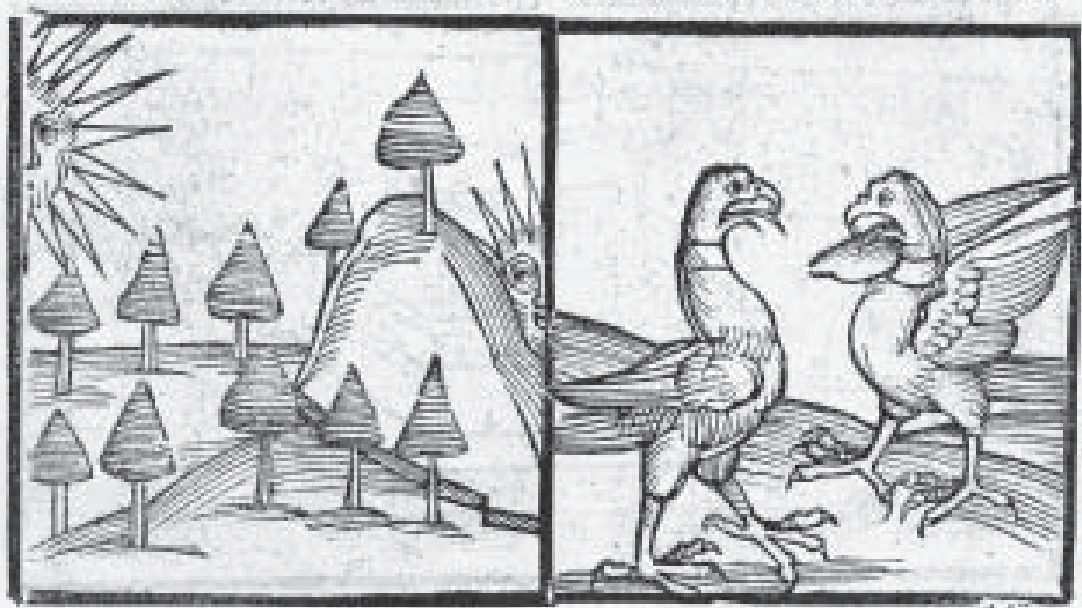

iii)

Abbildung 18 (Kat.Nr. 63)

John Mandeville: Voyages <dt.>, 1499, Abbildung von Fabelwesen. 
sen durch sein eygen erfarung erkant ... Mit eyner vorrede D. Joh. Dryandri, genant Eychman. - Getruckt zu Marpurg, 1557.

!HSD! 8 H AM I, 2880 RARA

1557 erschien in Marburg Hans Stadens (um 1525 - 1576) Warhaftig Historia und Beschreibung eyner Landschafft der Wilden, Nacketen, Grimmigen, Menschenfresser Leuthen, in der Newenwelt America gelegen ..., eine Schilderung von zwei Reisen nach Südamerika 1548 - 1555. Staden geriet dabei als Seemann in Brasilien in indianische Gefangenschaft. Sein Bericht ist eine der ersten Chorographien überseeischer Länder der beginnenden Neuzeit. Es wurde 'für breite Schichten des deutschen Volkes das begehrte Menschenfresserbuch', von dem bis heute 80 Ausgaben in acht verschiedenen Sprachen erschienen sind. Das Buch ist Zeugnis der portugiesischen Landnahme in Brasilien und beschreibt großartig die südamerikanischen Indianer. Es korrigierte die damals noch übliche antike Lehre einer verbrannten äquatorialen Zone zugunsten der Geographie einer tropischen Zone. Die Ausgabe ist reich an Holzschnitten nach Entwürfen des Verfassers.

65 Schmidel, Ulrich:

Vera Historia admiranda cuisdam navigationis, quam Huldericus Schmidel ab anno 1534 ad 1554 in Americam confectit. - Norimbergae: Impensis Levini Hulsij, 1599.

8 ITIN I, 4086

Ulrich Schmidel (um 1510 - nach 1564), deutscher Landsknecht aus Straubing, nahm am Entdeckungsfeldzug des Juan de Ayolas teil. Er kam bis nach Argentinien und Paraguay. Nach großen Entbehrungen und Gefahren kehrte er 1554 in seine Heimat zurück. Seine Vera Historia ist nicht nur eine der ganz wenigen authentischen Berichte über deutsche Konquistadoren, sondern auch eine hervorragende Quelle über Eroberungen im La-Plata-Raum.

66 Herberstein, Sigismund von:

Rervm Moscoviticarvm commentarij. Rvssiae breuissima descriptio, \& de religione eorum varia inserta sunt. Chorographia totius imperij Moscici, \& vicinorum quorundam mentio. - Antverpiae: In aedibus Ioannis Steelsij, Typis Ioannis Latij, 1557. 198 Bl.

8 H RUSS 180/23 


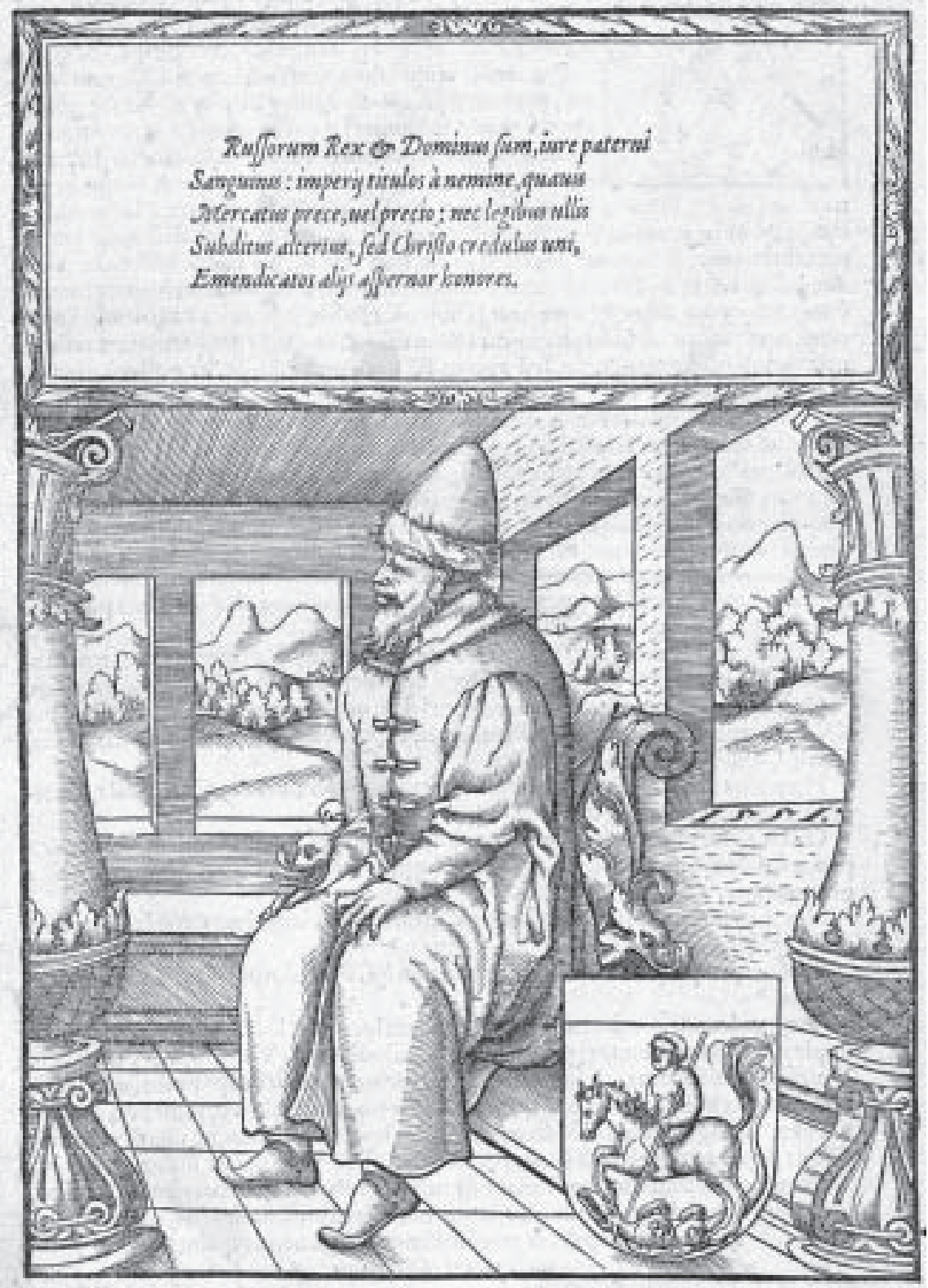

Abbildung 19 (Kat.Nr. 66)

Sigismund von Herberstein: Rervm Moscoviticarvm commentarij, 1557, Porträt eines Zaren. 
Der österreichische Diplomat und Historiker Siegmund Freiherr von Herberstein (1486-1566) bereiste als Gesandter am russischen Zarenhof große Teile Europas. Während seiner beiden russischen Reisen 1516 - 1518 und 1526 - 1527 machte Herberstein ausgezeichnete Beobachtungen über Land und Leute des im übrigen Europa noch unbekannten Russischen Reiches. Er verbreitete in Mitteleuropa die ersten genauen Berichte über Russland und das benachbarte Asien. Seine Rerum Moscovitarum commentarii gelten als das beste ältere Werk zur Geographie und Geschichte Russlands, das außerhalb Russlands erschienen ist, zusammengestellt aus Geschichtsquellen, Berichten anderer Reisender und eigenen Beobachtungen. Zum ersten Mal erfährt man in Europa näheres über den Lauf der Wolga und des Don, über Ob und Irtsch, über den Zusammenhang des Weißen Meeres mit dem Nordpolarmeer und über den Ural.

67 Nicolay, Nicolas de:

Schiffart und Rayß in die Türckey und gegen Orient ... Aus der frantzösischen Sprach in die Teutsche gebracht. - Nürnberg: Gerlatz, 1572. 174 Bl., zahlreiche Kupferstiche.

!HSD! 4 ITIN I, 27312/a RARA

Der französische Geograph Nicolas de Nicolay (1517 - 1583) diente in verschiedenen Armeen und bereiste als Artilleriekommandant Europa auf diese Weise. 1551 begleitete er den Gesandten Aramont als Kammerherr nach Konstantinopel. Nicolay beschreibt die Seereise über Algier, Malta und Tripolis sowie die Stadt Konstantinopel. Ein großer Teil des Werkes gilt den Sitten und Gebräuchen der Türken, Perser und Griechen. Zahlreiche Holzschnitte mit Trachten illustrieren die Beschreibung. Über die Originalausgabe von 1567 ist wenig bekannt, die erste deutsche Übersetzung erschien 1572.

68 Rauwolf, Leonhard:

Beschreibung der Reyß Leonhardi Rauwolffen, so er vor dieser Zeit gegen Aufgang in die Morgenländer, fürnemlich Syriam, Judeam, Arabiam, Mesopotamiam, Babyloniam, Assyriam, Armeniam, ... vollbracht: in 3 Theil abgetheylet. - Gedruckt zu Franckfurt am Mayn bey Christoff Raben, 1582. 8 ITIN I, 2318 


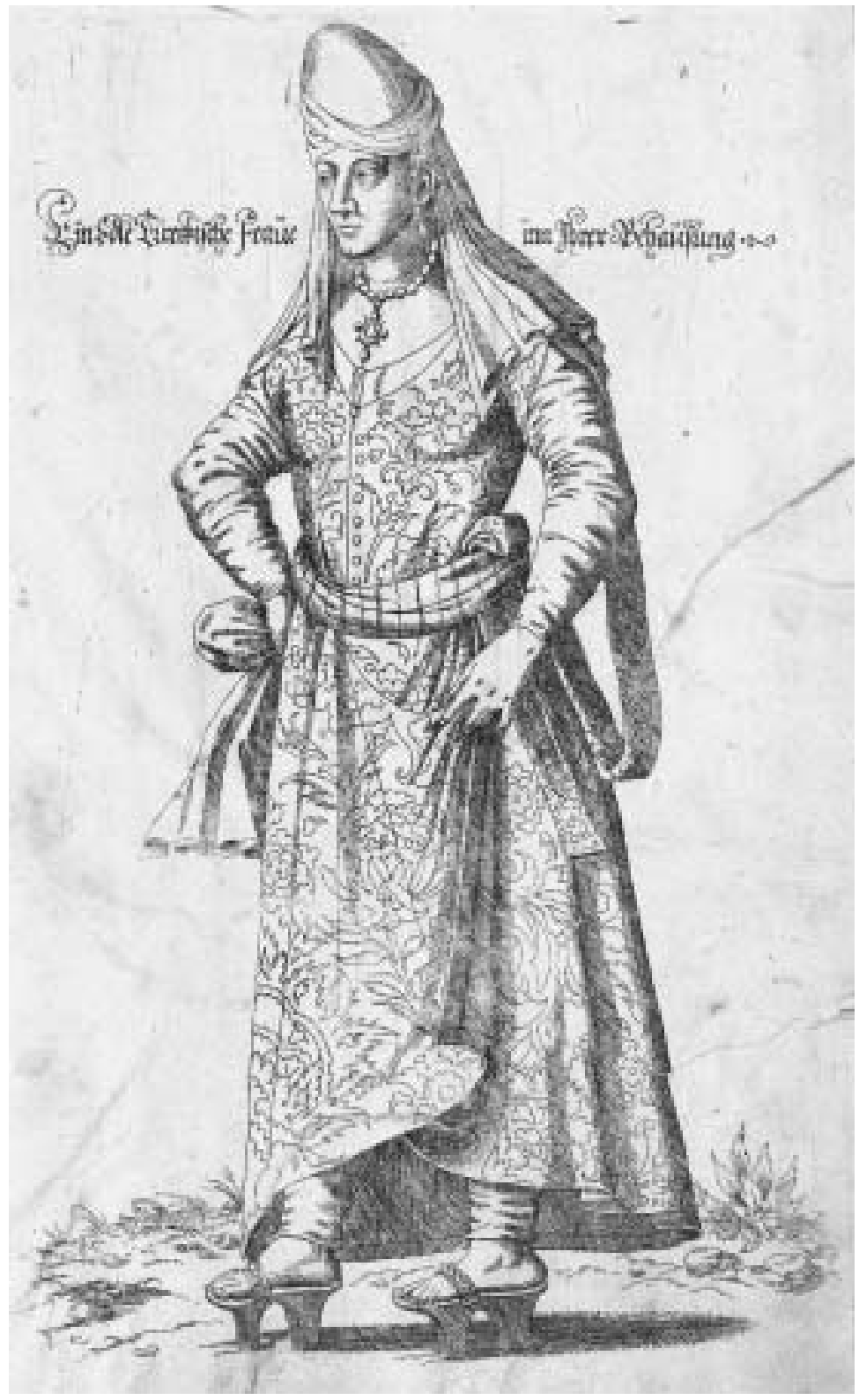

Abbildung 20 (Kat.Nr. 67)

Nicolas de Nicolay: Schiffart und Rayß in die Türckey ..., 1572, Türkin in Tracht. 
Leinhard Rauwolf (1535 - 1596), Augsburger Arzt, Botaniker und Reisender, brachte als erster Informationen über große Teile Syriens und Mesopotamiens von seinen ausgedehnten Reisen mit. Sein Bericht über eine botanische Sammelreise in den Orient 1573 - 1575 beschränkt sich jedoch nicht nur auf botanische Forschungen, sondern stellt auch die Topographie, die Geschichte, Sitten und Gebräuche der besuchten Volker eingehend dar. So wird die Einrichtung der türkischen Badehäuser ausführlich beschrieben und die Zubereitung des Kaffees erstmals in einer deutschen Schrift erläutert.

69 Martens, Friedrich:

Spitzbergische oder Groenlandische Reise Beschreibung, gethan im Jahr 1671. Aus eigener Erfahrung beschrieben ... - Hamburg: Schultze, 1675. 132 S., 14 Tafeln.

8 ITIN I, 1748

Friedrich Martens, Hamburger Wundarzt und Barbier, beteiligte sich im Jahr 1671 an der Walfangfahrt eines friesischen Schiffes nach Spitzbergen und Grönland und gelangte bis zum 81. nördlichen Breitengrad. Er fasste seine Beobachtungen in einem kleinen Buch zusammen, welches Reisebeschreibung und systematisch gehaltene Kapitel miteinander verbindet. Damit verfasste er die erste, seiner Zeit weit vorausgehende, wissenschaftliche Beschreibung des Nordpolargebietes. Es war für lange Zeit die beste Schilderung der polaren Natur, die selbst von Linné hochgeschätzt und ausgiebig benutzt wurde.

70
Linschoten, Jan Huygen van:
Itinerario. Voyage ofte Schipvaert naer Oost Portugaels Indien. - t'Amstel- redam: Claesz, 1596.
!HSD! 4 ITIN I, 3877 RARA

Jan Huyghen van Linschoten (1562 - 1611) war ein holländischer Ostindien-Reisender, der in den Jahren 1583 bis 1592 von Lissabon über die ostafrikanische Küste bis Goa und zurück über die Azoren nach Holland reiste. Die Bedeutung seines 1596 fertiggestellten Reiseberichtes liegt darin, dass er dem nichtiberischen Europa große Teile Asiens, bis dahin fast nur den Portugiesen bekannt, als eine neue Welt erschloss. Er schuf ein Grundwerk der Erd- und Völkerkunde Asiens, in 
dem sich eigene Erfahrungen mit angelesenem Wissen verbinden. Geschmückt ist das Buch mit einigen Karten, Ansichten von Häfen, Landschaften und Volkstypen, größtenteils nach den Zeichnungen Linschotens gefertigt. Sein Werk erwies seinen unmittelbar praktischen Wert, denn es wurde ab 1596 von den holländischen Flotten nach Ostindien mitgeführt. Der Reisebericht erschien in verschiedenen Auflagen und Übersetzungen.

71 Pigafetta, Philippum:

Regnum Congo, hoc est Vera Descriptio regni Africani, quod Congo appellatur. - Iconibus et imaginibus, opera et industria Joan. Theodori et Joan. Israelis de Bry exornata. - 1598.

!HSD! 4 ITIN I, 3844/b: 1 RARA

Pigafetta (1491? - 1525) aus Vicenza, italienischer Edelmann, war Teilnehmer und einziger Chronist der Weltumsegelung von Ferdinand de Magellan. Er gehörte zu den 18 Überlebenden - von 237 Ausgefahrenen -, die Sevilla wieder erreichten. Wahrscheinlich vollendete er 1524 in Rom seinen Reisebericht.

Die hier vorliegende Ausgabe stammt von Johann Theodor de Bry (1561 - 1623) und Johann Israel de Bry (vor 1598 - 1611). Zusammen mit ihrem Vater Theodor (1528 - 1598) gaben die Brüder eine Reihe von Reisebeschreibungen unter anderem über Amerika heraus, die besonders anschaulich durch die reiche Ausstattung mit Kupfern zur Landeskunde sind.

72 Dapper, Olfert:

Naukeurige beschrijving der Afrikaensche Gewesten van Egypten, Barbaryen, Libyen. - Amsterdam: Meurs, 1668.

!HSD! 2 H AFR 99 RARA

Olfert Dapper (1636/37 - 1689), niederländischer Historiker, Geograph und Mediziner, studierte zunächst in Utrecht und Amsterdam Medizin, beschäftigte sich anschließend aber überwiegend mit historischen und geographischen Studien. Obwohl er selbst nie gereist war, veröffentlichte er sieben umfangreiche geographisch-historische Beschreibungen unter anderen über Afrika, Asien, Palästina und Arabien, die er aus zahlreichen Quellen zusammengestellt hatte. 
73 Olearius, Adam:

Offt begehrte Beschreibung Der Newen Orientalischen Reise, So durch Gelegenheit einer Holsteinischen Legation an den König in Persien geschehen. Worinnen Derer Oerter vnd Länder, durch welche die Reise gangen, als fürnemblich Rußland, Tartarien vnd Persien, sampt jhrer Einwohner Natur, Leben vnd Wesen fleissig beschrieben ... - Schleßwig: Bey Jacob zur Glocken, 1647. 600 S., zahlreiche Illustrationen und Portraits als Kupferstiche und Holzschnitte.

!HSD! 4 ITIN I, 2883 RARA

Adam Olearius (eigentlich: Ölschläger) (1599 - 1671), einer der bedeutendsten deutschen Reisenden des Barock, nahm zusammen mit seinem Freund, dem Dichter Paul Fleming, im Auftrag Herzog Friedrichs III. von Schleswig-Holstein-Gottorp an zwei Handelsexpeditionen durch Russland 1633 - 1635 und Persien 1635 1639 teil. Er veröffentlichte sein Reisewerk erstmals 1647, zum zweiten Mal, beträchtlich ergänzt und überarbeitet, im Jahre 1656. Es erschienen in der Folgezeit zahlreiche weitere Ausgaben in verschiedenen Sprachen.

Olearius' Werk war die erste umfassende Persien-Beschreibung in der europäischen Literatur und zugleich die beste Russlandbeschreibung des 17. Jahrhunderts. Sie ersetzte das von Siegmund von Herberstein geschaffene Bild des Russischen Reiches. Was sein Werk darüber hinaus so wichtig machte, war, dass er als messender Beobachter erstmals Auskunft geben konnte über Lage und räumliche Beschreibung vage bekannter Landstriche. Durch sein Werk, das eine wichtige Quelle zur Kulturgeschichte Russlands und Persiens darstellt, gehörte er zusammen mit Engelbert Kaempfer zu den Begründern der wissenschaftlichen Reisebeschreibung.

74 Kaempfer, Engelbert:

Amœenitatum exoticarum politico-physico-medicarum Fasciculi $V$ quibus continentur varice Relationes, Observationes, et Descriptiones rerum Persicarum et ulterioris Asia, in Peregrinationibus per universum Orientem collecta. - Lemgovia, 1712.

!HSD! 8 ITIN I, 2986 RARA

Engelbert Kaempfer (1651 - 1716), deutscher Pfarrersohn, Arzt und Forschungsreisender, war einer der ersten Japanforscher. Er war von umfassender Bildung, 
unternahm schon früh weite Reisen und lernte viele Sprachen. Als Sekretär und Arzt kam er mit einer schwedischen Gesandtschaft über Moskau, die Wolga, Astrachan und das Kaspische Meer nach Persien, wo er sich von der Gesandtschaft trennte. Nach vier Jahren in Persien reiste er über Ceylon und das Bengalische Meer nach Sumatra, Java und Siam. Den Höhepunkt seiner Forschungen bildete der Aufenthalt in Japan. Auf der einzigen dort zugelassenen europäischen Handelsstation der Niederländer in der Nähe von Nagasaki sammelte er zwischen 1690 und 1692 umfassende Nachrichten über das Land, seine Kultur und Lebensformen. Außerdem hatte er die Gelegenheit, an zwei Gesandtschaftsreisen der Niederländer nach Tokio teilzunehmen. Seine Japanberichte sind die ältesten und vollständigsten, die außerhalb Japans über das Inselreich veröffentlicht worden sind. Das Ergebnis seiner Forschungen veröffentlichte er in den Amoenitates.

75 Kämpfer, Engelbert:

Geschichte und Beschreibung von Japan. - Aus der Original-Handschrift des Verf. hrsg. von Christian Wilhelm Dohm. - Lemgo: Meyer, 1777-1779. Zahlreiche Kupfer.

!HSD! 8 ITIN I, 3268:1,2 RARA

Die deutsche Ausgabe des Japanwerkes, herausgegeben von Christian Wilhelm Dohm, erschien erst 1777 - 1779 unter dem Titel Geschichte und Beschreibung von Japan. Die übrigen nachgelassenen Schriften Kaempfers, besonders seine Beobachtungen in Persien, liegen größtenteils unveröffentlicht im British Museum in London. 


\section{Sammlungen von Reiseberichten}

Neu war zum Ende des 16. Jahrhunderts, vor allem aber im 17. Jahrhundert das Publizieren von Sammlungen von Reisebeschreibungen, um die darin vorliegenden Informationen einem breiteren Publikum verfügbar zu machen. Unter dem Einfluss der Aufklärung und der aufstrebenden Naturwissenschaften kam das Lesen der Reisewerke bei Angehörigen verschiedener Schichten dem Bedürfnis entgegen, sich eigene Vorstellungen über fremde Länder, deren Einwohner und Gebräuche zu machen.

76 Novus Orbis Regionum ac Insularum veteribus incognitarum. Una cum Tabula Cosmographica, ... / (Simon Grynaeus [Hrsg.]) - Basilea: Apud Jo. Hervagium, 1555. - $677 \mathrm{~S}$.

4 ITIN I, 3843

Simon Grynaeus (1493 - 1541), Humanist und reformierter Theologe, wurde als großer Gelehrter verehrt, der in Heidelberg und später in Basel lehrte. Er verfügte über eine umfangreiche Kenntnis der griechischen Sprache, sein Interesse an der Philosophie und der Theologie erstreckte sich auf fast alle Autoren, so dass seine wissenschaftliche Arbeit ein sehr breites Spektrum abdeckte: Sie befasste sich mit Gott, mit dem Menschen und mit der Natur. So edierte er neben seiner Universitätstätigkeit unter anderen eine Sammlung von Reisebeschreibungen. Das Geographiebuch Novus orbis regionum ac insularum veteribus incognitarum erschien erstmals 1532 in Basel zum 40. Jahrestag der Entdeckung Amerikas.

Auf der beigegebenen Karte findet sich eine Darstellung des Kannibalismus auf der Randverzierung der Karte unten links. Die Canibali sind auf der Karte in Südamerika angesiedelt.

77 Schiffahrten/gesammelt u. hrsg. durch Levin Hulsius. - Franckfurt am Mayn: Richter, 1598 -

Wechselndes Impressum: u. a. ersch. bei Hulsius in Nürnberg und Hulsius in Hanau.

!HSD! 8 ITIN I, 3883 RARA 


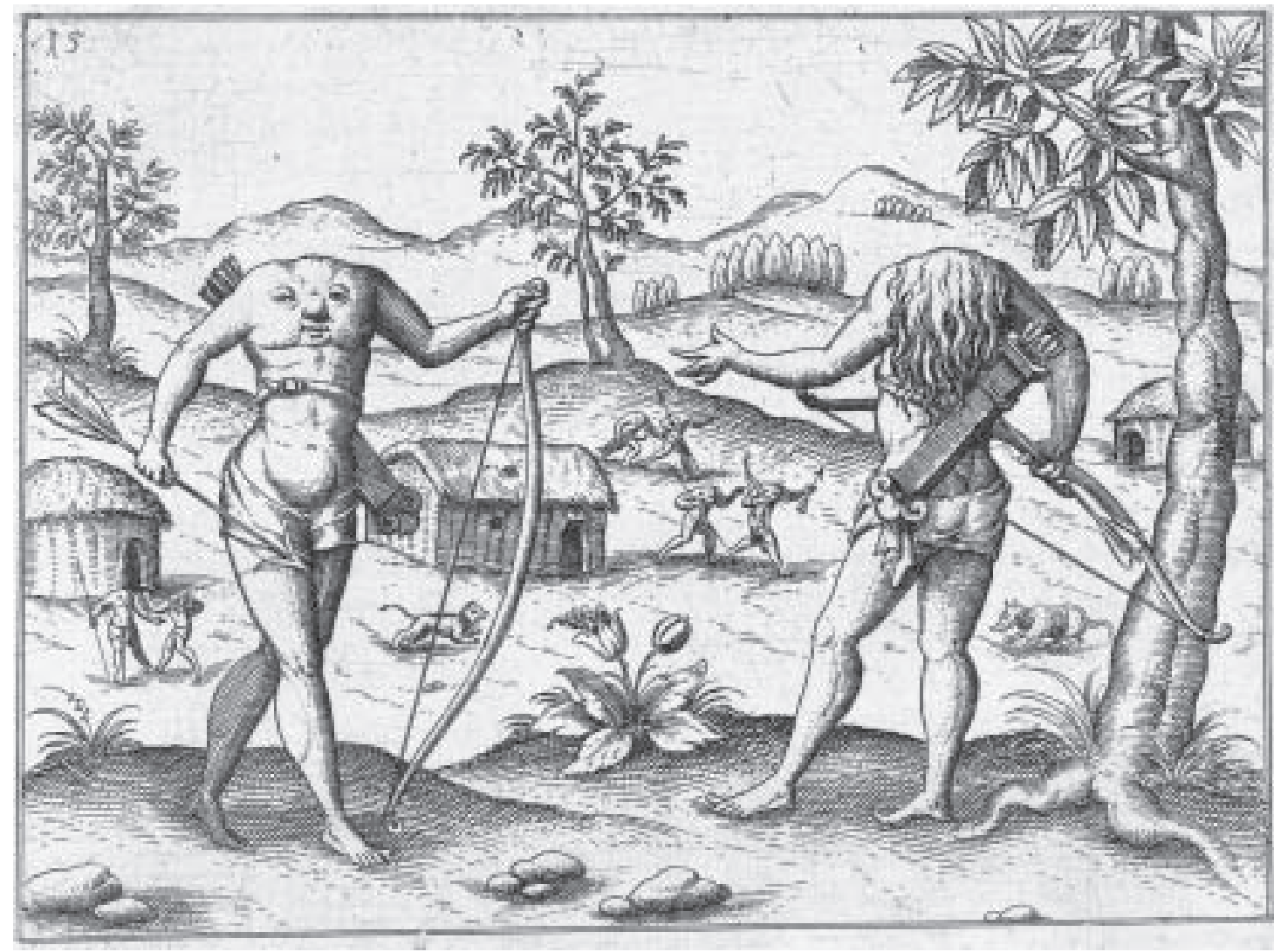

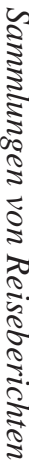

Abbildung 21 (Kat.Nr. 77)

Schiffahrten, hrsg. durch Levin Hulsius, 1598, Zwei kopflose Figuren. 
Der aus Gent stammende Nürnberger Bibliothekar und Buchverleger Levin Hulsius (1546 - 1606) war ein außerordentlich kreativer und tüchtiger Geschäftsmann und fleißiger Schriftsteller. Zwischen 1598 und 1630 verfasste oder bearbeitete er seine Sammlung von 26 Reisebeschreibungen (Schiffahrten) und veröffentlicht damit fast alle bis dahin erschienenen Entdeckungsreisen in deutscher Übersetzung. Die Bände sind reich illustriert. Die Beschreibungen der abenteuerreichen und gefahrvollen Übersee- und Entdeckungsfahrten vornehmlich der Holländer, aber auch der Engländer und Franzosen, fanden bei den deutschen Lesern ein sehr starkes Echo. Die Reihe wurde nach seinem Tode von den Erben bis 1650 fortgesetzt.

Der erste Einzelband ist zugleich der kostbarste: Er berichtet über die erste, 1595 gestartete niederländische Reise nach Ostindien unter Cornelis de Houtman und enthält mehrere Karten, darunter eine eingebundene Weltkarte mit den Weltumsegelungen von Magellan (1522) und Drake (1577).

78 Hackluyt, Richard:

The principal navigations, voyages, traffiques and discoveries of the English nation, made by sea or over land to the remote and farthest distant quarters of the earth, at any time within the compasse of these 1600 yeres. Divided into three severall volumes, according to the positions of the regions, where unto they were directed. The first volume containeth the worthy discoveries etc. of the English toward the north and northeast by sea as of Lapland, Scrikfinia, Corelia, the Baie of S. Nicolas, the Isles of Colgoieve, Vaigatz and Nova Zembla toward the great river $\mathrm{Ob}$ with the mighty Empire of Russia, the Caspian Sea, Georgia, Armenia, Media, Persia, Boghar in Bactria and divers kingdomes of Tartaria. Together with many notable monuments and testimonies of the ancient forren trades and of the warrelike and other shipping of this realme of England in former ages. Whereunto is annexed a briefe commentary of the true state of Island and of the northern seas and lands situate that way, as also the memorable defeat of the Spanish huge Armada anno 1588. The second volume comprehendeth the principall navigations, voyages, traffiques and discoveries of the English nation made by sea or over-land to the south and south-east parts of the world, as well within as without the streight of Gibraltar at any time within the compasse of these 1600 yeres, divided into two severall parts etc. Volume 1-3 ... London: Bishop, Newberie, Barker, 1599-1600.

!HSD! 4 ITIN I, 5245/2 RARA 
Richard Hakluyt (um 1552 - 1616) war englischer Geistlicher und Geograph in Oxford. Sein großes Interesse galt der Geschichte der Entdeckungen und so sammelte und publizierte er Berichte über Entdeckungsfahrten. Sein Hauptwerk Principal Navigations, Voyages, Traffics, and Discoveries of the English Nation, eine Sammlung von Reisebeschreibungen, erschien als einbändiges Werk zuerst 1589, in zweiter, erweiterter, dreibändiger Auflage 1598 - 1600. Die Publikation von Berichten über die frühen Reisen und Entdeckungen wird von der Hakluyt Society, gegründet 1846, bis in die heutige Zeit fortgesetzt.

79 Gottfried, Johann Ludwig:

Historia Antipodum, oder Neue Welt (und americanische Historien), das ist, Natur u. Eigenschafft des halben Theils der Erden, so West-Indien genannt wird, (inhaltende warhaftige u. vollkommene Beschreibung aller WestIndianischen Landschafften, p. p. in diesem halben Theil des Erdkreyses, ) der Elementen, Geschöpfen, Nationen, u. Inwohner, (desgleichen gründlicher Bericht von der Inwohner Beschaffenheit, p. p. p.) u. wie dieß alles durch mancherley Schiffahrten entdecket worden, ... Alles aus verschiedenen West-Indianischen Historien-Schreibern u. mancherley Sprache zusammengetragen, durch Johann Ludwig Gottfried. Mit Landtafeln u. Kupferstücken gezieret von Matthäo Merian. - Franckfurt: bey denen Merianischen Erben, 1655. 661 S., zahlreiche Kupferstiche.

!HSD! 4 H AM I, 311 RARA

Johann Ludwig Gottfried (um 1584 - 1633), Historiker und reformierter Theologe, stand in engem Kontakt zu Merian d. Ä. Unter dem Pseudonym Johann Philipp Abelin versah er Merians Werke zum Teil mit lateinischen und deutschen Texten. Er selbst wirkte als Herausgeber einiger Bände der de Bry'schen Reisen, die ihren Wert aber erst durch die Kupferstiche Merians erlangten. 


\section{Die Geographie als Wissenschaft zwischen Renaissance und Barock}

Zum Ende des 17. Jahrhunderts vollzog sich die Wandlung der Geographie von der reinen Beschreibung hin zu einer systematischen Wissenschaft, die sich mit der kausalen Erforschung der Erde beschäftigt. Es entwickelten sich eine Reihe von systematischen Zweigen der Geographie, die bis heute als grundlegende Teile der allgemeinen Geographie angesehen werden.

80 Clüver, Philipp:

Introductionis in Universam Geographicam, tam Veterem quam Novam Libri VI, ... - Lugduni Batavorum: Elzevir, 1624. - 245 S.

!HSD! 8 GEOGR 385/m RARA

Philipp Clüvers geographisches Elementarbuch Introductio in universam geographicam diente in zahlreichen Auflagen und Bearbeitungen ein Jahrhundert lang als Grundlage des Geographieunterrichts. Anstelle von Kosmographie für Gesamtdarstellungen der Erde benutzte Clüver die Bezeichnung Geographie. Seine Werke waren sehr erfolgreich. Clüver durchbrach damit die Autorität des Ptolemaeus, indem er lehrte, die historische Geographie müsse von modernen Gegebenheiten ausgehend die frühere Situation erschließen. Diese kritische Einstellung fand erst im 19. Jahrhundert wieder Anerkennung.

Vgl. auch Nr. 46.

81 Keckermann, Bartholomaeus:

Systemis Geographici, Libri II. o. O. 1617.

In:

Systema compendiosum totius mathematices, hoc est geometriae, opticae, astronomiae et geographiae, publicis praelectionibus, anno 1605, in Gymnasio Dantiscano / Propositum a Bartholomaeo Keckermanno. Accessit: Commentatis nautica. - Hanoviae, 1617.

!HG-FB! 8 PHYS MATH I, 203 


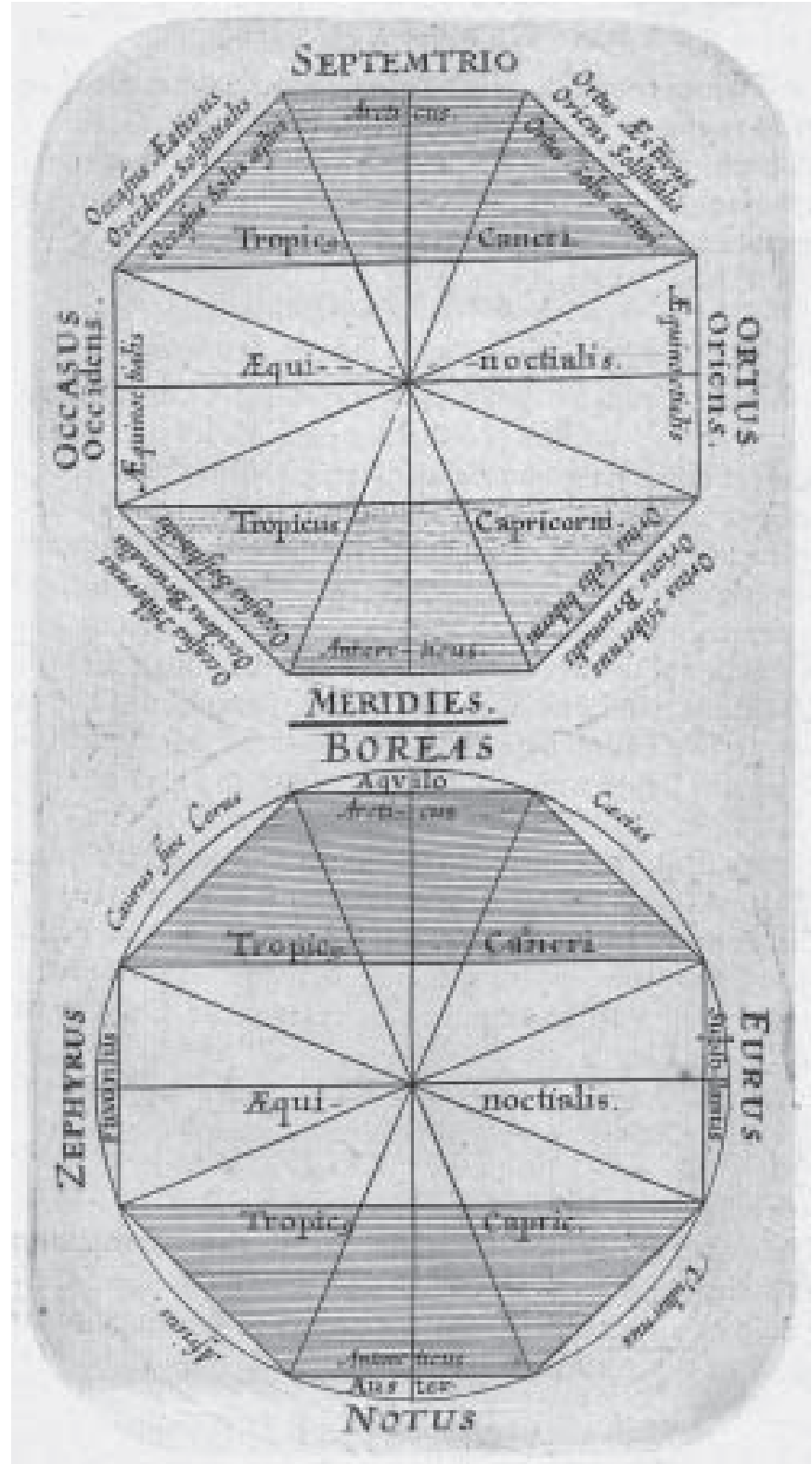

Abbildung 22 (Kat.Nr. 80)

Philipp Clüver: Introductionis ... libri VI, 1624, Zonale Gliederung der Erde. 
Keckermann (1571 - 1608), bekannter Theologe aus Danzig und Mitbegründer der allgemeinen Geographie, diskutierte wohl als erster zu Anfang des 17. Jahrhunderts die Zweiteilung in eine allgemeine und eine spezielle Geographie. Darüber hinaus setzte er sich für eine Trennung von Theologie und Geographie ein. Nach seiner Auffassung sollte sich der Theologe nur mit der göttlichen Leitung des Menschen, nicht aber mehr aristotelisch mit der Providentia in der Natur befassen. Diese Aufgabe sollten die Theologen den Geographen überlassen. Durchgesetzt hat sich Keckermanns Versuch, die Theologie von der Geographie zu lösen, in der damaligen Zeit noch nicht.

82 Christiani, David:

Systema geographiae generalis duobus libris absolutum. - Marpurgi Cuttorum: Hampel, 1645. $723 \mathrm{~S}$.

8 GEOGR $391 / \mathrm{m}$

David Christiani (1610 - 1688) war als Professor der Mathematik und Theologie in Marburg und Gießen tätig und verfasste in dieser Zeit auch geographische und astronomische Werke. Seine Systema geographiae generalis kann als Vorläufer der Schriften von Bernhard Varenius verstanden werden. Christiani hatte zwar schon die Idee, dass man die allgemeine Geographie systematisch aufbauen müsse, ihm gelang aber die Umsetzung noch nicht, wie Varenius sie fünf Jahre später entwickeln sollte.

83 Varenius, Bernhard:

Geographia generalis in qua affectiones generales telluris explicantur. Amstelodami: Elzevir, 1650. - 64, 786 S.

8 GEOGR PHYS 256

Bernhard Varenius (1622 - 1650), Pfarrersohn aus Hitzacker, Mediziner und Geograph, studierte in Königsberg und Leiden und war als Hauslehrer in Amsterdam tätig. Seine Arbeiten waren systemgeographisch und methodologisch von großer Bedeutung für die Entwicklung der Geographie als wissenschaftliche Disziplin. Von Humboldt wurde Varenius aus diesem Grund als Begründer der modernen Geographie bezeichnet. 


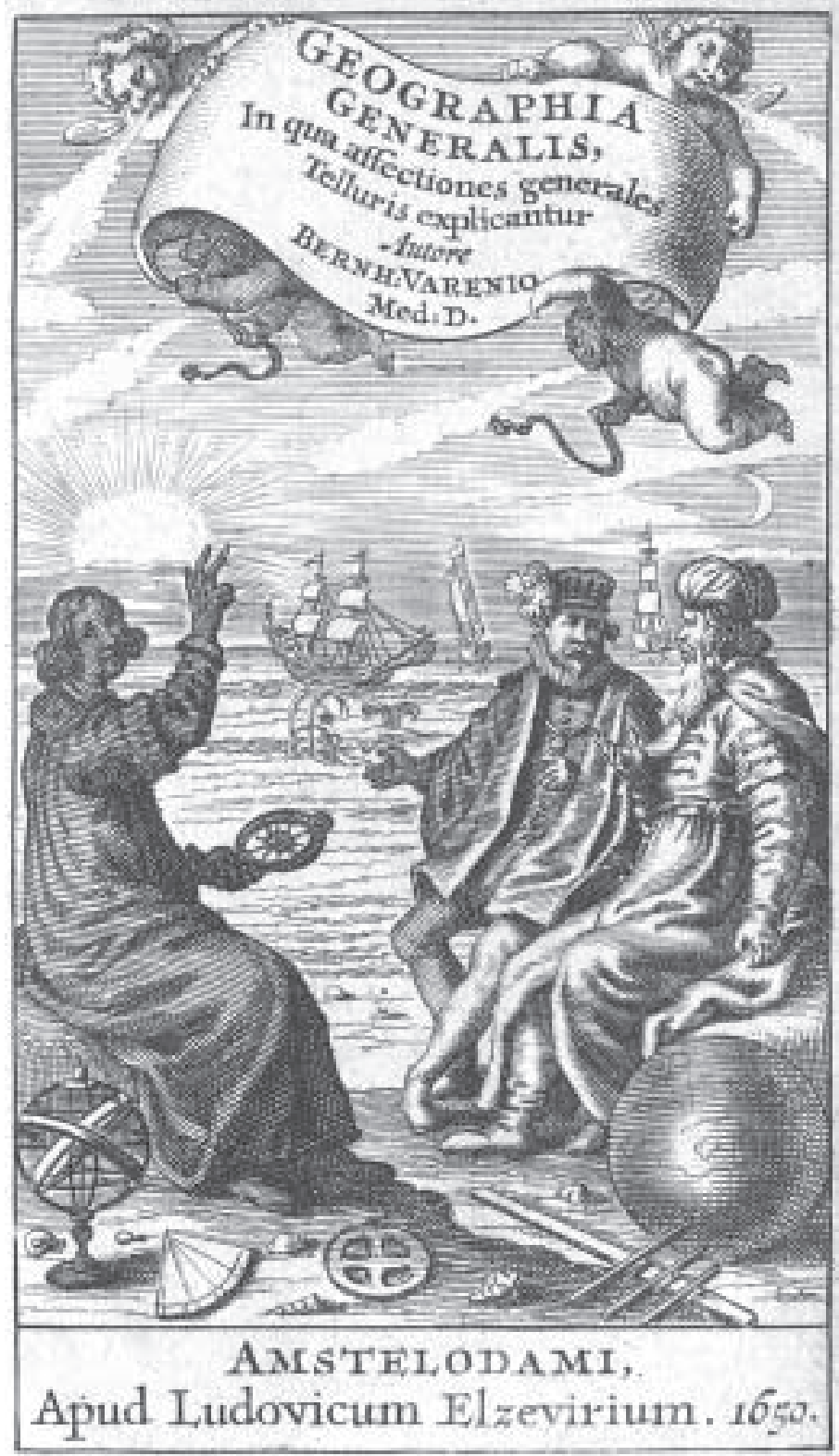

Abbildung 23 (Kat.Nr. 83)

Bernhard Varenius: Geographia generalis, 1650, Titelkupfer. 
Varenius hat selbst nie im Gelände gearbeitet oder Forschungsreisen unternommen. Alles, was er an Material verwandte, war bereits bekannt. Die Bedeutung seines Werkes liegt darin, dass er die kritische Auswertung von Beobachtungen und Tatsachen dazu nutzte, die ursächlichen Zusammenhänge zwischen den Einzelfaktoren zu erforschen und darzustellen. Er war der erste Geograph der Neuzeit, der die Geographie in ein wissenschaftliches System brachte, in dem wir zum Teil heute noch zu denken gewohnt sind. Varenius starb verarmt bereits mit 28 Jahren, sein Hauptwerk erschien erstmals 1650 kurz nach seinem Tod.

Vgl. auch Nr. 47.

84 Varenius, Bernhardus:

Geographia Generalis. In qua Affectiones Generales Telluris Explicantur. Summa cura quam plurimis in locis Emendata, \& XXXIII Schematibus Novis, Aere incisis, una cum Tabb. aliquot quae desiderabantur Aucta \& Illustrata I Ab Isaaco Newton .... - Editio Secunda Auctior \& Emendatior. - Cantabrigiae: Ex Officina Joann. Hayes, ... Sumptibus Henrici Dickinson Bibliopolae, 1681. $511 \mathrm{~S}$.

8 GEOGR PHYS 262

Die Nachfolger der Kosmographen, die in der zweiten Hälfte des 17. Jahrhunderts Staatsbeschreibungen verfassten, waren von Varenius noch wenig beeinflusst. Es dauerte längere Zeit, bis sein Werk Geltung erlangte.

Die Aufnahme und Verbreitung des Gedankenguts von Varenius ist vor allem Isaac Newton (1643 - 1727) zu verdanken, der die Geographia Generalis in England für lange Zeit zum Standardwerk der Geographie gemacht hat. Für Isaac Newton war die Geographia Generalis das wissenschaftlich führende Werk der Geographie seiner Zeit. Er edierte 1672 eine revidierte Neuauflage, von der 1681 ein Neudruck erschien.

85 Coronelli, Vincenzo:

Epitome cosmografica, o compendiosa introduttione all' astronomia, geografia, \& idrografia, per l'uso, dilucidatione, e fabbrica delle sfere, globi, planisferj, astrolabj, e tavole geografiche. - Colonia, 1693. $458 \mathrm{~S}$.

!HSD! 8 BIBL UFF 302 RARA 
Vincenzo Coronelli (1650 - 1718), Ordensgeneral der Minoriten, war als Kosmograph und Globenbauer in Ravenna und Venedig tätig. 1684 gründete er in Venedig die Academia Cosmographica degli Argonauti, die erste Geographische Gesellschaft der Welt, die ihm den nötigen finanziellen Rückhalt für seine Publikationen brachte. Im Jahr darauf wurde er zum Kosmographen der Republik Venedig ernannt. Seine 1701 ausgesprochene Ernennung zum Generalobersten der Minoriten wurde 1704 auf päpstlichen Bescheid wieder zurückgezogen. Coronelli musste Untersuchungen über die zu hohen Kosten seiner zahlreichen Veröffentlichungen über sich ergehen lassen.

Als Globenherausgeber trat Coronelli die Nachfolge von Willem J. Blaeu an und erreichte dort einen hohen Bekanntheitsgrad, wie z. B. die Internationale CoronelliGesellschaft beweist, die als Vereinigung der Globenfreunde und -kenner Coronelli als Namensgeber gewählt hat. 


\section{Literaturverzeichnis}

Allgemeine deutsche Biographie, hrsg. durch die Historische Commission bei der Königl. Akademie der Wissenschaften, 2., unveränd. Aufl., Berlin 1967-1971.

Beck, Hanno: Geographie. Europäische Entwicklung in Texten und Erläuterungen, (Orbis academicus, 2, 16), Freiburg 1973.

Reisen nach Jerusalem. Das Heilige Land in Karten und Ansichten aus fünf Jahrhunderten. Bestandkatalog der Sammlung Loewenhardt, [Eine Ausstellung des Jüdischen Museums (Abteilung des Berlin-Museums) vom 2. April bis 6. Juni 1993], bearb. von Anemone Bekemeier, Wiesbaden 1993.

Blotevogel, Hans H. / Vermij, Rienk: Gerhard Mercator und die geistigen Strömungen des 16. und 17. Jahrhunderts, (Duisburger Mercator-Studien, 3), Bochum 1995.

Büttner, Nils: Die Erfindung der Landschaft. Kosmographie und Landschaftskunst im Zeitalter Bruegels, (Rekonstruktion der Künste, 1), Göttingen 2000, zugl.: Göttingen, Univ., Diss., 1998/99.

Embacher, Friedrich: Lexikon der Reisen und Entdeckungen. In 2 Abteilungen: 1. Die Forschungsreisenden aller Zeiten und Länder. 2. Entdeckungsgeschichte der einzelnen Erdteile, Nachdr. der Ausg. Leipzig, 1882, Amsterdam 1961.

Die Entdeckung und Erforschung der Erde. Mit einem ABC der Entdecker und Forscher, hrsg. von Walter Kraemer, 6. Aufl., Leipzig 1974.

Grosjean, Georges / Kinauer, Rudolf: Kartenkunst und Kartentechnik. Vom Altertum bis zum Barock, 2. Aufl., Bern 1975.

Henze, Dietmar: Enzyklopädie der Entdecker und Erforscher der Erde, Graz 1978-.

Kartographie. Revidiert und hrsg. durch R. A. Skelton. Erl. Texte zu den Abb. von Heinrich Winter, (Meister der Kartographie), 4., neu bearb. und erw. Aufl., Berlin 1973. Frühere Ausg. u. d. T.: Bagrow, Leo: Die Geschichte der Kartographie.

Kind, Helmut / Rohlfing, Helmut: Gutenberg und der europäische Frühdruck. Zur Erwerbungsgeschichte der Göttinger Inkunabelsammlung, Göttingen 1995. 
Lexikon zur Geschichte der Kartographie.Von den Anfängen bis zum Ersten Weltkrieg, verf. von zahlr. Experten, bearb. von Ingrid Kretschmer, (Die Kartographie und ihre Randgebiete, C), Wien 1986. 2 Bde.

Luber, Susanne: Reiseliteratur und Geographica in der Eutiner Landesbibliothek, hrsg. von Wolfgang Griep, (Kataloge der Eutiner Landesbibliothek, 2), Heide 1990.

Pleticha, Heinrich / Schreiber, Hermann: Lexikon der Entdeckungsreisen, Stuttgart 1999, 2 Bde.

Schmithüsen, Josef: Geschichte der geographischen Wissenschaft. Von den ersten Anfängen bis zum Ende des 18. Jahrhunderts, (BI-Hochschultaschenbücher, 363/ 363a), Mannheim 1970.

Tooley, Ronald Vere: Maps and map-makers, 6.ed., repr., London 1982.

Vierhundert Jahre Mercator, vierhundert Jahre Atlas. „Die ganze Welt zwischen zwei Buchdeckeln“. Eine Geschichte der Atlanten. [Zum 400. Todestag Gerhard Mercators anläßlich einer Ausstellung der Bayerischen Staatsbibliothek vom 5. April 1995 bis 1. Juli 1995], hrsg. von Hans Wolff im Auftr. der Bayerischen Staatsbibliothek, (Ausstellungskataloge / Bayerische Staatsbibliothek, 65), Weißenhorn 1995.

Weltbild im Spiegel der Kartographie des 16. bis 18. Jahrhunderts. [Sonderausstellung des Böblinger Bauernkriegsmuseums in Verbindung mit der Bibliothek des Nationalmuseums in Prag (Národní muzeum v Praze) 27. November 1994 bis 5. Februar 1995, Museumsgebäude Zehntschauer, Böblingen], Böblinger Bauernkriegsmuseum, mit Beitr. von Pavel Brodský und Günter Scholz, hrsg. von Günter Scholz, (Böblinger Museumsschriften, 12), Böblingen 1994.

Wüthrich, Lucas Heinrich: Die großen Buchpublikationen. II, Die Topographien, (Das druckgraphische Werk von Matthaeus Merian d. Ae., Bd. 4), Hamburg 1996.

Zögner, Lothar: Kartenschätze. Aus den Sammlungen der Staatsbibliothek zu Berlin, unter Mitarb. von Klaus Lindner ... Hrsg. von Antonius Jammers, Braunschweig 2000 .

Zur Geschichte der geographischen Wissenschaft, 15. bis 17. Jahrhundert. Auswahl von Dokumenten aus den Beständen der Niedersächsischen Staats- und Universitätsbibliothek Göttingen. Ausstellung anlässlich des 42. Deutschen Geographentages in Göttingen, 5. bis 8. Juni 1979, Auswahl und Zusammenstellung: Uta Klaer und Magdalene Leimkühler, (Kleine Ausstellungsführer / Niedersächsische Staats- und Universitätsbibliothek Göttingen, 5), Göttingen 1979. 


\section{Kurzbiographie der Autorin}

\section{Mechthild Schüler}

Diplom-Geographin, geboren 1959, Studium der Geographie, Geschichte und Soziologie an der Ruhr-Universität Bochum, seit 1989 Leiterin der Kartenabteilung und Fachreferentin für Geographie an der Niedersächsischen Staats- und Universitätsbibliothek Göttingen. 


\section{Göttinger Bibliotheksschriften}

(lieferbare Titel)

1. Edith Stein. Studentin in Göttingen 1913-1916. Ausstellung zum 100. € 4,Geburtstag 7.10. - 28.10.1991. 1991. 118 S. mit Abb.

2. Der Brocken und sein Alpengarten. Erinnerungen - Dokumentationen. $€ 4$,Ausstellung vom 17.3.-5.6.1993. 1993.81 S.

3. Übersicht über die Systematik des Bandrealkataloges der Niedersäch$€ 5,-$ sischen Staats- und Universitätsbibliothek Göttingen. Bearb.: G.-J. Bötte u. D. Sickmüller. 1993. XIII, 75, 126 S.

4. Neues Heimatland Brasilien. Texte und Bilder zur kulturellen Entwicklung der deutschbrasilianischen Bevölkerung in Südbrasilien. Begleitband zur Ausstellung vom 10.1.-19.2.1994 / Sandra Messele-Wieser, Lothar Wieser. 1994. IV, 84 S. mit Abb.

6. Kröger, Detlef: European and international Copyright protection. Microcopies and databases. 1995. $283 \mathrm{~S}$.

7. Bestandserhalt durch Konversion: Microverfilmung und alternative Technologien. Beiträge zu drei Fachtagungen des EU-Projekts MICROLIB. Hrsg.: Werner Schwartz 1995. 208 S.

10. Sibirien Finnland Ungarn : Finnisch-ugrische Sprachen und Völker in der $€ 6,-$ Tradition eines Göttinger Sondersammelgebiets. Ausstellung in der Paulinerkirche vom 28.02.-09.04.1998

11. "ganz vorzügliche und unvergeßliche Verdienste"- Georg Thomas Asch als Förderer der Universität Göttingen. Ausstellung im Historischen Gebäude der Niedersächsischen Staats- und Universitätsbibliothek 20.4.22.5.1998

13. "Göthe ist schon mehrere Tage hier, warum weiß Gott und Göthe": Vorträge zur Ausstellung "Der gute Kopf leuchtet überall hervor" - Goethe, Göttingen und die Wissenschaft / hrsg. von Elmar Mittler, Red.: Elke Purpus. 2000

14. Towards consensus on the electronic use of publications in libraries: strategy issues and recommendations / Thomas Dreier. 2001

16. Zehn Jahre Pica in Niedersachsen und Deutschland. Skizzen eines Erfolges / Red. Elmar Mittler 2001. 181 S. 
17. "Wohne immer in meinem Herzen und in den Herzen meiner Freunde allesbelebende Liebe!" Friedrich Leopold Graf zu Stolberg (1750-1819). Aus der literarisch-historischen Sammlung des Grafen Franz zu StolbergStolberg, 1210-1750-2001 / Bearb. von Paul Kahl. Hrsg. von Elmar Mittler und Inka Tappenbeck. 2001. 143 S. mit Abb.

18. Johann Heinrich Voß. 1751-1826. Idylle, Polemik, Wohllaut / Hrsg. von Elmar Mittler und Inka Tappenbeck. 2001. 298 S. mit Abb.

19. Weltbild - Kartenbild. Geographie und Kartographie in der frühen Neuzeit / Bearb. von Mechthild Schüler. Hrsg. von Elmar Mittler und Inka Tappenbeck. 2., durchgesehene Aufl. 2002. 94 S. mit Abb.

20. LIBER - Ligue des Bibliothèques Européennes de Recherche. Architecture Group Seminar. Leipzig, March 19 - March 23, 2002. The Effective Library. Vision, Planning Process and Evaluation in the Digital Age.

Documentation of new library buildings in Europe. Elmar Mittler (Ed.) Göttingen 2002. 319 p. 